\title{
Improving Real-time Methane Monitoring in Longwall Coal Mines Through System Response Characterization of a Multi-Nodal Methane Detection Network
}

\author{
Brian Philip Cappellini \\ West Virginia University, bcappel1@mix.wvu.edu
}

Follow this and additional works at: https://researchrepository.wvu.edu/etd

Part of the Computer-Aided Engineering and Design Commons, Energy Systems Commons, Mining Engineering Commons, Operations Research, Systems Engineering and Industrial Engineering Commons, and the Risk Analysis Commons

\section{Recommended Citation}

Cappellini, Brian Philip, "Improving Real-time Methane Monitoring in Longwall Coal Mines Through System Response Characterization of a Multi-Nodal Methane Detection Network" (2021). Graduate Theses, Dissertations, and Problem Reports. 8333.

https://researchrepository.wvu.edu/etd/8333

This Thesis is protected by copyright and/or related rights. It has been brought to you by the The Research Repository @ WVU with permission from the rights-holder(s). You are free to use this Thesis in any way that is permitted by the copyright and related rights legislation that applies to your use. For other uses you must obtain permission from the rights-holder(s) directly, unless additional rights are indicated by a Creative Commons license in the record and/ or on the work itself. This Thesis has been accepted for inclusion in WVU Graduate Theses, Dissertations, and Problem Reports collection by an authorized administrator of The Research Repository @ WVU. For more information, please contact researchrepository@mail.wvu.edu. 
Improving Real-time Methane Monitoring in Longwall Coal Mines Through System Response Characterization of a Multi-Nodal Methane Detection Network

Brian P. Cappellini

Thesis submitted to the Benjamin M. Statler College of Engineering and Mineral Resources at West Virginia University

In partial fulfillment of the requirements for the degree of

Master of Science in

Mechanical Engineering

Derek Johnson, PhD, PE, Chair

V'yacheslav Akkerman, PhD

Scott Wayne, $\mathrm{PhD}$

Department of Mechanical Engineering

Morgantown, West Virginia

2021

Keywords: Methane Detection, Multi-Nodal System, Longwall Coal Mining, Modeling Copyright 2021 Brian Cappellini 


\section{ABSTRACT \\ Improving Real-time Methane Monitoring in Longwall Coal Mines Through System Response Characterization of a Multi-Nodal Methane Detection Network \\ Brian P. Cappellini}

Machine automation and atmospheric monitoring are used by many industries to improve safety and productivity in the workplace. The underground Methane Watchdog System (MWS) is a multi-nodal network of sensors currently under development. The MWS aims to improve safety and productivity by introducing 10 compact sampling units designed to be easily integrated within the current roof support equipment of the mine. Each unit contains an array of sensors used to continuously monitor the environmental conditions which include methane concentration, temperature, pressure, and relative humidity. All MWS units report information back to a remote central processing hub (CPH) which collects nodal signals, converts them to useful engineering units, records data for historical analysis, and provides control capabilities.

The following work describes the methodology used to evaluate the MWS's effectiveness within the laboratory setting and characterize the system's response for improved performance. Reduced onedimensional (1-D) modeling studies provided a useful structure to develop the longwall mining environment. Two-dimensional (2-D) computational fluid dynamic (CFD) models were also developed to evaluate timescales of mixing and formation of methane as a function of shearer position throughout a cutting sequence. From the 1-D studies, scenarios were constructed to generate temporal methane distributions that were the result of ventilation and production patterns. Model results were extracted from the proposed MWS sampling locations and used to demonstrate usefulness and effectiveness within the laboratory setting. The resulting outputs from the system were then used to develop a signal reconstruction technique to sharpen the responses and improve accuracy of real-time measurements. Commonly, system delay times result in a characteristic delayed and diffused output from the original input data.

The second-generation prototype of the MWS improved performance with the addition of a new methane sensor and signal reconstruction technique. When the developed reconstruction method was employed, measurement error for time aligned data was reduced by $78 \%$ on average. Moreover, system response times were reduced from 17 seconds to approximately 5 seconds. The reconstructed output captured all instances for a given scenario where methane emissions quickly rose above the regulatory threshold $\left(1 \% \mathrm{CH}_{4}\right)$ from a baseline concentration of $0.4 \% \mathrm{CH}_{4}$. A vast improvement from the original output, where no instances were detected. Original simulated concentrations, measured signals, and sharpened signals are provided to demonstrate the improvement. 


\section{Acknowledgements}

I would first like to sincerely thank my advisor Dr. Derek Johnson for seeing my potential early on and hiring me as a graduate student. I am very thankful for the opportunities and place you have provided me among your research, and I feel confident that your mentoring has provided me the tools I need to be a successful engineer.

I would like to thank all current and former members of our research team that I have been so grateful to be a part of over the last few years: Mahdi Darzi, Chris Ulishney, Dakota Oliver, Rob Heltzel, and Diego Dranuta. An extended gratitude is given to Mr. Nima Zamani. From one of his students, to a colleague and friend, his knowledge and support has contributed greatly to the success of this work.

A special thanks is given to Ms. Amber Barr, who worked alongside me and put up with me most over the last two years. Amber's friendship and assistance in and outside the laboratory has contributed greatly to the success of this project.

I would like to thank my committee members Dr. V'yacheslav Akkerman and Dr. Scott Wayne for their time, instruction, and guidance throughout my graduate career. Their passion and expertise have provided an enjoyable and valuable learning experience among my graduate classes and research. In addition, I would like to thank Dr. Nigel Clark as the Co-investigator on this project. His knowledge and charisma provided a valuable asset to our research team and its success.

Recognition must be given to the Alpha Foundation for their continual support and providing the funding necessary to complete this work.

Lastly, I would like to thank my family and girlfriend for all their support, encouragement, and patience over the years. In addition, the countless letters filled with wisdom and motivation from my grandfather have truly provided me the focus and additional support needed to make all this possible. 


\section{Table of Contents}

Acknowledgements ......................................................................................................

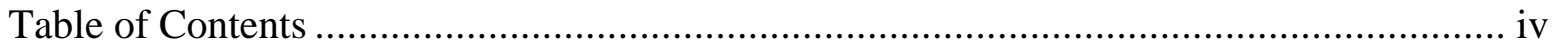

Table of Figures ..................................................................................................... vii

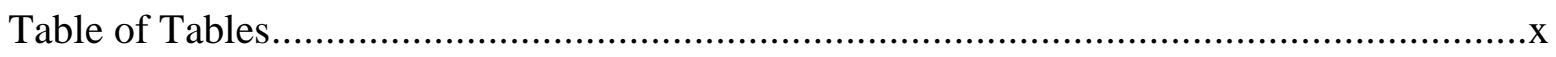

List of Acronyms and Abbreviations ...........................................................................

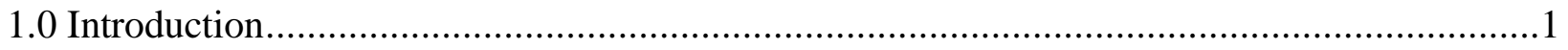

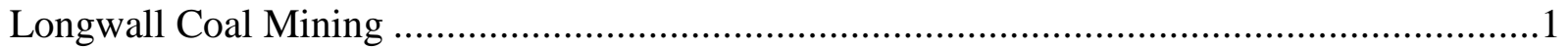

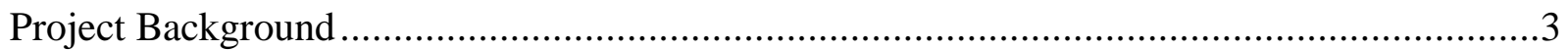

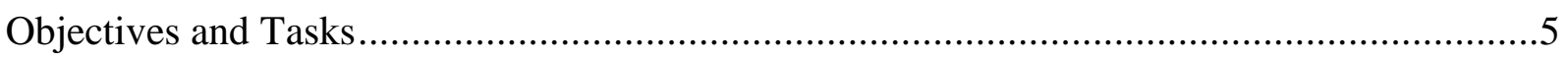

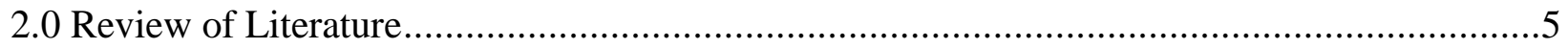

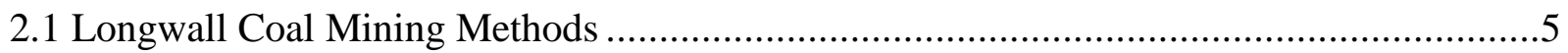

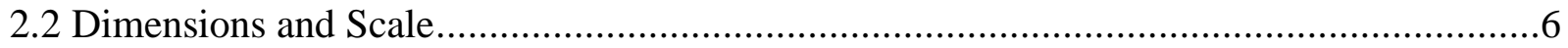

2.3 Methane Sources and Its Formation Along the Longwall .............................................

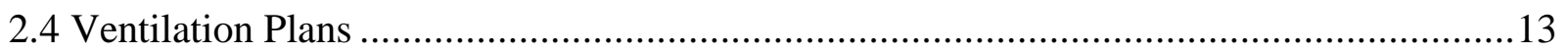

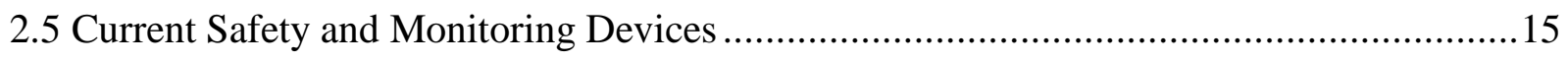

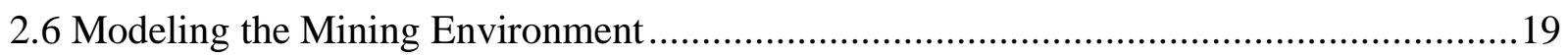

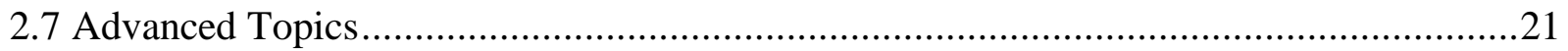

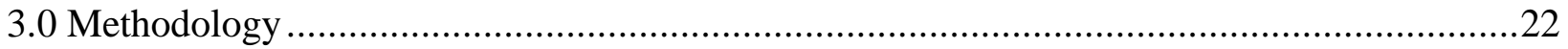

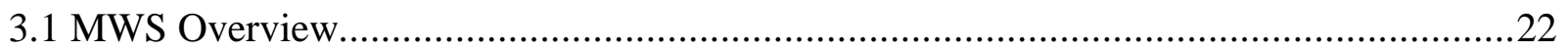

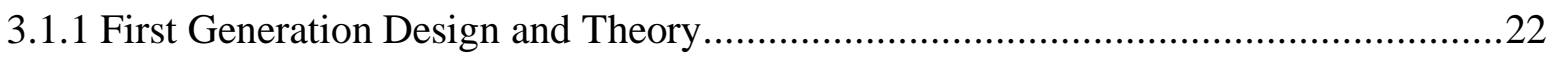

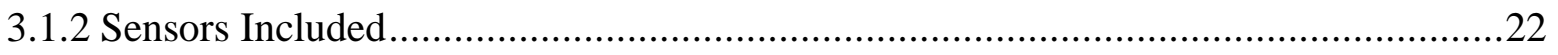

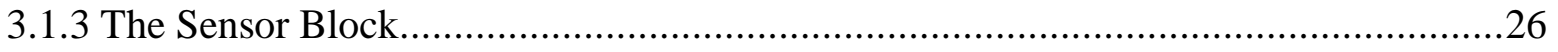

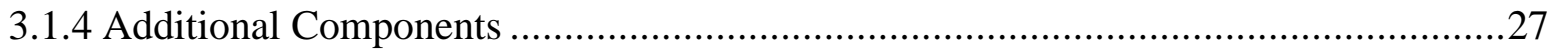

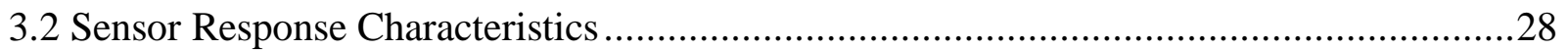

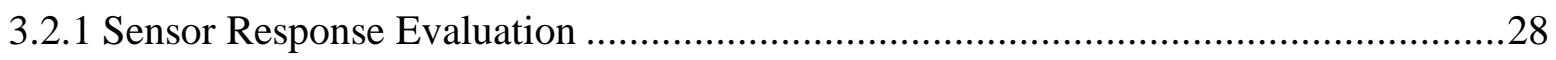

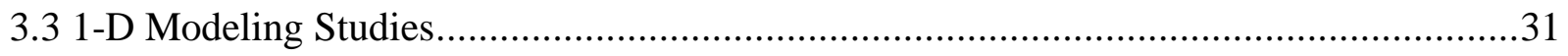

3.3.1 Constructing an Appropriate Model ....................................................................... 31

3.3.2 Solving the Problem One-dimensionally: The Finite Volume Method ........................32

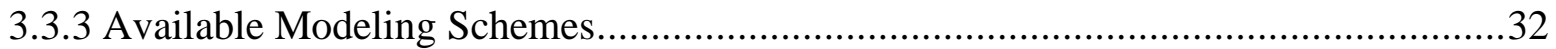

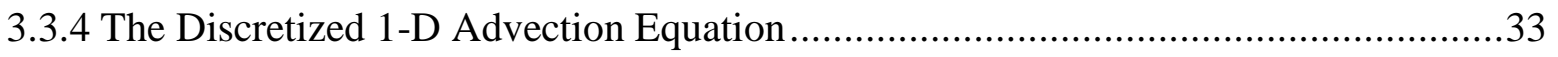

3.3.5 Study of Explicit Numerical Differencing Schemes ..................................................34 
3.3.6 Modeling the Longwall Environment.......................................................41

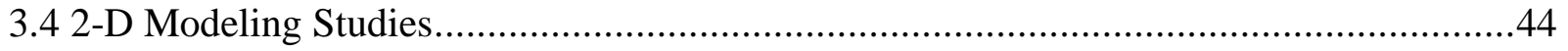

3.4.1 Overview of 2-D Longwall Model ..................................................................44

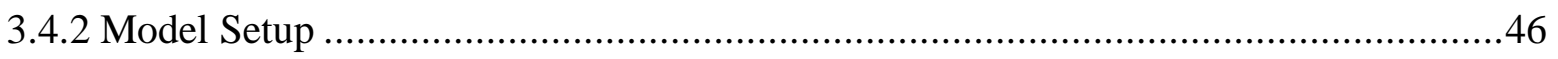

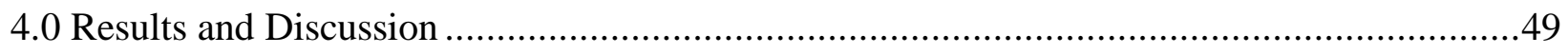

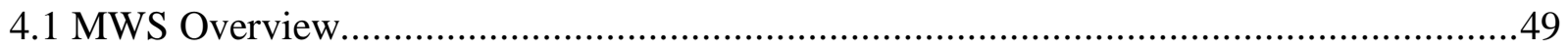

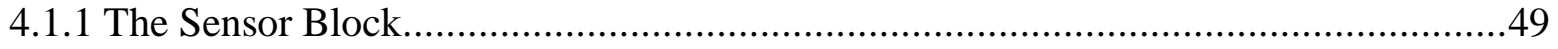

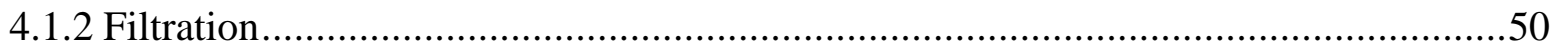

4.1.3 Proposed Sampling Mode (The Water Ejector) ............................................54

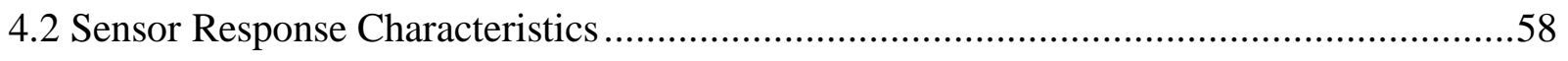

4.2.1 Defining Error and Non-dimensional Analysis ................................................59

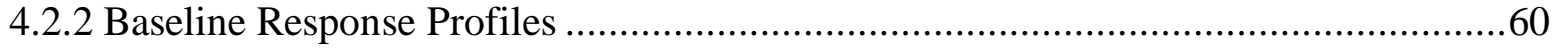

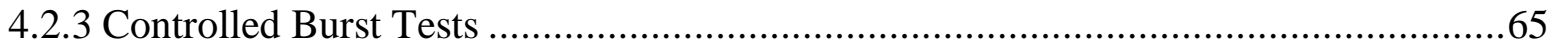

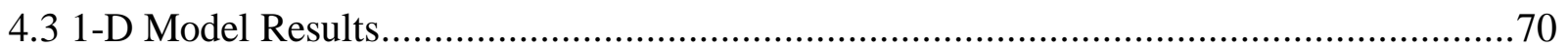

4.3.1 Baseline Emission Profile .......................................................................... 71

4.3.2 Sensitivity of Boundary Conditions (Transient Cases) ........................................73

4.3.3 Evaluation of System Performance Through Simulation Data .............................. 74

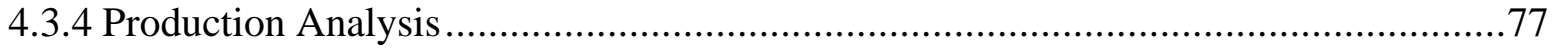

4.4 Developing Reconstruction Technique .......................................................... 79

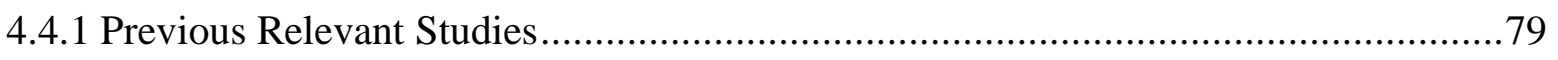

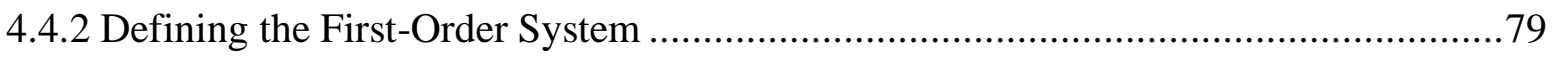

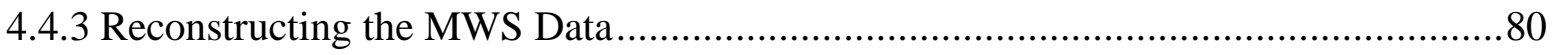

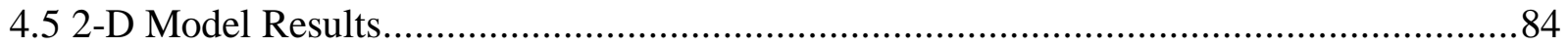

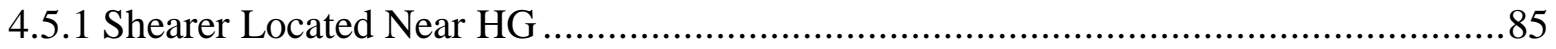

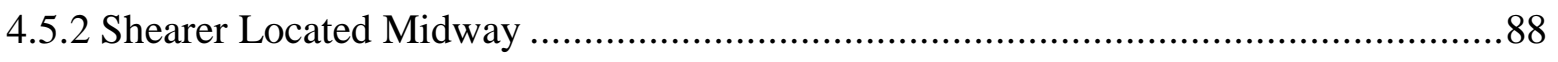

4.5.3 Shearer Located Near TG....................................................................... 91

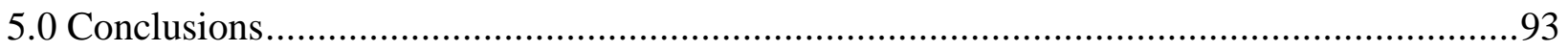

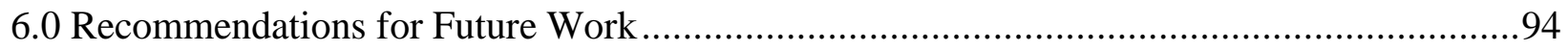

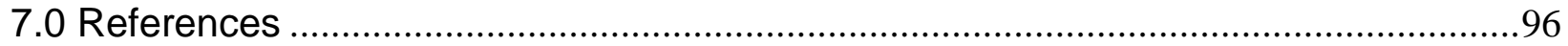

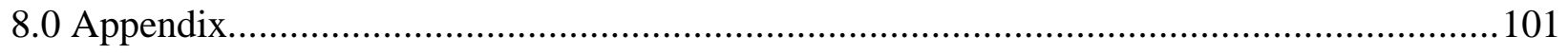

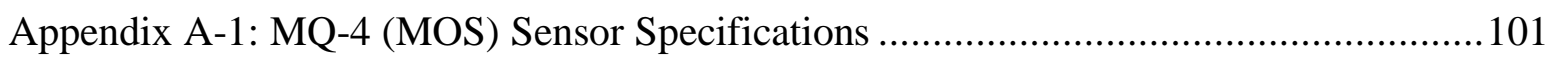

Appendix A-2: Dynament (IRS) Sensor Specifications ......................................... 102 
Appendix A-3: Gasmitter (NDIR) Sensor Specifications 104

Appendix B: MATLAB code for Study on Discretized Schemes (Upwind, Lax, Lax-

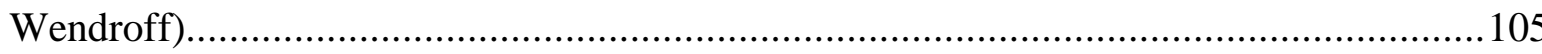

Appendix C: MATLAB code for 1-D Longwall Model.................................................108

Appendix D: MATLAB code for conditional MWS reconstruction technique...................111

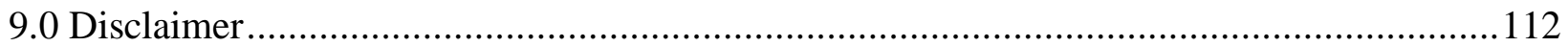


Figure 1.0-1 General layout of longwall mining operations and equipment used to mine a panel of coal [2].

Figure 1.0-2 Ten sampling units of the MWS deployed at mock mine in WVU's research wind tunnel. Dimensions of mock longwall: 4.9 x 2.4 x $30.5 \mathrm{~m}(16 \times 8 \times 100 \mathrm{ft})$

Figure 1.0-3 Inside of a first-generation prototype MWS sampling unit that contains sensors including: Metal-Oxide-Semiconductor (MOS) and Infrared (IRS) type methane sensors, temperature, absolute pressure, and relative humidity. Control and data transmissions devices are also included and consist of 3-way valve, de-energizing relay, and data acquisition device..........4

Figure 2.2-1 Reference for selected dimensions used to construct relevant models. ..................7

Figure 2.3-1 U.S. coal rank system chart and the defining characteristics [10] .......................8

Figure 2.4-1 Example of Ventilation Plan (U-System Bleederless) [16]............................... 14

Figure 2.5-1 Common handheld methane detection device containing a catalytic bead type sensor used for regulatory checks [21].....

Figure 2.5-2 Common vane type anemometers used for air velocity measurements underground. An older analog version depicted on the [left] and a current digital pocket-sized instrument on the [right]. .18

Figure 3.1-1 The MQ-4 (MOS type) methane sensor and its adoption of the breakout board.....23 Figure 3.1-2 Wiring and pin configuration of the MQ-4 methane sensor [30] ......................24 Figure 3.1-3 The Dynament (NDIR type) methane sensor. ...........................................25 Figure 3.1-4 The Gasmitter (NDIR-dual wavelength) methane sensor [31] .........................25 Figure 3.2-1 Laboratory setup for administering controlled samples to the MWS unit. ............30 Figure 3.2-2 Examples of step inputs used to characterize the sensors response. a) Single step input. b) Periodic step input. c) Ramp input.

Figure 3.3-1 Advection of 1-D square function using the upwind differencing scheme.

Simulation solved on the domain $\mathrm{x} \in[0,10]$ with $\mathrm{c}=0.5, \Delta \mathrm{t}=0.05, \Delta \mathrm{x}=0.05$. Solutions were obtained and plotted for $\mathrm{t}=0, \mathrm{t}=40, \mathrm{t}=80, \mathrm{t}=120, \mathrm{t}=180$.

Figure 3.3-2 Advection of 1-D Gaussian distribution using the upwind differencing scheme. Simulation solved on the domain $\mathrm{x} \in[0,10]$ with $\mathrm{c}=0.5, \Delta \mathrm{t}=0.05, \Delta \mathrm{x}=0.05$. Solutions were obtained and plotted for $\mathrm{t}=0, \mathrm{t}=40, \mathrm{t}=80, \mathrm{t}=120, \mathrm{t}=180$.

Figure 3.3-3 Advection of 1-D square wave using the Lax method. Simulation solved on the domain $\mathrm{x} \in[0,10]$ with $\mathrm{c}=0.5, \Delta \mathrm{t}=0.05, \Delta \mathrm{x}=0.05$. Solutions were obtained and plotted for $\mathrm{t}=$ $0, \mathrm{t}=40, \mathrm{t}=80, \mathrm{t}=120, \mathrm{t}=180$.

Figure 3.3-4 Advection of 1-D Gaussian distribution using the Lax method. Simulation solved on the domain $\mathrm{x} \in[0,10]$ with $\mathrm{c}=0.5, \Delta \mathrm{t}=0.05, \Delta \mathrm{x}=0.05$. Solutions were obtained and plotted for $\mathrm{t}=0, \mathrm{t}=40, \mathrm{t}=80, \mathrm{t}=120, \mathrm{t}=180$. 38

Figure 3.3-5 Advection of 1-D square wave using the Lax-Wendroff method. Simulation solved on the domain $\mathrm{x} \in[0,10]$ with $\mathrm{c}=0.5, \Delta \mathrm{t}=0.05, \Delta \mathrm{x}=0.05$. Solutions were obtained and plotted for $\mathrm{t}=0, \mathrm{t}=40, \mathrm{t}=80, \mathrm{t}=120, \mathrm{t}=180$.

Figure 3.3-6 Advection of 1-D Gaussian distribution using the Lax-Wendroff method. Simulation solved on the domain $\mathrm{x} \in[0,10]$ with $\mathrm{c}=0.5, \Delta \mathrm{t}=0.05, \Delta \mathrm{x}=0.05$. Solutions were obtained and plotted for $\mathrm{t}=0, \mathrm{t}=40, \mathrm{t}=80, \mathrm{t}=120, \mathrm{t}=180$. 
Figure 3.4-1 Layout of 2-D model flow domain with shearer located in the middle of a cutting sequence cutting from HG to TG. Numbered circles represent the locations of the 10 proposed MWS nodes. .45

Figure 3.4-2 Defining active species within the species transport model definitions................47

Figure 4.1-1 Completed MWS sampling unit with sampling line and filter. .........................49

Figure 4.1-2 Completed sensor block containing the methane and climate sensors..................50

Figure 4.1-3 Solberg filter selected for final design of MWS prototype. ..............................54

Figure 4.1-4 Initial design of 3-D printed water ejector..............................................55

Figure 4.1-4 Ejectors performance curve as a function of operational suction pressure [35].....56

Figure 4.1-5 Images of 3-D printed multi-nozzle ejector..............................................57

Figure 4.1-6 Multi-nozzle ejector performance curve at constant inlet pressure of 55 psig. .......58

Figure 4.2-1 Rise and Decay time definitions for a sensor's response to a step input...............60

Figure 4.2-2 Non-linear calibration curve of the MQ-4 Sensor. ..........................................61

Figure 4.2-3 MQ-4 response to 1.01\% methane input. ..................................................61

Figure 4.2-5 Dynament response to $1.01 \%$ methane input............................................62

Figure 4.2-6 a) Linear span calibration for Gasmitter sensor. b) Performance at lower detection

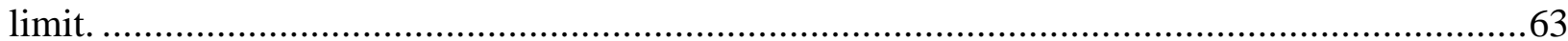

Figure 4.2-7 Gasmitter response to $1.01 \%$ methane. .................................................63

Figure 4.2-8 Evaluation to system response to step inputs of $1.01 \% \mathrm{CH}_{4}$ for durations of: 50, 40, 30, 20, and 10 seconds. a) MQ-4 Sensor, b) Dynament Sensor, c) Gasmitter Sensor.................66

Figure 4.2-9 Dynamic response of Gasmitter sensor to periodic step inputs at durations (frequencies) of: a) 40, b) 30, c) 20, d) 10, and e) 5 seconds ..........................................68

Figure 4.2-10 Projected Gasmitter dynamic response characteristics to periodic step inputs of $1 \% \mathrm{CH}_{4}$. Equivalent to the amplitude ratio and dynamic error...........................................69

Figure 4.2-11 Definitions used to evaluate ramp input results........................................69

Figure 4.2-12 MWS Response to the ramp input........................................................... 70

Figure 4.3-1 Linear Baseline Emission Profile......................................................... 72

Figure 4.3-2 Constant shearer rate and constant ventilation rate profile..............................72

Figure 4.3-3 Resulting methane profile from fluctuations in ventilation rate while shearer rate

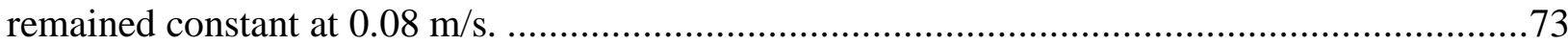

Figure 4.3-4 Nodal concentration profile of Node 5 from a single pass simulation..................74

Figure 4.3-5 Laboratory evaluation of MWS performance using 'Node 5' simulation data.

Fluctuation in ventilation rates at increments of: a) 6, b) 9, c) 12, d) 15 , e) 18 , and f) 21 seconds.

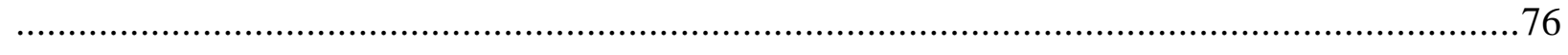

Figure 4.3-5 State flow diagram used in Simulink to complete production analysis. ................78 Figures 4.4-1 First-order reconstructed output of MWS with time constant of 16.5. a) Real-time delayed signal. b) Time aligned to input data......................................................... 81

Figure 4.4-2 Program controlled reconstruction technique utilizing a rise constant of 20, decay constant of 12 , and a cancelation threshold of $0.07 \mathrm{CH}_{4} / \mathrm{s}$.

Figure 4.4-3 Time aligned reconstructed MWS output from program-controlled method. a) continuous data. b) Parity plot showing improved correlation.

Figure 4.4-4 Reconstructed output capturing all six events where methane spikes above $1 \% \mathrm{CH}_{4}$. 
Figure 4.5-1 2D Model domain of longwall face during production where shearer is located near the start of a pass $(70 \mathrm{~m})$ from $\mathrm{HG}$ to $\mathrm{TG}$.

Figure 4.5-2 Development of methane distribution along the longwall face for the shearer cutting near the HG.

Figure 4.5-3 2D Model domain of longwall face during production where shearer is located hallway through a pass $(152 \mathrm{~m})$ from $\mathrm{HG}$ to $\mathrm{TG}$.

Figure 4.5-4 Development of methane distribution along the longwall face for the shearer cutting halfway through a cutting sequence.

Figure 4.5-5 2D Model domain of longwall face during production where shearer is located near the end of a pass (224 $\mathrm{m}$ ) from HG to TG.

Figure 4.5-6 Development of methane distribution along the longwall face for the shearer cutting near the TG. 


\section{Table of Tables}

Table 2.2-1 Average working longwall coal mine dimensions. ..........................................

Table 2.3-1 Average Coalbed Methane Content and Rank of Coal by U.S. State reported in 1986.

Table 2.3-2 Coal production analysis from previous work [9] ........................................ 10

Table 2.3-3 Average cutting (production) rate for a single $750 \mathrm{ft}$ pass [8]............................11

Table 2.3-4 Average cutting (production) rate for a single $1000 \mathrm{ft}$ pass [8]..........................11

Table 2.4-1 Average ventilation velocity along the longwall face ......................................15

Table 3.1-1 List of filters selected for experimental testing............................................27

Table 3.4-1 General dimensions of 2-D longwall model. .............................................45

Table 4.1-1 Examination of flow restriction across dry unloaded filter at various flow rates. .....51

Table 4.1-2 Spectre Filter coal dust loading results....................................................51

Table 4.1-3 Cylindrical Filter (white) coal dust loading results........................................52

Table 4.1-4 Solberg Filter (black) coal dust loading results. ............................................52

Table 4.1-5 Spectre Filter (Blue) water loading results. ......................................................53

Table 4.1-6 Cylindrical Filter (White) water loading results. ..........................................53

Table 4.1-7 Solberg (Black) water loading results. ........................................................53

Table 4.1-8 Performance of initial ejector design at constant air suction pressure. ...................56

Table 4.1-9 Performance of multi-nozzle ejector with constant air suction pressure...................58

Table 4.2-1 Rise and Decay times for the MQ-4, Dynament, and Gasmitter sensors. ................64

Table 4.2-2 Rise and Decay times for tunned Gasmitter sensor.........................................65

Table 4.2-3 Collective results of the various duration tests with errors of the three sensors.......67

Table 4.3-1 1-D Model Parameters ............................................................................. 71

Table 4.3-2 Average regional methane content of coal. ......................................................71

Table 4.3-3 List of evaluation points and the resulting minimal and maximal methane

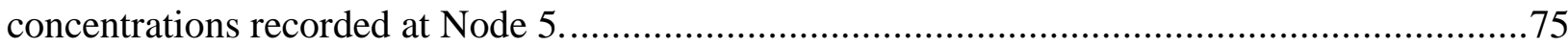

Table 4.3-4 Various production rates and reported max concentration at TG for a single pass. ..77

Table 4.3-5 Production analysis with transient ventilation rates.........................................78

Table 4.4-1 Error analyses showing improved accuracy with the reconstructed technique. ........83

Table 4.5-1 CFD nodal results of the HG, midway, and TG geometries................................85 


\section{Acronym/Abbreviation}

${ }^{\circ} \mathrm{C}$

A

AFC

ANN

BSL

C

$\mathrm{C}_{2} \mathrm{H}_{6}$

CAD

CBM

CFD

CFL

cfm

CFR

$\mathrm{CH}_{4}$

$\mathrm{CPH}$

DAQ

DLL

fpm

$\mathrm{ft}$

g

GD

h

$\mathrm{H}_{2} \mathrm{O}$

$\mathrm{HG}$

HV-A

in

in $_{2} \mathrm{O}$

IRS

$\mathrm{kPa}$

$\mathrm{k} \Omega$

$\mathrm{L}$

LEL

LPM

LVA

LW

$\mathrm{m}$

$\mathrm{mA}$
Word or Phrase

Degree Celsius

Area

Armored Face Conveyer Artificial Neural Network

Beam Stage Loader

Velocity

Ethane

Computer Aided Design

Coal Bed Methane

Computational Fluid Dynamics Courant-Fredrick-Lewy Criterion

Cubic Feet per Minute Code of Federal Regulations

Methane

Central Processing Hub

Data Acquisition

Dynamic Link Library

Feet per Minute

Foot

Gram

Gas Divider

Height

Water

Headgate

High Volatile A

Inch

Inches of Water

Infrared Sensor

Kilopascal

Kilohm

Length

Lower Explosive Limit

Liters per Minute

Longwall Visual Analysis

Longwall

Meter

Milliampere 


MCP
MFC
min
MOS
MSHA
MWS
NDIR
NIOSH
PDE
ppm
psia
psig
PTFE
PUD
RANS
RH
s
SCF
SCFM
SF9
SIMPLE
SLPM
SME
SnO
t
T.E.
TG
TUD
V
VAM
VDC

Methane Control and Prediction
Mass Flow Controller
Minutes
Metal-Oxide-Semiconductor
Mine Safety and Health Administration
Methane Watchdog System
Non-Dispersive Infrared
National Institute of Occupational Safety and Health
Partial Differential Equation
Parts per Million
Pounds per Square Inch Absolute
Pounds per Square Inch Gauge
Polytetrafluoroethylene
Procedural Utilization Degree
Reynolds-Averaged Navier Stokes
Relative Humidity
Seconds
Standard Cubic Feet
Semi-Implicit Method for Pressure-Linked Equations
Standard Liters per Minute
Specific Methane Emissions
Tin Dioxide
Time or time step
Truncation Error
Tailgate
Standard Cubic Feet per Minute
Time Utilization Degree
Volt
Ventilation Air Methane
Volts of Direct Current




\subsection{Introduction}

The following research presents the design and development of a new methane detection network for longwall coal mining that promotes a safer and more productive work environment. Access to a working underground mine was prohibited at this stage of development, therefore 1-D and 2-D modeling techniques were employed to generate methane profiles that were characteristic of a working mine. The methane profiles provided data sets that were used for the examination of system performance within the laboratory setting. The MWS's performance was defined as the ability for the system to accurately capture temporal methane emissions in nearly real-time as they are transported past the units. Additionally, controlled inputs (step and ramp) characterized the MWS's response profile which gave rise to a signal sharpening method. The sharpening technique improved system performance by reducing real-time measurement error and response time. The nodal array of sensors the detection network provides throughout the longwall support the opportunity for additional control strategies that aim to monitor and control methane emissions.

\section{Longwall Coal Mining}

Longwall coal mining is a highly productive form of underground coal extraction. Their operations support the mining industry in producing over 500 million short tons of coal every year to meet energy demands in the United States (U.S.) [1]. Though longwall mining is considered the safest form of underground mining, remote operations impose significant limitations to emergency rescue teams and control of unexpected situations. Figure 1.0-1 presents the general layout of a longwall mining operation and includes the key components and equipment used. With today's technological advances, automation and control have been adapted in many industries to promote

production and safety among large operations like underground mining. However, due to the high level of uncertainty and unpredictability of the atmospheric parameters underground, automation and control techniques are limited and therefore the degree of utilization still suffers. 


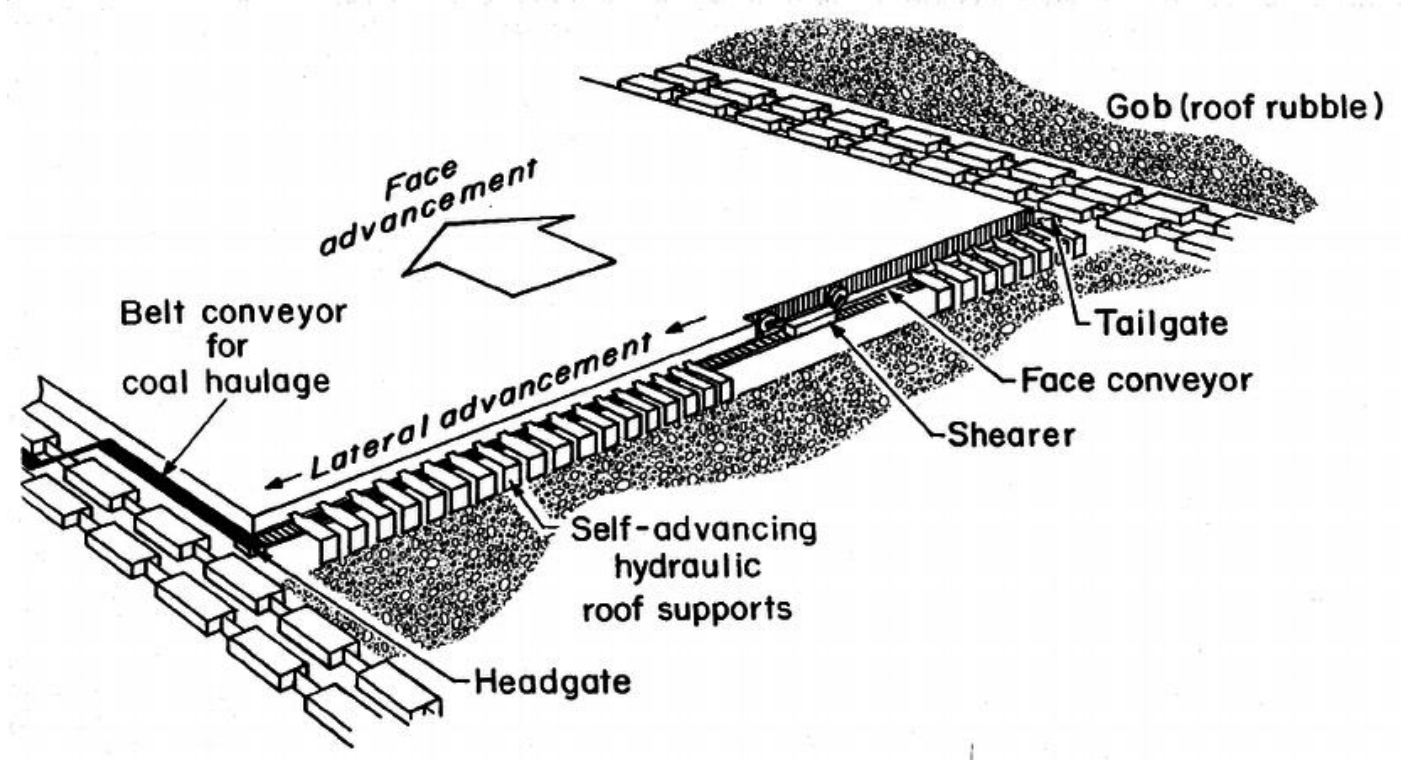

Figure 1.0-1 General layout of longwall mining operations and equipment used to mine a panel of coal [2].

Discontinuity in longwall production can be the result of many factors. Unscheduled shutdowns or reduced rates of production are commonly the result of mechanical complications and methane related events. Methane plays an important role in the overall production of a coal mine as it is heavily regulated to prevent any chances of explosions within the working area. An explosion or even flare up within an underground mine can be catastrophic given the nature of the mining environment and has led to fatal incidents in the past. Methane is a natural component of coal, therefore its release is a direct consequence of mining and fracturing the coal in the extraction process.

Methane emissions, ventilation rates, and several other mining processes are monitored during operation and must comply with local and federal regulation standards for mining to continue. Every longwall coal mine must adapt a specific plan when starting a new mine that proposes mining methods and ventilation strategies to safely extract the coal of that region. In the U.S., current standards set forth by the Code of Federal Regulations (CFR) mandate methane concentrations in any working section of the mine cannot exceed 1\%. In the event a concentration exceeds this threshold, all powered equipment must be de-energized and full disconnection of power when $1.5 \%$ methane is present. Minimal ventilation air requirements are stated within the CFR Part 30 Section 75, however these standards often vary from mine to mine and are exceeded in order to achieve their local mining and ventilation plan [3]. 
Regulatory checks are performed by the section boss or a certified worker during his or her shift and are often performed twice a shift (every four hours of an eight-hour shift) at designated locations. These tests include a measurement of both methane concentration and ventilation rate with an MSHA approved handheld device. Samples are limited to the precision and placement of the user as they are taken at an arm's length and averaged over a given time. A single methane sensing head is also located on the shearer and continuously samples during production. The sensor on the shearer is calibrated regularly and has the ability to deactivate the shearer when $1 \%$ methane is detected. Currently, this sensor only serves that purpose and provides no additional information to the operator. Because of this, unplanned shutdowns due to elevated methane emissions are common and significantly contribute to lost production time.

\section{Project Background}

The Methane Watchdog System (MWS) consists of an array of sensors contained within several sampling units that can be placed along the entire longwall section and continuously monitor atmospheric parameters. A second generation system is currently being developed under the funding of the Alpha Foundation to promote mine safety with a particular interest in methane detection [4]. Current methane monitoring techniques are limited among many mining operations and still impose serious threats to both the miner's safety and production utilization. The MWS would be a cost-effective approach to combating the constant uncertainty of methane formation as it fluctuates due to mining operations. The system will also possess some "intelligent" features that aid in prediction and accident avoidance. Data collected from production history will also be beneficial in planning future mining operations and may promote optimized cutting sequences.

The current design of the MWS consists of 10 sampling units, each with the ability to sample from two locations (front and back of shield). The samples collected from each unit report and process the data at a central processing hub $(\mathrm{CPH})$, which is remotely located in a safe location. The prototype is presented in Figure 1.0-2, undergoing developmental testing at the WVU Reedville wind tunnel. The primary targeted parameter of the MWS is methane, at concentrations less than $2 \%$. Note the lower explosive limit (LEL) of methane is $5 \%$ when mixed with air. Each prototyped unit was also equipped with temperature, pressure, and relative humidity $(\mathrm{RH})$ sensors. Initial attempts were made to include anemometers for wind speed measurements on the units near the headgate $(\mathrm{HG})$ and tailgate (TG) regions of the longwall. Figure 1.0-3 is an inside shot of one of 
the 10 sampling units containing the sensors and internal components of the first-generation prototype.

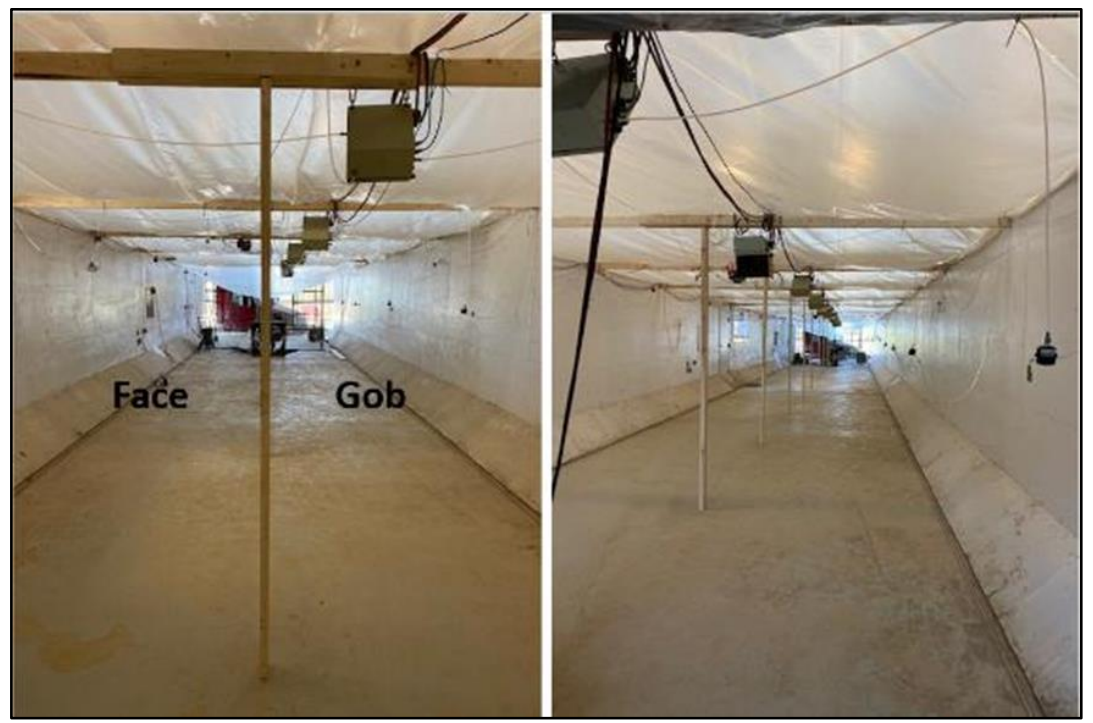

Figure 1.0-2 Ten sampling units of the MWS deployed at mock mine in WVU's research wind tunnel. Dimensions of mock longwall: 4.9 x 2.4 x $30.5 \mathrm{~m}(16 \times 8 \times 100 \mathrm{ft})$

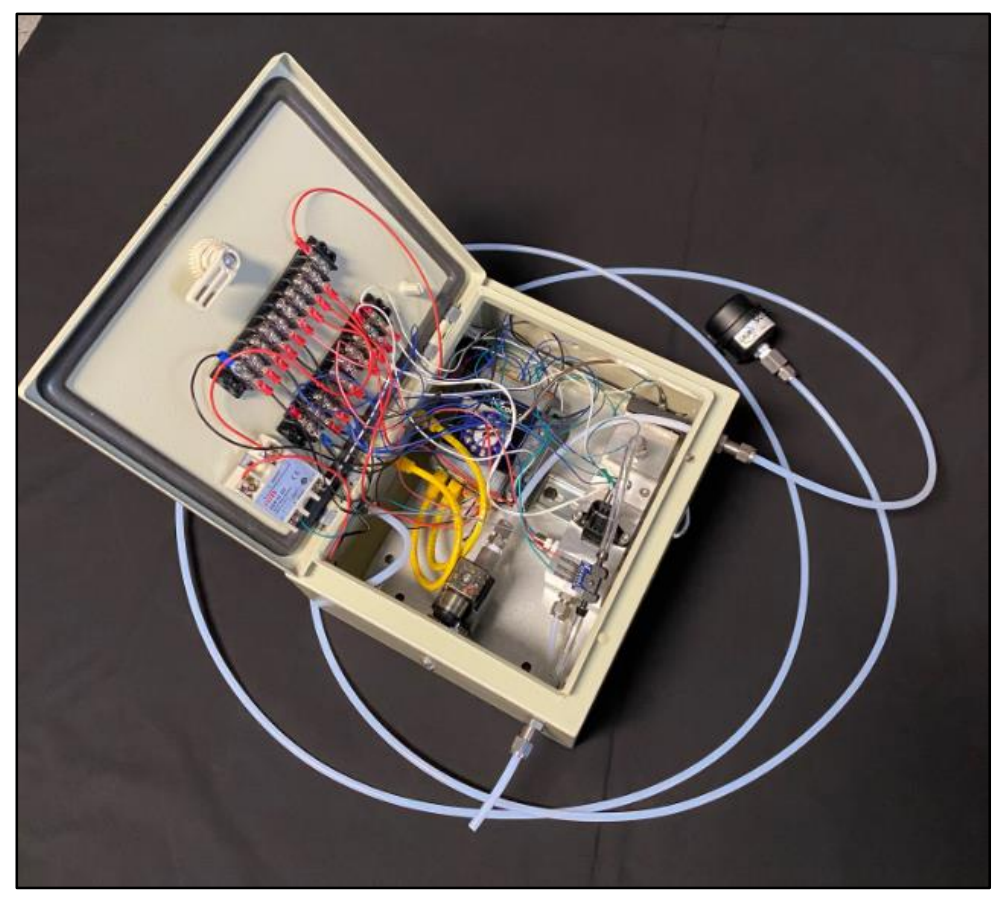

Figure 1.0-3 Inside of a first-generation prototype MWS sampling unit that contains sensors including: Metal-Oxide-Semiconductor (MOS) and Infrared (IRS) type methane sensors, temperature, absolute pressure, and relative humidity. Control and data transmissions devices are also included and consist of 3-way valve, de-energizing relay, and data acquisition device. 


\section{Objectives and Tasks}

The objective of this work is to evaluate the effectiveness and utilization of the MWS for further development towards future integration. The functionality of the MWS will be assessed through models and methods to simulate system response and identify limitations. In addition, when adopting a multi-nodal network in the longwall mining environment, system responses must be rapid and accurate to utilize effective adaptive control for minimizing risk and downtime. These results will lead to a proposal of simple control strategies to control methane formation and increase production if possible.

The overall objective was met by a series of tasks that aimed to evaluate the total system for its effectiveness and capabilities. To achieve the overall objectives my research focused on the following key areas:

- Data collection and review of relevant literature as it pertained to the characteristics of methane within the longwall mines.

- Developing 1-D and 2-D models from the collected data to represent the longwall mining environment.

- Evaluating and characterizing the MWS's response through theoretical scenarios generated by the models.

- Assessing signal reconstruction techniques to improve system effectiveness and accuracy.

\subsection{Review of Literature}

\subsection{Longwall Coal Mining Methods}

When developing a novel instrument such as the MWS that consists of an array of sensors, it is important to understand the environment in which they will operate. The environment will impose not only spatial limitations in the design and concealment of such system but will also challenge the integrity and accuracy of the sensors onboard. Therefore, these factors must be taken into consideration when developing and proposing an effective control strategy for the MWS, as it may be possible to integrate collected data into automation strategies with the other equipment.

Longwall coal mining is a form of highly productive underground mining that uses a shearer to cut the coal in large sections called panels. The shearer traverses back and forth along the section of coal on the armored face conveyor (AFC) as it cuts the coal away from the face and on to the 
conveyor below. The coal is carried out along the face to the beginning of the panel or HG where it is crushed and continues on its way out of the mine. As the shearer makes a pass along the face, large hydraulic roof supporting shields will advance and support the newly exposed roof. Any coal that is left above along with rock makes up the roof, which falls behind the shield as it advances with each pass. This area of coal left behind the shield is referred to as the gob and creates a porous void that acts as a source and sink for methane.

Other methods of underground coal extraction include the use of mechanized plow systems for low seams as well as room and pillar mining which uses a continuous miner as opposed to the shearer. The MWS may be configured and implemented within all these forms of mining, however this research focused only on the innerworkings of longwall coal mining and its integration within current shield designs.

\subsection{Dimensions and Scale}

Characteristic dimensions of working longwalls vary from region to region due to geological differences and resources, therefore an average length and effective cross-sectional area were considered from relevant data to support the developed models. Figure 2.2-1 presents the general flow domain of the working section (longwall face) on which dimensions were based. Krog presented longwall dimensions collected from reports that showed the increase in longwall panel dimensions from 1990 to 2014. The reported values showed an average panel width (i.e. longwall face length) increase from 210 to $370 \mathrm{~m}$ (700 to $1200 \mathrm{ft}$ ) and an increase in length from 2100 to $3400 \mathrm{~m}$ (7,000 to 11,000 ft) (i.e. increased number of passes). As a result, the average panel acreage increased from 100 to 300 acres per panel [5]. In 2009, an analysis was performed which aimed to compare both plow and shearer performance in longwall mining of medium seam thickness to produce a cost and optimization evaluation. The optimized model consisted of a longwall face length of $300 \mathrm{~m}(984 \mathrm{ft})$ with a seam thickness or equal face height of $1.8 \mathrm{~m}(5.91 \mathrm{ft})$ [6].

Consequently, an increase in production scale over the last 25 years has imposed a greater risk of methane occupying the working area. A study completed in 2006 aimed to predict longwall methane emissions that resulted from increasing longwall face length in a Pittsburgh coalbed [7]. The actual working face in their study was $315 \mathrm{~m}$ (1032 ft), and projections for methane emission rates were made up to $488 \mathrm{~m}(1600 \mathrm{ft})$. The coal thickness or height $(\mathrm{h})$ of the working area was 2.0 to $2.4 \mathrm{~m}(6.5-8.0 \mathrm{ft})$. Based on the time period and region of mining, it was more than likely 
a typical shield had a canopy length of $4.9-6.1 \mathrm{~m}(16-20 \mathrm{ft})$. From this, an assumed effective width of the longwall was $4.9 \mathrm{~m}$ (16 ft). Another study conducted a similar set of experiments that evaluated differences in two adjacent longwalls in Pocahontas No. 3 Coalbed (VP-1 Mine and VP3 Mine) [8]. The VP-1 Mine had a working longwall face of $228.6 \mathrm{~m}$ (750 ft) whereas the VP-3 Mine was $304.8 \mathrm{~m}(1000 \mathrm{ft})$. Coal thickness ranged from 1.5 to $1.9 \mathrm{~m}$ (5.0 to $6.3 \mathrm{ft}$ ) at the VP-1 site and 1.7 to $2.0 \mathrm{~m}$ (5.5 to $6.5 \mathrm{ft}$ ) at the VP-3 site. Once again, an effective width was assumed to be $4.8 \mathrm{~m}$ (16 ft). A later study was conducted in a longwall section of a Lower Kittanning mine in central Pennsylvania where continuous monitoring of both ventilation air flow and methane emissions were recorded in the return airways [9]. The longwall face in that study was $178.3 \mathrm{~m}$ $(585 \mathrm{ft})$ long and had an average thickness of $1.37 \mathrm{~m}(4.5 \mathrm{ft})$. The type of shield used during these operations was unknown, though they were reported to have four 42-ton-capacity hydraulic props. An effective width was assumed to be less than that of the more recent studies due to smaller operations and age of equipment. Table 2.2-1 shows a summary of the collected dimensions from the previous studies. The dimensional values found here appear to get larger with time. This finding supports other claims and projections made to the increasing size of longwall panels of recent years and will be considered when defining an effective flow domain for the respective models.

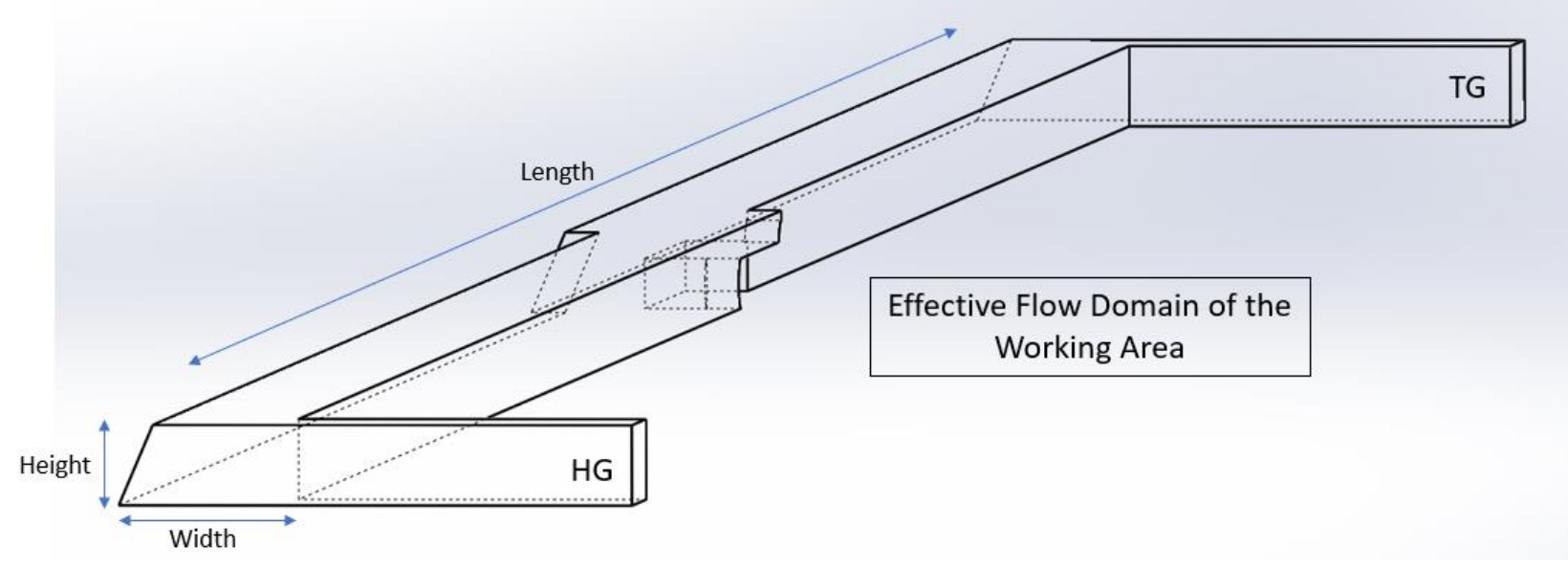

Figure 2.2-1 Reference for selected dimensions used to construct relevant models. 
Table 2.2-1 Average working longwall coal mine dimensions.

\begin{tabular}{cccc}
\hline \hline \multirow{2}{*}{ Mine } & Length & Width & Height \\
\cline { 2 - 4 } & {$[\mathbf{m}(\mathbf{f t})]$} & {$[\mathbf{m}(\mathbf{f t})]$} & {$[\mathbf{m}(\mathbf{f t})]$} \\
\hline Optimization Model (2009) & $300(984)$ & $4.9(16)$ & $1.8(5.9)$ \\
Pittsburgh Coalbed (2006) & $315(1032)$ & $4.9(16)$ & $2.0-2.4(6.5-8.0)$ \\
Pocahontas No.3 VP-1 (1999) & $229(750)$ & $4.9(16)$ & $1.5-1.9(5.0-6.3)$ \\
Pocahontas No.3 VP-3 (1999) & $305(1000)$ & $4.9(16)$ & $1.7-2.0(5.5-6.5)$ \\
Lower Kittanning (1969) & $178(585)$ & $<4.9(16)$ & $1.4(4.5)$ \\
\hline Average & $\mathbf{2 6 5 ( 8 6 9 )}$ & $\mathbf{4 . 9 ( 1 6 )}$ & $\mathbf{1 . 8 ( 5 . 9 )}$ \\
\hline \hline
\end{tabular}

\subsection{Methane Sources and Its Formation Along the Longwall}

Methane is a natural component of bituminous coal as a result of its formation. Coal is typically classified by several physical and chemical characteristics that define the overall quality of the coal as it matures from peat to anthracite. Figure 2.3-1 below depicts the stages and characteristics of coal as it transitions from its beginning composition (left of graph) to its purest form and highest rank (right of graph) [10]. The methane content of coal varies with these stages of coal formation; therefore, it is important to address this parameter when attempting to quantify released methane due to production in an underground coal mine.

\begin{tabular}{|c|c|c|c|c|c|c|c|c|c|c|c|c|c|c|}
\hline \multirow{4}{*}{$\begin{array}{l}D \\
D\end{array}$} & \multicolumn{5}{|c|}{ Low-rank coal } & \multirow{2}{*}{\multicolumn{5}{|c|}{$\frac{\text { Medium-rank coal }}{\text { Bituminous }}$}} & \multirow{2}{*}{\multicolumn{3}{|c|}{$\frac{\text { High-rank coal }}{\text { Anthracitic }}$}} & \multirow{4}{*}{$\begin{array}{c}\text { Method } \\
\text { for } \\
\text { determining } \\
\text { rank } \\
\text { (dmmf) } \\
\text { (U.S. ASTM) }\end{array}$} \\
\hline & \multirow{2}{*}{\multicolumn{2}{|c|}{ Lignite }} & \multirow{2}{*}{\multicolumn{3}{|c|}{$\begin{array}{c}\text { Sub- } \\
\text { bituminous }\end{array}$}} & & & & & & & & & \\
\hline & & & & & & \multirow{2}{*}{ 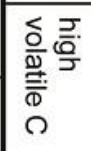 } & \multirow{2}{*}{ 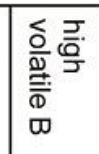 } & \multirow{2}{*}{ 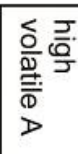 } & \multirow{2}{*}{ 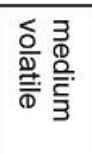 } & \multirow{2}{*}{ 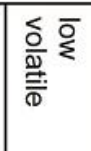 } & \multirow{2}{*}{ 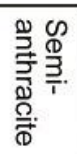 } & \multirow{2}{*}{ 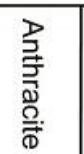 } & \multirow{2}{*}{ 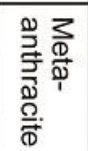 } & \\
\hline & $\infty$ & $D$ & 0 & $\infty$ & $D$ & & & & & & & & & \\
\hline & & & w & & 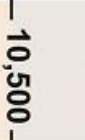 & $\overrightarrow{\vec{V}}$ & $\begin{array}{l}\vec{\omega} \\
\dot{े} \\
\dot{0}\end{array}$ & $\overrightarrow{8}$ & Less & distinct & r chang & ng rank & & $\begin{array}{l}\text { Calorific } \\
\text { value } \\
\text { (Btu/lb.) }\end{array}$ \\
\hline & & & Less $d$ & $n c t$ & changir & g rank & & & & N & & & & $\begin{array}{c}\text { Volatile } \\
\text { matter } \\
(\%)\end{array}$ \\
\hline & & & Less d & & chans & grank & & & 1 & $\infty$ & & & 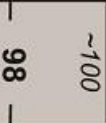 & $\begin{array}{c}\text { Fixed } \\
\text { Carbon } \\
(\%)\end{array}$ \\
\hline
\end{tabular}

Figure 2.3-1 U.S. coal rank system chart and the defining characteristics [10]. 
In 1982 the Bureau of Mines had organized a collection of approximately 1,500 coal samples from the previous decade. These core samples originated from more than 250 coal beds in the U.S. and provided gas content values for direct-method determination of local preliminary mining strategies. Eastern U.S. coal beds including Pennsylvania and West Virginia as well as central regions such as Colorado, New Mexico, and Oklahoma were reviewed for average coalbed gas content and rank of coal. The relative data can be found below in Table 2.3-1 [11].

Table 2.3-1 Average Coalbed Methane Content and Rank of Coal by U.S. State reported in 1986.

\begin{tabular}{ccc}
\hline \hline Region/U.S. State & $\begin{array}{c}\text { Coalbed Gas Content } \\
\text { [SCF/Ton] }\end{array}$ & Rank \\
\hline Pennsylvania & 127 & HV-A \\
West Virginia & 173 & HV-A \\
Colorado & 120 & HV-A \\
New Mexico & 67 & Various Bituminous \\
Oklahoma & 344 & HV-A \\
\hline \hline
\end{tabular}

Methane becomes explosive within the range of 5-15\% at standard atmospheric conditions, therefore it is important to monitor and control when maintaining a safe and productive work environment underground. Unfortunately, the gases presence and formation within the coal seam can be rather difficult to predict due to the dynamic nature of underground mining. Due to the global variance and uncertainty of coal bed methane (CBM) that may be expected at a working site, both a direct and indirect approach were taken when gathering relative data from previous studies. Geological surveying data as well as reported values found within active production sites were used to access the sensitivity of methane content as a function of mining and ventilation.

\section{Methane Formation and its Influence on Productivity}

Methane levels can rise as production rates increase from the advances in technology and automation among longwall mining. These elevated emissions can have a negative effect on production as levels rise above regulatory limits and impose shutdowns. Production studies were completed to access the overall performance of longwall coal mining and to identify production limitations with a particular interest in methane related events. Time utilization degree (TUD) and procedural utilization degree (PUD) were indicators used to measure productivity for a given shift. TUD expresses the percentage of the shearers total daily operating time to the daily working time, 
while PUD measures the productivity due to a chosen procedure for the daily working time. As of 2008, longwalls on average can experience a TUD between 40 and 70\% [6]. These inhibitors of performance are the result of both routine maintenance and unplanned events from methane concentrations exceeding regulatory limits.

A production analysis from the VP-1 and VP-3 mines categorized data into three bins that were defined by the percentage of delay time: All Data, <50\% delay, and <25\% delay [8]. With <25\% data being the most stringent case where delay time during segment passes was minimal, data collected within this scenario were minimal and showed how significant delay time was throughout production due to elevated methane levels. No ventilation flow rates were reported, only flow rates of methane, therefore an actual percentage profile of methane experienced during the study was unknown.

Production data were compiled from a study in a central Pennsylvania coal mine as provided in the Table 2.3-2. It is noted that this study was older but did provide useful data regarding production utilization [9].

Table 2.3-2 Coal production analysis from previous work [9].

\begin{tabular}{|c|c|c|c|c|}
\hline \multicolumn{5}{|c|}{ Production data from 1969 Study } \\
\hline Working & Idle & Coal Produced & Production Rate & Idle Percentage \\
\hline [min] & [min] & [tons] & [Tons/min] & {$[\%]$} \\
\hline 140 & 340 & 180 & 1.286 & 71 \\
\hline 30 & 450 & 40 & 1.333 & 94 \\
\hline 10 & 470 & 1 & 0.100 & 98 \\
\hline 120 & 360 & 154 & 1.283 & 75 \\
\hline 45 & 435 & 58 & 1.289 & 91 \\
\hline 0 & 480 & 0 & 0.000 & 100 \\
\hline 110 & 370 & 131 & 1.191 & 77 \\
\hline 180 & 300 & 231 & 1.283 & 63 \\
\hline 100 & 380 & 129 & 1.290 & 79 \\
\hline 0 & 1400 & 0 & 0.000 & 292 \\
\hline 0 & 1440 & 0 & 0.000 & 300 \\
\hline 120 & 360 & 154 & 1.283 & 75 \\
\hline 0 & 480 & 0 & 0.000 & 100 \\
\hline 152 & 328 & 185 & 1.217 & 68 \\
\hline 155 & 325 & 199 & 1.284 & 68 \\
\hline 120 & 360 & 154 & 1.283 & 75 \\
\hline 45 & 435 & 59 & 1.311 & 91 \\
\hline 130 & 350 & 167 & 1.285 & 73 \\
\hline
\end{tabular}

Note: Approximately 200 tons of coal were produced during a single pass. Average Production Rate $=0.9288$ tons $/ \mathrm{min}$ (volumetric equivalent $=22.1 \mathrm{cfm})$ 
Production rates directly correlated to the shearer velocities. Shearer velocities were much slower than ventilation velocities along the face. Mitchell examined various shearer and cutting methods and peak shearer velocities ranged from 0.16 to $0.25 \mathrm{~m} / \mathrm{s}$ (32 to $50 \mathrm{fpm}$ ) [12]. Similar values of 0.17 to $0.25 \mathrm{~m} / \mathrm{s}$ (33 to $50 \mathrm{fpm}$ ) were also referenced in Guidelines for the Prediction and Control of Methane Emissions in Longwalls [13]. Krog et al., later referenced average shearer velocities as $0.23 \mathrm{~m} / \mathrm{s}$ (46 fpm) with an average longwall face ventilation velocity of $2.5 \mathrm{~m} / \mathrm{s}$ (500 fpm) [14]. Shearer rate data were also compiled from a 1999 NIOSH study and are presented in Tables 2.3-3 and 2.3-4.

Table 2.3-3 Average cutting (production) rate for a single 750 ft pass [8].

\begin{tabular}{cccc}
\hline \hline \multicolumn{4}{c}{ Avg. Single pass data (750ft long face) } \\
\cline { 2 - 4 } Working & Idle & Total Time & Shear Rate \\
\hline [min] & [min] & [min] & [fpm] \\
\hline 45.8 & 6 & 51.8 & 14.5 \\
42.1 & 2.6 & 44.7 & 16.8 \\
39.9 & 1 & 40.9 & 18.3 \\
\hline Average & - & - & $\mathbf{1 6 . 5}$ \\
\hline \hline
\end{tabular}

Table 2.3-4 Average cutting (production) rate for a single $1000 \mathrm{ft}$ pass [8].

\begin{tabular}{cccc}
\hline \hline \multicolumn{4}{c}{ Avg. Single pass data (1000 ft long face) $\mathbf{1 9 9 9}$} \\
Working & Idle & Total Time & Shear Rate \\
\hline$[\mathbf{m i n}]$ & {$[\mathbf{m i n}]$} & {$[\mathbf{m i n}]$} & {$[\mathbf{f p m}]$} \\
\hline 65.9 & 27.7 & 93.6 & 10.7 \\
49.6 & 11.5 & 61.1 & 16.4 \\
\hline Average & - & - & $\mathbf{1 3 . 5}$ \\
\hline \hline
\end{tabular}

Yearly production reports are readily available for most mines in the country and can be dated back nearly 100 years. Unfortunately, the industry only reports coal production on a tons per year basis and a total number of hours worked by underground employment. Sometimes a production or efficiency rate can be found that divides the produced tons by the total number of hours worked to obtain a 'tons per miner hour'. These values provide little insight into deriving an equivalent emission rate based on a time varying volumetric removal. 


\section{Continuous Influence of Lost Coalbed Methane}

The methane content of bituminous coal is released or desorbed as a result of fracturing and shearing the coal. Therefore, the rate at which the coal is cut or produced can directly affect the methane concentrations downwind near the TG where the air exits the face. These emissions can be immediate contributors, whereas fallen coal in the gob is constantly releasing and accumulating methane as it is desorbed. Models and weighted contribution factors have been created in the past to better define methane sources. The development and usefulness of these models have proven difficult and limited however due to the environmental complexity and uncontrollable parameters of a working underground mine. These methane sources have been simplified and reduced to the following three major components: lost gas, desorbed gas, and residual gas [15].

When predicting methane emissions along the face and determining its correlation to production, a few considerations must be examined. Standard practice in longwall coal mining requires fresh ventilated air to always flow from HG to TG along the working section of the face. The shearer on the other hand, will cut coal in both the HG to TG and TG to HG directions in a bi-directional cutting procedure. This meant that coal is mined both with and against the direction of ventilated air with each pass. Because of this, the question may arise whether methane emissions are greater at the TG (downstream of ventilation) for one of these scenarios. It was reported that methane emissions were slightly higher in $\mathrm{HG}$ to TG passes than those of TG to HG [8]. From a production analysis conducted in their study, it was reasoned that elevated emissions may have been the cause of longer production times required to cut in the HG to TG direction, allowing more time for methane to bleed off from the recently fractured coal.

In 2006, a case study was conducted that aimed to predict longwall methane emissions as a consequence of increasing longwall face lengths [7]. Their findings were more complete and provided insight to methane emission profiles along the face for uninterrupted production. By implementing three stations where methane was continuously monitored at shields 20,80 , and 145, multiple passes were recorded in both the HG to TG and TG to HG directions. From these data, an analysis was performed on both a single pass and daily operational basis. The difference in concentrations measured between the consecutive sensors (shield locations) was plotted and fitted to form a linear relation, shown by Eq. 2.3.1. This equation was used to solve for expected methane concentrations for extended longwall faces of $426 \mathrm{~m}$ (1400 ft) and $488 \mathrm{~m}$ (1600 ft). From Eq. 2.3.1, a relationship was made from this trend and the amount of coal produced from the single 
pass. Note, methane was considered negligible at the entry and therefore no data were provided before the first sensor at shield 20 .

$$
y=0.0002329 x-0.00783 ; \quad R^{2}=0.993
$$

\subsection{Ventilation Plans}

Adequate ventilation along the longwall is crucial for the control of methane emissions in an active longwall site. Methane ventilation plans are required for all longwall mines. Such plans vary from mine to mine to overcome geological differences and ensure minimal federally regulated flow rates are upheld. Mining regions that experience increased levels of methane due to an abundance of CBM may require additional ventilation strategies such as bore hole degasification and inert gas injection techniques to combat fugitive gas. In addition, seam height and cross-sectional flow area vary, thus leading to variable flow velocities in mines. Ventilation goals aim to direct the majority of air across the face however some air flow is lost past curtains and into areas such as the gob. Complexities of pathways along the entry and returns of a longwall mining operation can limit the amount of available fresh air to send down the face. Because of these limitations, production may be stopped due to rising methane levels. Figure 2.4-1 presents an example of a typical bleederless U-System ventilation plan. The figure displays the pathways of the fresh air as it is brought into the mine, traverses the mining face, and returns to exit the mine. Other configurations and strategies exist such as the Y-System and methane drainage holes (borehole degasification) [16]. 


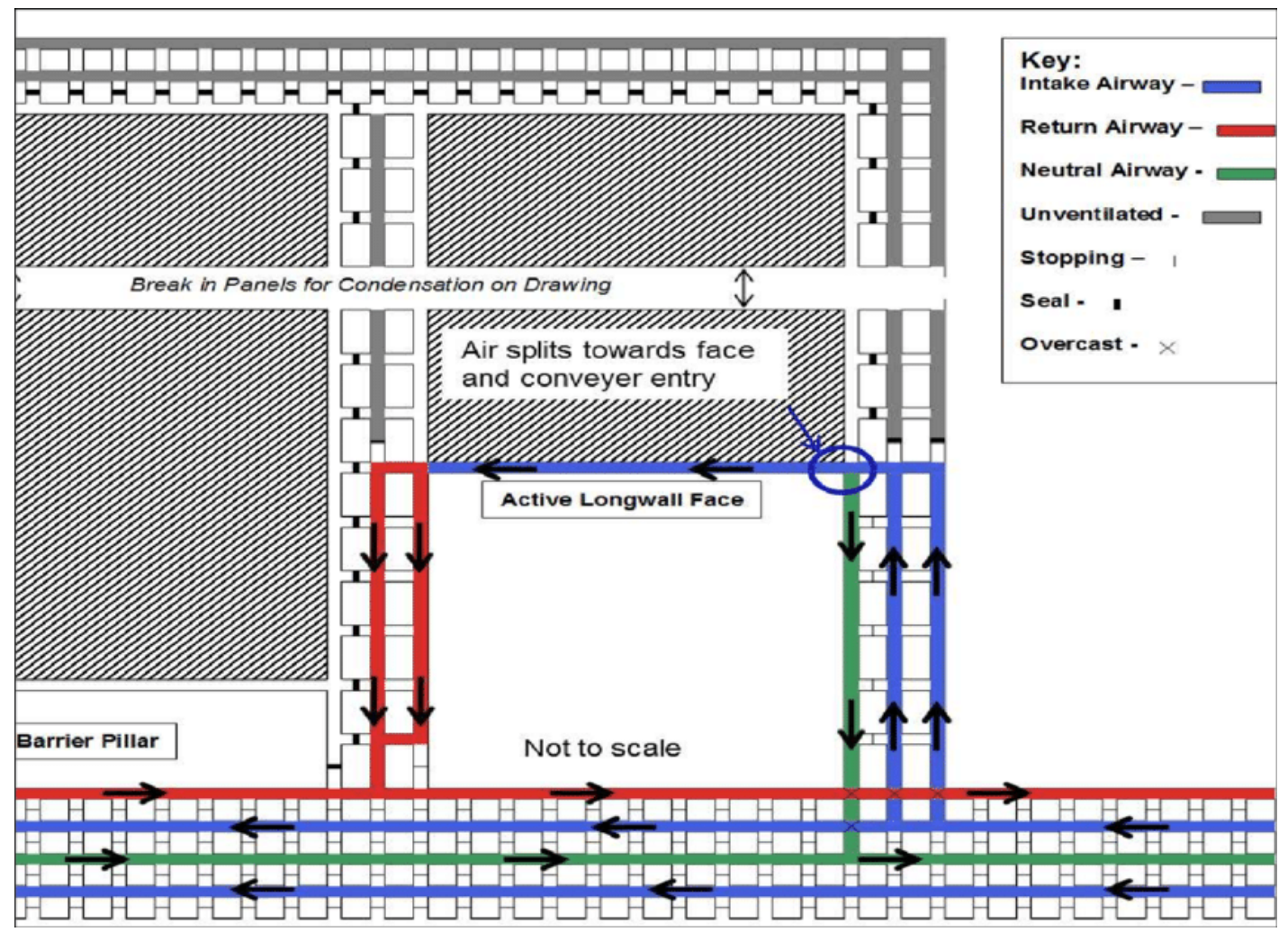

Figure 2.4-1 Example of Ventilation Plan (U-System Bleederless) [16].

Early studies showed dilution flow rates of $47.2 \mathrm{~m} / \mathrm{s}(100,000 \mathrm{cfm})$ with velocities over $5.1 \mathrm{~m} / \mathrm{s}$ (1000 feet per minute $(\mathrm{fpm})$ ). Krog et al., used sulfur hexafluoride $\left(\mathrm{SF}_{6}\right)$ releases to study air flow pattern along longwall faces and through ventilation systems. Velocities varied throughout the mine and along the face but they reported velocities as high as 3.6 to $6.1 \mathrm{~m} / \mathrm{s}$ (700 to $1200 \mathrm{fpm}$ ) [17]. Schatzel et al., also reported average face velocities from 2.2 to $3.0 \mathrm{~m} / \mathrm{s}$ (433 to $596 \mathrm{fpm}$ ) in another study [18]. Recently, modeling efforts presented average face velocities from around 1.5 to $4.6 \mathrm{~m} / \mathrm{s}$ (300 to $900 \mathrm{fpm})[14]$.

Methane emissions and airflow patterns in a bleederless longwall operation were studied by the Pittsburgh Mining Research Division (PMRD) and the U.S. National Institute for Occupational Safety and Health (NIOSH) [17]. This study was conducted in a western longwall coal mine with a working face of $300 \mathrm{~m}(984 \mathrm{ft})$ where the average face air velocities were reported to be 3.03 $\mathrm{m} / \mathrm{s}(596 \mathrm{fpm})$ at shield 57 and $2.20 \mathrm{~m} / \mathrm{s}(433 \mathrm{fpm})$ at shield 165 . The longwall used 176 shields to support the roof which had a mining height of $3.4 \mathrm{~m}(11 \mathrm{ft})$. A more recent study was also conducted at the NIOSH PMRD laboratory where a scaled physical model of a longwall operation was constructed to access the impact of caving on mine ventilation. The Longwall Instrumented 
Aerodynamic Model (LIAM) is a 1:30 scale physical model that geometrically represents a longwall panel with three back bleeders and a two-part heterogeneous gob. The model includes all critical details of the mining process such as the shearer, shields, and pan-line. Eight anemometers along the face and 32 anemometers within the gob captured velocity data as different caving scenarios were configured behind the shields. Resulting data suggested that ventilation air loss at the TG was greater when the void space behind the shields increased. Air velocities in the gob were reported to be as high at $0.61 \mathrm{~m} / \mathrm{s}(120 \mathrm{fpm})$ in a bleederless scenario [18].

From the Lower Kittanning study of 1969, air velocities were measured in the return airway of two different mining sections [9]. An average was taken from a set of measurements along the cross-section in a grid fashion with a hand-held, vane-type anemometer. The average velocity for the first section was $2.5 \mathrm{~m} / \mathrm{s}(495 \mathrm{fpm})$ at a cross-sectional area of $6.1 \mathrm{~m}^{2}\left(66 \mathrm{ft}^{2}\right)$ and $2.3 \mathrm{~m} / \mathrm{s}(454$ $\mathrm{fpm})$ at $7.7 \mathrm{~m}^{2}\left(83 \mathrm{ft}^{2}\right)$ for the second section. The respective volumetric flow rates would be 15.4 $\mathrm{m}^{3} / \mathrm{s}(32,670 \mathrm{cfm})$ and $17.8 \mathrm{~m}^{3} / \mathrm{s}(37,683 \mathrm{cfm})$. Values were also estimated by industry from a Pennsylvania mining operation to be $23.6 \mathrm{~m}^{3} / \mathrm{s}(50,000 \mathrm{cfm})$ of air along the face, where a velocity of $2.54 \mathrm{~m} / \mathrm{s}(500 \mathrm{fpm})$ at shield 20 and $2.03 \mathrm{~m} / \mathrm{s}$ (400 fpm) at shield 270 must be maintained. Table 2.4-1 shows the summary of ventilation data reviewed.

Table 2.4-1 Average ventilation velocity along the longwall face.

\begin{tabular}{ccc}
\hline \hline \multirow{2}{*}{ Mine } & $\begin{array}{c}\text { Velocity } \\
\text { HG and TG }\end{array}$ & Volumetric Flow \\
\cline { 2 - 3 } & {$[\mathbf{m} / \mathbf{s}(\mathbf{f p m})]$} & {$[\mathbf{c f m}]$} \\
\hline Western longwall & $3.03(596)$ and $2.20(433)$ & 105,000 \\
Lowe Kittanning & $2.50(495)$ and $2.31(454)$ & 32,670 and 37,683 \\
Pennsylvania mine & $2.54(500)$ and $2.03(400)$ & 50,000 \\
\hline Average & $\mathbf{2 . 6 9 ( 5 3 0 )}$ and $\mathbf{2 . 1 8}(\mathbf{4 2 9})$ & - \\
\hline Note: $\mathrm{HG}=$ Headgate, $\mathrm{TG}=$ Tailgate & & \\
\hline \hline
\end{tabular}

\subsection{Current Safety and Monitoring Devices}

Mining accidents and fatal events related to methane explosions have historically burdened the industry. The range at which methane becomes explosive in the presence of an ignition source is 5 to $15 \%$ by volume when mixed with air. Due to these low explosive ranges, methane emissions are heavily regulated in underground mining. Part 30 of the CFR contain key regulations and are summarized below [3]. 
- 75.342 - Methane Monitors

$\circ$ Require sensor on cutting machines and face equipment, placed as near the face as possible

- Provide a warning signal at $1 \%$ to enable a person to deenergize equipment

○ Automatically deenergize at $2 \%$

○ Monthly calibrations (31 days)

- 75.323 - Excessive Methane

- Changes to ventilation or work at $1 \%$

○ Removal of non-key personnel at $1.5 \%$

- Limit bleeders to $2.0 \%$

- 75.325 - Air Quantity

○ In longwalls - at least $30,000 \mathrm{cfm}$ at the face

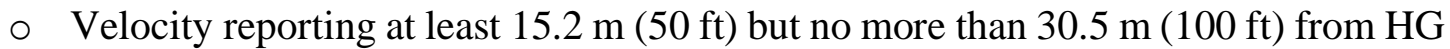
and TG, respectively

- Part 22-Portable Methane Detectors

- Minimum indication range of 0.25 to $4.0 \%$

- Other standards for permissibility

The workings of an underground coal mine possess many hazards and limitations when it comes to managing unexpected events such as flare ups or explosions. The closed channel like features of an explored mine with the presence of combustible coal dust particles could facilitate a combustion event and lead to a much more fatal event. Though the number of mines has decreased in the last 50 years, the amount of methane released from the existing mines has increased due to larger and more efficient mining practices [19].

\section{Regulatory Methane Measurements}

Methane emissions are rendered harmless through dilution with the fresh ventilation air that traverses the working area. Because this ventilation air is the only tool available underground to help regulate methane emissions as a result of mining, it is crucial that its supply is continuous and abundant. These two parameters are therefore regulated and require attention through the use of handheld and machine mounted devices. Methane concentration measurements conducted underground are typically completed by hand at a predetermined interval and location. A methane 
detector is also mounted on the shearer near the cutting face and continuously measures methane concentrations. The shearer mounted device is calibrated at regulatory intervals and is set to deenergize the equipment when a specific threshold is reached.

Figure 2.5-1 provides an example of a handheld methane detector that would be used to make admissible methane concentration checks. The sensor used onboard most of these MSHA approved devices operates on a catalytic bead or LEL type principle. Catalytic-type sensors, or catalytic combustion sensors, reduce the ignition temperature of combustible gasses as they interact with the catalytic material of the sensor element. As a result, oxidation of the gas molecule will occur and cause the temperature of the catalytic element to increase. The resulting temperature changes from the reaction of the target gas will vary the voltage output and therefore be correlated to the concentration of gas present [20].

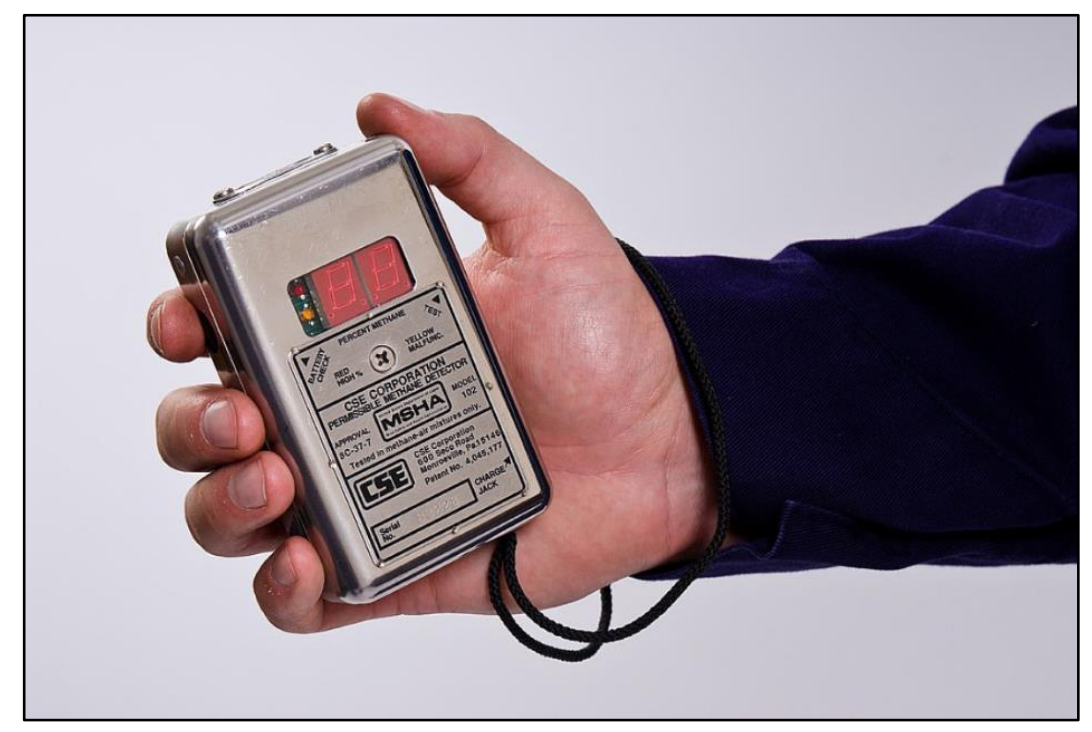

Figure 2.5-1 Common handheld methane detection device containing a catalytic bead type sensor used for regulatory checks [21].

The LEL type sensors have been an industry standard due to their robustness and fast response times. As a relatively inexpensive and easily maintainable sensor, it is suitable for the demands required in mining applications. Fast response times $(<20 \mathrm{~s})$ are crucial features of these types of sensors, as fluctuations in methane concentration may be considerable and short lived due to transport from ventilation rates of $\sim 2 \mathrm{~m} / \mathrm{s}$ (394 fpm). When developing a system such as the MWS and constructing an appropriate control strategy around its spatial recognition, sensor response 
times and sampling delays will ultimately define the systems effectiveness. Therefore, these characteristics must be accounted for and addressed when analyzing the model results.

\section{Regulatory Ventilation Measurements}

As previously mentioned, every longwall mine must adopt a ventilation plan that will adequately regulate methane emissions from production and comply with local and federal regulations. Similarly, to methane measurements, ventilations checks must be conducted at a respective location and interval during a working shift. At these check points a handheld anemometer is used by certified personnel to complete the air flow procedure. Historically, vane style anemometers have been the preferred instrument for making flow rate measurements underground as they require no complex or electrical components [22]. Digital versions of these vane style anemometers are now available and are pre-integrated with auditory and visual ques for performing regulatory procedures. Figure 2.5-2 provides examples of the handheld devices, with an older version of the vane style on the left and a more current example on the right.
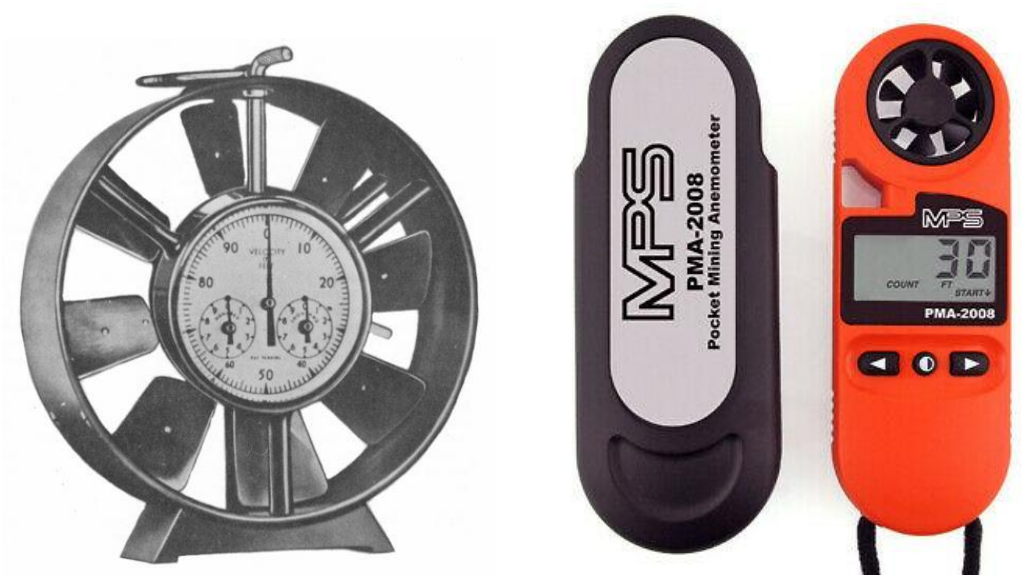

Figure 2.5-2 Common vane type anemometers used for air velocity measurements underground. An older analog version depicted on the [left] and a current digital pocket-sized instrument on the [right].

Limitations imposed by the inherent dangers of underground mining consequently limit the devices and methods deemed acceptable in the working environment. Therefore, current methane concentration and flow rate monitoring procedures possess a number of limitations. Methane measurements are typically both spatially and temporally limited to HG and TG regions and are only as accurate as the sensor's response characteristics. Air flow measurement errors contributed by the user have been reported to account for up to 30\% [23]. These errors and temporal gaps in 
velocity measurements can significantly contribute to lost time in the future and trends in air flow patterns as a longwall advances. An evaluation for the need of a real-time air velocity monitoring system over current practices in underground mines was conducted in 2013. Velocity measurements made along the face of three different longwalls by two different operators showed a significant deviation in readings depending on the operation of the shearer and day. Velocity contours were also generated from these measurements normal to the direction of flow at the face main gate, mid gate, shearer, and tailgate. These contours were reported to help access locations where elevated gas concentrations may form due to restrictions in ventilation or areas where ventilation air may leak into the gob. Benefits of a real-time air velocity monitoring were suggested to aid in estimation and reconciliation of specific methane emissions (SME), improve in Ventilation Air Methane (VAM) emission data, and provide more complete data for Longwall Visual Analyses (LVA) tool [24].

\subsection{Modeling the Mining Environment}

Various software and modeling packages have been created in the past that provide useful information to engineers when planning a new mine or control strategy. The information generated from the models is based on local mining parameters such as rank, productivity, and scale of operation and is used to predict preventive measures needed to provide a safe and productive work environment. NIOSH's Methane Control and Prediction (MCP) is a software suite containing a Dynamic Link Library (DLL) and was created from artificial neural networks (ANN). This software uses input parameters from the mining operation site of interest and assigns weighted contribution factors, to model and predict ventilation emissions as well as gob gas venthole performance. It was noted that a typical ventilation system should be able to handle specific emission rates of around $1000 \mathrm{ft}^{3}$ of methane per ton of mined coal. The predictive capabilities of this software are useful for sensitivity analyses where input parameters can be varied to help advise an optimal mining or ventilation strategy to combat methane emissions [25].

Other design and analysis software such as Ventsim have been used alongside CFD models to better capture and define the pathways of ventilation air throughout the mine [26]. Sensitivity assessments have been made in Polish mines with another predictive software (Ventgraph); a ventilation network simulator. This software encompasses the complex flow networks of the 
underground mine to help evaluate stability and sensitivity of the main flows that provide the critical airflow required at the face [27].

\section{CFD Studies}

As the computational power has increased in the last decade, multi-dimensional and computational fluid dynamic (CFD) models have been used as tools in mining development. These models have become very popular in complex flow analysis as flow domains and boundary conditions can be interchanged and redefined with greater ease. When developing a multi-nodal methane detection network such as the MWS, spatial and temporal characteristics become important when advising a deployment and control strategy. These characteristics that define the inputs for the system would require field data that continuously monitored and recorded an array of relative parameters. Due to regulations on permissible equipment and interference with production, such field data found in literature is limited and does not contain all parameters of interest. Therefore, modeling techniques are implemented to reconstruct the working environment for analysis.

Entryways and sections of a longwall mine that have been previously excavated can account for a significant amount of acreage. Though the computational power has improved for such CFD studies, the environmental scale of interest within the mine must be broken down and analyzed by sections. A study in 2018 was conducted by Wang et al. that aimed to fully capture and define the working area of an active longwall site in Australia through CFD models [26]. For the first time, Wang constructed a geometry that contained all major features of a working longwall face that included: 132 hydraulic supports, shearer, AFC, Beam Stage Loader (BSL), and the breaker/feeder of the belt conveyor. The methodology for simulating air flow effects during mining activity constituted six static scenarios (no moving parts or machinery during simulation). Six geometries were created that placed the shearer in three locations (near HG, middle, near TG) for both a HG to TG and TG to HG cutting sequence. Air flow through the domain was solved with ReynoldsAveraged Navier-Stokes (RANS) models containing the Standard k- $\varepsilon$ turbulence equations. Results suggested that regions of slow-moving air at the TG corner and recirculation zones due to flow separation around the shearer resulted in elevated gas emission rates from both the face and gob regions.

Methane can enter the working area from a number of sources. Reports have discussed the dynamics of gob gas formation and its subsequent interaction with ventilation flow at the face. This released methane may create unidentified hazardous events from behind the working area. A 
study from 2014 reconstructed the general area of the longwall outlet using CFD techniques. Skotniczny aimed to identify the characteristics of methane formation at the TG as a result of transient methane release from behind the shields in the gob region [28]. A constant flux of $20 \%$ methane was also defined along the gob boundary and resulted in an average $0.6 \%$ methane along the TG region. Once a steady-state was reached, a methane source located 12 meters upstream released $30 \%$ methane-air at $1 \mathrm{~m}^{3} / \mathrm{s}$ for 60 seconds. Methane sources were defined as mass-flowinlets at the respective boundaries. During the event, 2 to $15 \%$ methane was experienced through the distribution.

\subsection{Advanced Topics}

Standards and concepts change as the ever-evolving processes in manufacturing and industries grow due to advances in technology. Merging concepts from across science fields often lead to alternative methods that improve upon a previous challenge or limitation. The material presented here challenges previous safety and health methods adapted in underground mining in attempts to provide the next level of safety and productivity. In order to do so, spatial and temporal limitations as well as instrumental inefficiencies must be reduced. These characteristics commonly associated with a production or manufacturing process have been addressed and some advanced concepts have been proposed as such.

In order to decisively say that a system such as the MWS is effective among the mining environment, the sensitivity of time scales among emission rates and system response must be addressed. Forecasting and learning methods such as artificial neural networks (ANN) have become popular tools among many fields of science. A study in 2019 was performed using an ANN scheme to predict methane concentrations in longwall regions to forecast methane concentrations and avoid undesirable events. The neural network was trained on collected data from a number of sensors placed throughout the entry and return ways of a working longwall panel. Validation data verified that this method could predict methane concentrations within $0.05 \%$ of the actual data values and forecast emissions by 15 minutes in advance [14].

The MWS has already showed significant improvement over the course of this work in reducing response times while improving measurement accuracy. Still, these developments have only been made possible within the laboratory setting. A fully deployable system provided in the future will 
aim to collect all relevant continuous data for which further "intelligent" strategies such as the ANN's can be constructed and further promote safety and productivity.

\subsection{Methodology}

\subsection{MWS Overview}

\subsubsection{First Generation Design and Theory}

The following design of the MWS was derived from the original proposition to develop a system that continuously monitors methane emissions within the longwall as well as possess some feedback control features to other mining equipment [29]. The system's initial configuration consisted of 10 sampling units, each with the ability to sample from both the face and gob regions (not simultaneously) through the use of an on-board three-way valve. All units were connected in series and relayed information between each other through the $\mathrm{CPH}$ where all the data are collected, analyzed, and stored. Initial regards to power supply along the longwall at the shields was believed to be $24 \mathrm{VDC}$, therefore all components of the MWS operated on 24 or 5 VDC respectively through the use of a power converter. All electrical components were contained and sealed within each unit to represent an intrinsically safe container which would abide to underground mining safety standards. Samples at each node may be transported by the use of an initially proposed water ejector technique. This method may prove to be ideal if steady state operational parameters can be obtained as the ejector requires no moving or electrical parts. More on the ejector's theory can be found below in Proposed Sampling Mode (The Water Ejector).

\subsubsection{Sensors Included}

Each of the 10 sampling units contained a variety of methane and environmental monitoring sensors. These sensors consisted of two methane sensors, temperature, pressure, and humidity sensors. A flow sensor was also included to measure sampling rate. Anemometers were included to measure ventilation rates and were placed externally on Boxes 2 and 9 to provide measurement locations near the HG and TG sections of the longwall face. An additional methane sensor, the Gasmitter from Sensors Inc., was evaluated and integrated into the second-generation system which proposed to increase accuracy and reduce system response times. The Gasmitter sensor had not yet been integrated within the MWS units, therefore relevant tests consisted of a single unit which accommodated the sensor. 


\section{MQ-4 Sensor (MOS)}

One of the two methane sensors evaluated in each unit of the MWS was the low-cost, off the shelf, MQ-4 sensor valued at around \$5. Since the proposed MWS was to be low cost, the MQ-4 provided an evaluation of performance and accuracy under expected mining conditions at the lowest possible price point. The metal-oxide semi-conductor (MOS) bead found within the MQ-4 provides a simple thermal-chemical operational principle that is responsible for the measurement of methane within the air. In this case, the metal-oxide bead is coated in $\mathrm{SnO}_{2}$ and is heated to promote its catalytic properties in the presence of methane. The resulting reaction affects the conductivity through the sensor and therefore alters the output voltage. The MQ-4 operates on an input voltage of $5 \mathrm{VDC}$ and requires a load resistor of $4.7 \mathrm{k} \Omega$ as recommended by the manufacturer. Through the use of a data acquisition device (DAQ), the signal from the sensor will report the full potential $(\sim 5 \mathrm{~V})$ at the maximum concentration allowed by the sensor, which is reported as $1.5 \%$ $\mathrm{CH}_{4}$ in the manufacture's specifications sheet. An available and inexpensive $(\sim \$ 1)$ breakout board for the MQ-4 sensor was also purchased to alleviate wiring and replacement of sensors among the proposed system. A closer examination of the sensor's response characteristics will be discussed in later sections as it pertains to the performance, accuracy, and control strategies proposed by the MWS. An example of the MQ-4 and its wiring configurations can be found in Figures 3.1-1 and 3.1-2. Appendix A-1 contains the specifications and dimensions of the MQ-4 sensor.
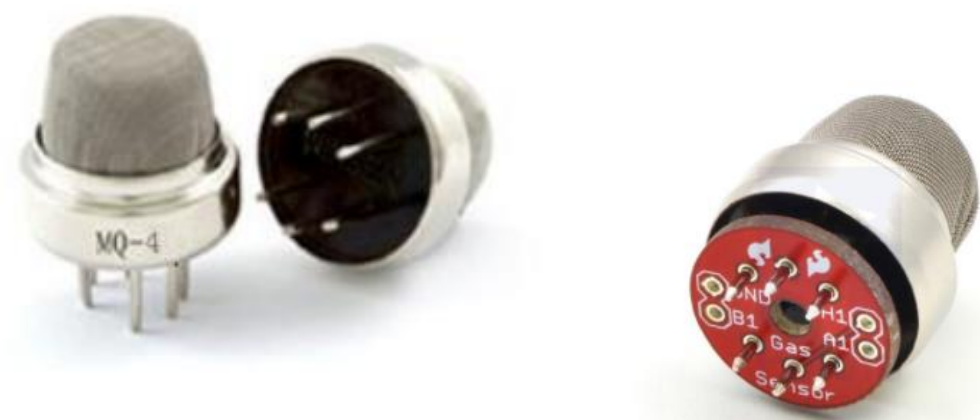

Figure 3.1-1 The MQ-4 (MOS type) methane sensor and its adoption of the breakout board. 


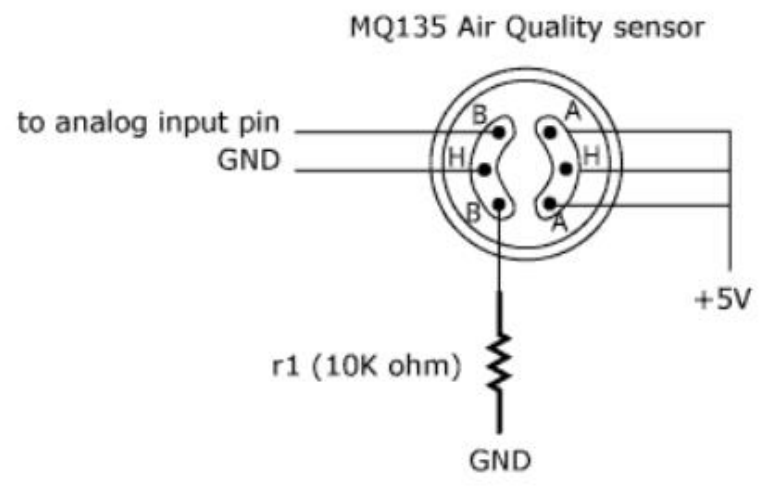

Figure 3.1-2 Wiring and pin configuration of the MQ-4 methane sensor [30].

\section{Dynament Sensor (IRS)}

The Dynament sensor is the second of the two methane sensors evaluated within each MWS unit. At a higher price point to that of the MQ-4 sensor, of around \$150, the Dynament was purchased to evaluate the performance and limitations of an infrared based methane sensor (IRS). The alternative operating principle of the non-dispersive infrared sensor (NDIR) was supposedly less susceptible to contributions in error from atmospheric conditions such as temperature and humidity. Water sprayers are used on the mining equipment underground to help control dust and heat at the cutting face of the shearer. As a result, relative humidity in the sampled air may be expected to reach upwards of $90-100 \%$. Due to the thermal-chemical operating principle of the MQ-4, temperature and humidity had a significant impact in accuracy on reported methane concentrations in initial laboratory experiments. It was believed that the Dynament sensor would be superior to the MQ-4 sensor in these regards and at the very least be used in conjunction. The power supply and wiring requirements are similar to that of the MQ-4 sensor operating at 5 VDC. The Dynament is factory calibrated and tuned to be used within 0-5\% methane and has a respective output voltage of 0.2-2.4 V. Figure 3.1-3 depicts the Dynament sensor as it would be found outside of its wiring harness and housing. The sensor specification sheet can be found in Appendix A-2. 


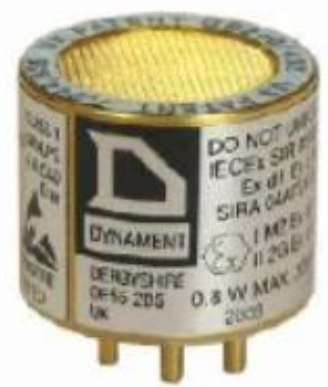

Figure 3.1-3 The Dynament (NDIR type) methane sensor.

\section{Gasmitter Sensor (NDIR-dual wavelength)}

The Gasmitter sensor was later purchased for evaluation of the second-generation prototype of the MWS. Like the Dynament sensor, the Gasmitter operates on a NDIR principle, however an additional filter is present to compensate long-term drift. This additional measure characterizes the Gasmitter as a dual-wavelength NDIR sensor and is superior to the Dynament's single wavelength principle for long-term measurement accuracy. The additional features and accuracy the Gasmitter provide places it at the highest price point within the scope of research for this project of $\$ 800$. Presented in Figure 3.1-4, the Gasmitter's design is unlike the MQ-4 and Dynament sensors in that it is not a single sensing head, but rather a modular analyzer that consists of a closed cell and circuit board. The Gasmitter sensor specifications can be found in Appendix A-3.

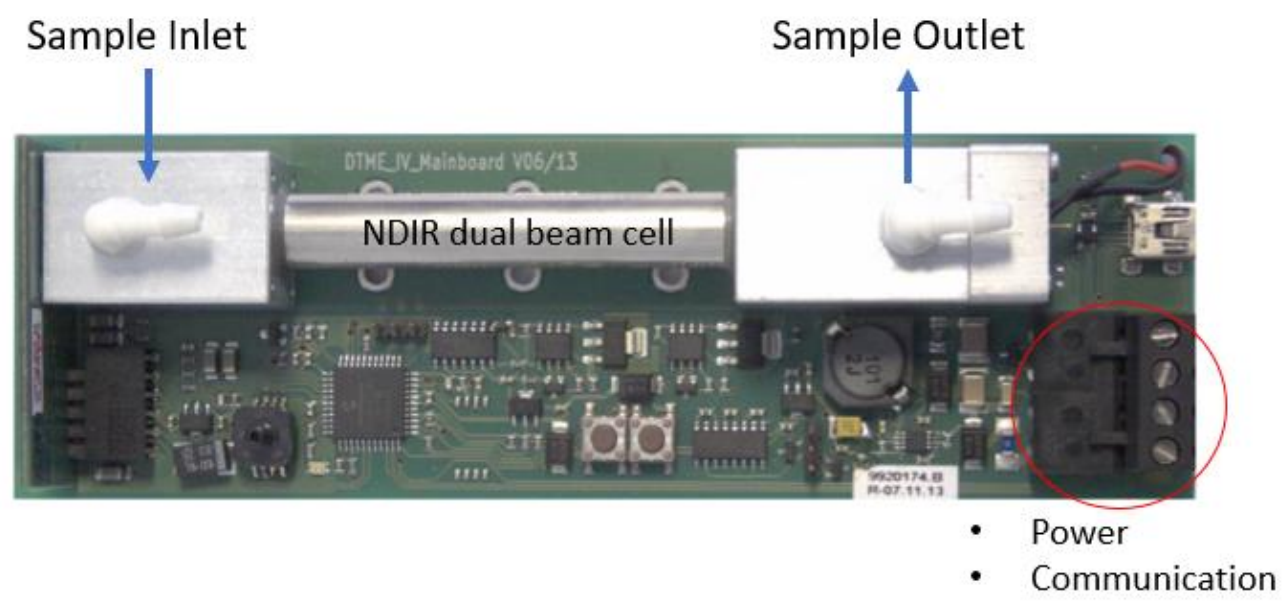

Figure 3.1-4 The Gasmitter (NDIR-dual wavelength) methane sensor [31]. 


\section{Atmospheric Monitoring Sensors}

In addition to continuously measuring methane emissions, it appeared advantageous to also measure temperature, relative humidity, and pressure, since these parameters appeared to negatively impact methane measurements of both the MOS and even IRS type sensors. Therefore, a Type T thermocouple as well as relative humidity and pressure sensors were added to the MWS unit. With the addition of these sensors, humidity, and temperature corrections could be performed on the MOS and IRS methane sensors as well as provide useful system diagnostic information. Since coal dust and debris must be filtered out of the sample prior to entering the MWS unit, the pressure sensor can aid in alerting insufficient sampling rates or undesirable vacuum pressures.

\subsubsection{The Sensor Block}

With a suite of sensors selected to measure the atmospheric parameters of interest, a housing unit was then required to fit both methane sensors, the thermocouple, relative humidity sensor, and pressure sensor. The function of the "sensor block" was to provide a single unit that would transport the air sampled from the mine through the sensing heads of the respective sensors with minimal flow restrictions and dead volume; much like the Gasmitter's module contains it's sample detection cell. Figure 3.1-5 shows the isometric CAD drawing of the sensor block used. The aluminum sensor block was constructed in a way that conformed to the unique features of each sensor to ensure a proper sealed fitment. With the sample transported under vacuum through the MWS, an adequate seal around each sensor was crucial to ensure no dilution occurred.

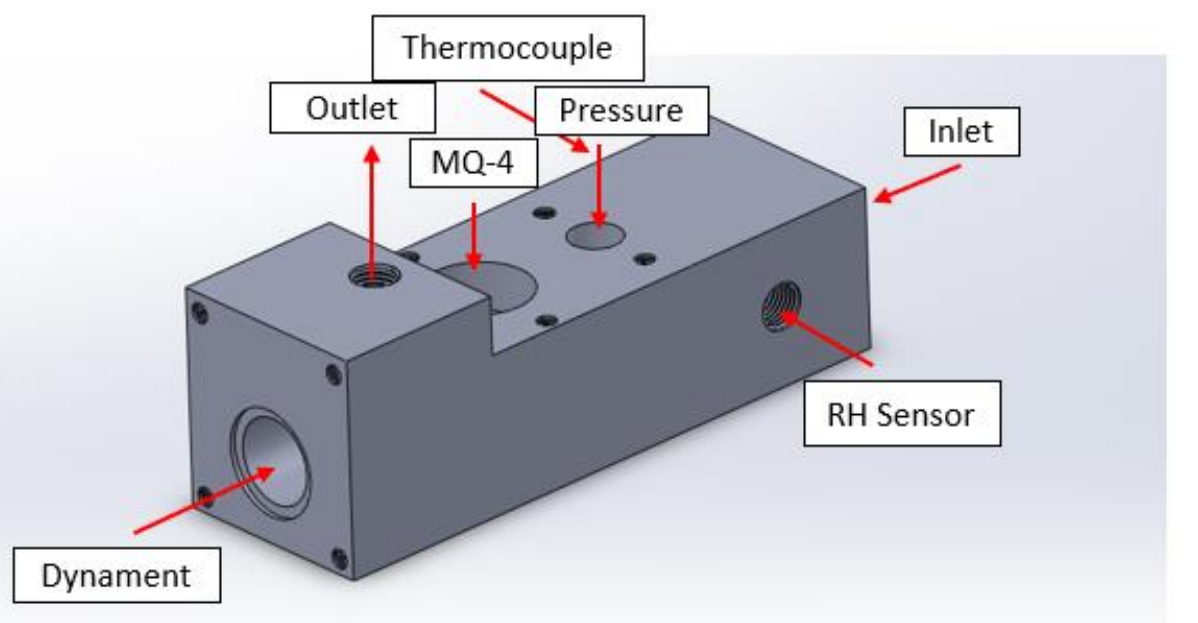

Figure 3.1-5 Sampling block constructed to house both methane sensors (MQ-4 and Dynament), pressure sensor, and thermocouple. 


\subsubsection{Additional Components}

\section{Filtration}

Coal dust and water particles become suspended and swept along the mining section as a result of the longwall mining process. In most cases, sensitive instrumentation such as the sensors on board the MWS unit require the sample to be free of particles and water to insure longevity and accuracy. Therefore, it was essential that the each MWS unit have a proper filtration system to filter out debris.

After an initial assessment of commercially available filters that would function under the systems requirements, three filters were purchased for experimental testing. All three filters were pleated and varied in geometry. These geometries consisted of a conical, cylindrical, and flat/cassette type structure. The list of filters can be found below in Table 3.1-1, which also includes individual filter details. The three filters were assessed on a number of criteria that would be crucial to the performance and integrity of the filter in the harsh environment of a coal mine. Due to the presence of water and coal dust that are associated with mining, it is imperative that the filtration system performs effectively and efficiently as to not effect or damage the methane detection system itself. Therefore, a series of tests were administered to each filter that assessed the effects of pressure losses over the system due to water and coal dust loading on the filter media.

Table 3.1-1 List of filters selected for experimental testing.

\begin{tabular}{ccc}
\hline \hline Filter & Geometry & Effective Filtration Area $\left[\mathrm{m}^{2}\right]$ \\
\hline Spectre & Conical & 0.0102 \\
McMaster Carr & Cylindrical & 0.0147 \\
Solberg & Flat & 0.0185 \\
\hline \hline
\end{tabular}

\section{Transporting the Sample}

Methane measurements would ideally be taken near the coal face were the shearer cuts away the coal, releasing the CBM. Additionally, the gob region behind the shields acts as a source for desorbed methane from the previous workings and may consequently escape into the working area given the right conditions (pressure gradients, roof caving, flow diversion) [18]. In attempts to capture methane at its sources, the MWS was designed to sample from both the face and gob region while sample measurements were made within the MWS unit at a central location on the shield. This required a seven-foot sampling line that connects the filter at the face and gob regions respectively to the MWS unit. The sample would then travel through a three-way valve before 
entering the sampling block. From the sampling block the sample would exit the unit and be discharged through the sampling mechanism. All sampling line was constructed of 0.25 " outerdiameter PTFE tubing with all connections being made with 0.25 " Yor-Lok fittings.

\section{Proposed Sampling Method - Water Driven Ejector}

A water ejector was designed and tested by Ms. Amber Barr to provide the MWS with a means of continuous sampling. The water powered ejector requires no electrical or moving parts and runs on the readily available water source that is supplied to each shield. Water pressure at each shield was reported by an industry manufacturer as $689.5 \mathrm{kPa}$ (100 psig). The ejector encompasses a nozzle to locally increase water velocity within a mixing chamber. The expanded volume of the mixing chamber results in a low-pressure region, utilizing the Bernoulli principle to create a vacuum, thus proving an active (continuous) sampling system.

The water driven sampling technique of the ejector was to perform within desired limits to ensure methane measurements are both adequate and continuous. It was determined that sample flow rates would need to be around 2 SLPM (0.071 scfm) to achieve reasonable sensor response and minimize system delay time. The vacuum created by the ejector would need to be sufficient enough to maintain the 2 SLPM flowrate while overcoming pressure loses through the entire MWS unit. The total pressure differential of one MWS unit was found to be approximately $1.4 \mathrm{kPa}(0.2 \mathrm{psig}$, $5.55 \mathrm{inH}_{2} \mathrm{O}$ ). This value is the result of the initial design including the constructed sensor block.

Pressure losses may differ with design and replacement of onboard components and sensor configurations.

\subsection{Sensor Response Characteristics}

\subsubsection{Sensor Response Evaluation}

Depending on the application of methane detection, certain characteristics of the sensor's performance may be more desirable than others. For the MWS, dependence lays heavily on response time. Accuracy is also important, however confidence and certainty in real time concentrations are necessary when constructing an accurate correlation of spatial and temporal emission profiles. Therefore, sensor response and system delay times were evaluated in the laboratory at proposed operating conditions. 


\section{Calibration and Response Profiles}

Before the MWS unit was subjected to any controlled tests, the methane sensors and the additional atmospheric monitoring sensors were calibrated. The recommended calibrations from the respective specification sheets were initially used to verify the sensors accuracy within the MWS unit. A typical verification procedure for the methane sensors would be performed with the use of a HORIBA manual ten-point gas divider (GD) to achieve various methane concentration points. A wide range of calibration points were achieved with the use of $0.1 \%, 1 \%$, or $2 \%$ methane gas bottles [32-34]. The gas divider operates on a component gas (methane) and dilution gas (air) at a specific inlet pressure to the divider. This method of calibration verification administers a dry sample to the MWS unit. Unlike the conditions that can be expected within the longwall mine, an additional calibration technique was constructed with the use of a gas hygrometer (bubbler) to control the humidity of the sample. Initial calibrations were then replaced with temperature and humidity corrected equations. Additional information pertaining to sensor calibrations and verifications were addressed by Ms. Barr [35]. These corrections only benefit the accuracy of the reported concentration under the expected operational environment. System delay times including the sensors response to a step function of methane concentration were evaluated separately.

\section{Controlled Burst Tests}

Single step, periodic, and ramp inputs categorized the three sets of tests conducted to evaluate the response characteristic of the MWS and the respective sensors. Methane was administered directly into the MWS's sampling node (at the filter) to mark the start and end of an input event. Figure 3.2-1 depicts the laboratory setup for the controlled experiments where the MWS is operating as proposed for deployment. The start and stop of an event were precisely controlled with a Alicat ${ }^{\odot}$ mass flow controller (MFC) [36]. The MFC supplied the methane to the filter housing through a short tube at a set flowrate greater than that of the sampling flowrate ( 2 SLPM) to unsure no dilution occurred within the filter volume. Sampling flow rate was always monitored with a Alicat ${ }^{\odot}$ mass flow reader (MFR) [37]. It was also assumed that delay of the supplied sample was minimized by placing the MFC directly near the filter $(<1 \mathrm{ft})$. Figure 3.2-2 presents the three characteristics inputs that define the Controlled Burst Tests. 


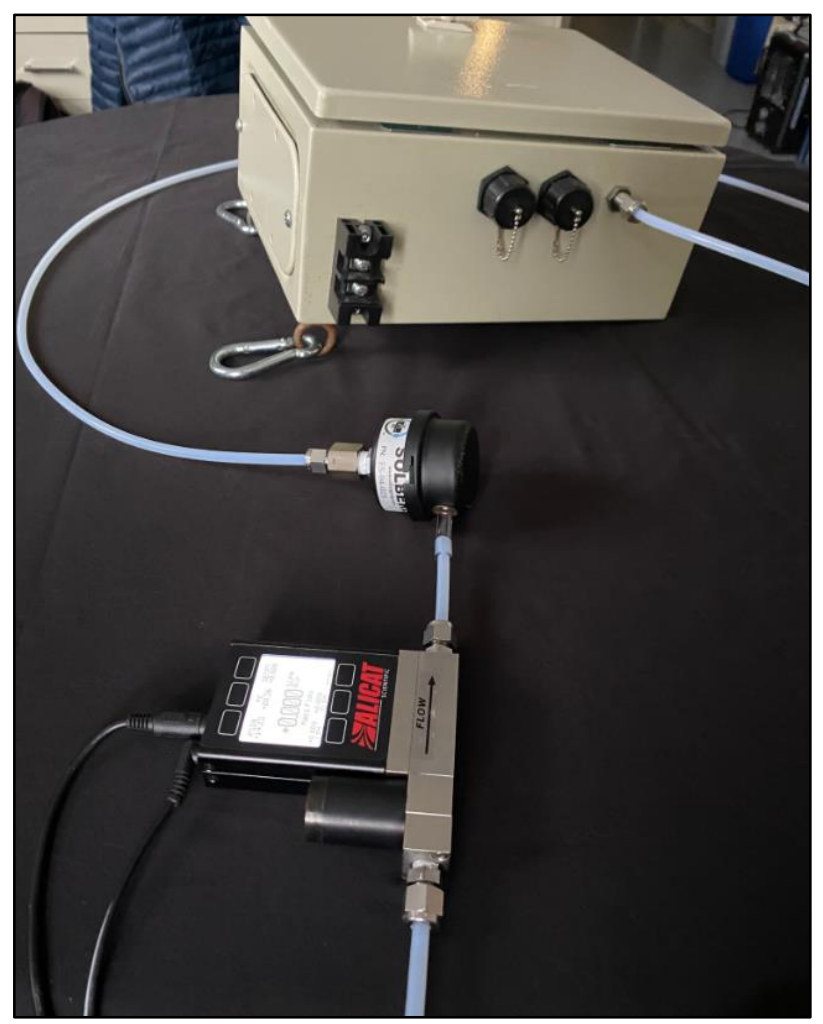

Figure 3.2-1 Laboratory setup for administering controlled samples to the MWS unit.

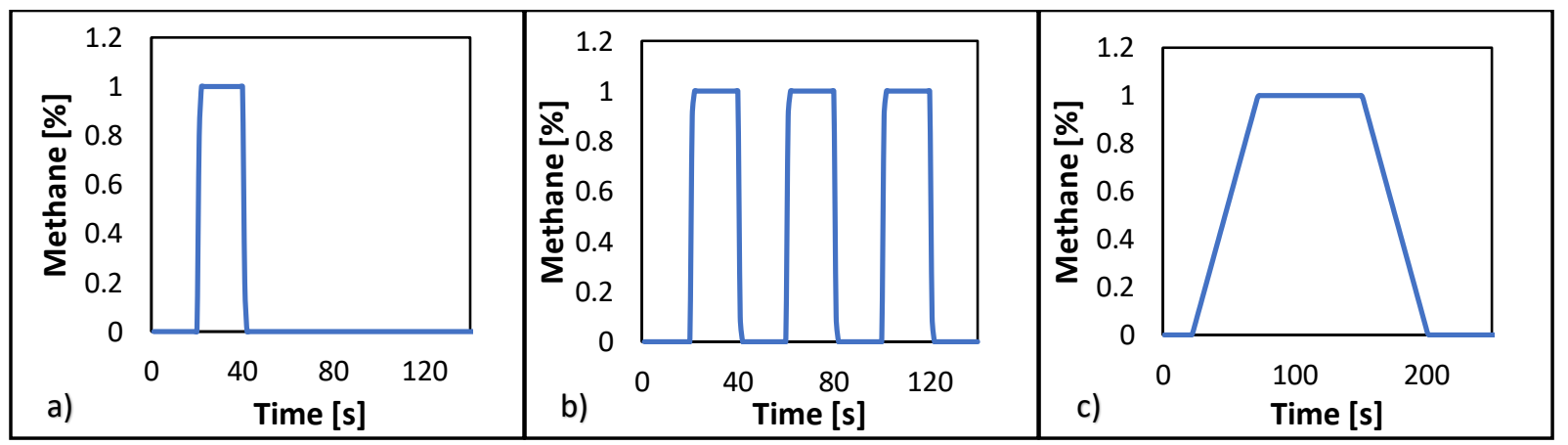

Figure 3.2-2 Examples of step inputs used to characterize the sensors response. a) Single step input. b) Periodic step input. c) Ramp input.

The duration and frequency of the successive bursts were defined at various time scales. Single step inputs were conducted to find response and decay times for the system at various sampling rates. Apart from single events that allow a sensor to return to its baseline reading before a successive burst is released, periodic events of equal time on and off were conducted. Periodic inputs captured the sensors ability to detect an input concentration and return to its original value before a successive burst is administered.

The burst tests were characterized by a sudden change in methane concentration to the MWS system for some duration. The sudden change is ideally a plume of methane at some fixed 
concentration with very little diffusion at the interface. The interface being the gradient of concentration in the plume to the air just outside the plume, which is assumed to be zero percent. The square wave provides a sudden on and off of supplied methane to the MWS filter. By introducing a sample of this kind to the MWS, a response profile from the sensor of interest should indicate the systems distortion of the original square plume. The characteristics of the distorted or diffused sample should indicate both system and sensor inefficiencies to report the true value in real time. These characteristics are what provided the components needed to define the signal sharpening technique that could be deployed to process and sharpen the real-time concentrations.

\subsection{1-D Modeling Studies}

A reduced modeling approach was conducted to further simplify the domain and produce methane concertation profiles that were a function of both space and time. Real data sets collected from a production site underground were not available during these studies, therefore my models aimed to take relative data collected from literature and produce reasonable scenarios to aid in the evaluation of the MWS's theoretical deployment. Basic scenarios included variation in critical parameters such as mining and ventilation rates to trigger undesirable fluctuations in methane concentrations within the mining environment. Ultimately, the MWS aims to combat these undesired scenarios by recognizing their onset and constructing an evaluation on the current operating parameters e.g., mining rate and ventilation rate. With this information, an advised course of action may be taken to alleviate the unwanted situation or avoid it all together.

\subsubsection{Constructing an Appropriate Model}

A desirable model should possess both the fundamental characteristics of the environment of interest and the associated governing laws. The modeling objective and elements associated with the fluid domain aided in selecting an appropriate method to solve and structure the problem. The following components were selected to include in the modeled environment, as they appear to play a direct role in the formation of methane: The rate of production as it pertains to the immediate release of methane, the availability of fresh ventilation air, and the long term methane release as it is naturally desorbed from recent activity.

Fresh air enters the HG of the working area and traverses the face diluting methane and carrying away respirable coal particles as it exits the face at the TG. The ventilation air played two roles in the modeled environment. The fresh air not only determined the effectiveness of dilution or 
resulting methane concentration, but also the transport of fluid through the domain. The ventilation rate within the 1-D model can now be thought of as the transport rate as it plays the crucial role in how information is carried from the HG to TG. Recall that average ventilation rates $(>2 \mathrm{~m} / \mathrm{s})$ are significantly greater that the average rates of the shearer/production $(\sim 0.1 \mathrm{~m} / \mathrm{s})$ to ensure removal of released methane and coal particles.

The transport or advection of information through the working environment is important to the effectiveness and operating parameters of the MWS as it tries to quickly interpret it. These operating parameters consist of sampling rate, sensor selection, and data interpretation strategies; all of which directly affect the systems deviation to the true response. Though the single sampling nodes of the MWS are fixed and spatially limited in that sense, the expansion of multiple sampling nodes evenly spaced along the entire working section can work together to interpret trends from one node to the next as information travels.

\subsubsection{Solving the Problem One-dimensionally: The Finite Volume Method}

Finite element and differencing methods are predominantly used among CFD models to achieve iterative numerical solutions. The finite volume method is a particular method that quantifies and conserves one or more quantities of the respective fluid through a series of control volumes that construct the flow domain. The numerical algorithms carried through this finite volume scheme construct the resulting flow as defined by steady state or transient conditions. The structure of numerical algorithm can be outlined as follows [38].

- Integration of the governing equations of fluid flow over all the (finite) control volumes of the domain.

- Discretization - conversion of the resulting integral equations into a system of algebraic equations.

- Solution of algebraic equations by an iterative method.

\subsubsection{Available Modeling Schemes}

Various numerical schemes provide useful building blocks for solving problems that consist of partial differential equations (PDEs). Classic mathematical modeling schemes such as these include the heat equation, the wave equation, and Laplace's equation [39]. These equations model physical phenomena that appear in a variety of common engineering problems and their discretized forms provide simple and reasonable initial approximations. As for the problem at hand, a simple advection model making use of the wave equation should be advantageous for coupling the 
temporal and spatial characteristics of the resulting methane profiles. As the resulting methane concentration is defined as $Y(x, t)$ and is transported as some rate $c$, then the problem can simply be described as a 1-D advection process where the motion of scalar $\mathrm{Y}$ is a result of some known velocity field (ventilation rate).

\subsubsection{The Discretized 1-D Advection Equation}

The 1-D advection equation used to model the transport of methane is obtained from the 1-D second-order hyperbolic PDE wave equation given by

$$
\frac{\partial^{2} u}{\partial t^{2}}=c^{2} \frac{\partial^{2} u}{\partial x^{2}}
$$

where $c$ represents the velocity at which sound waves propagate through a uniform medium with respect to both space $(x)$ and time $(t)$. Equation 3.3.1 can be reduced to its first-order form for the sake of modeling general scenarios in the longwall mine while containing the original properties of the second-order equation. This form of the wave equation is also commonly referred to as the 1-D linear convection equation and describes a wave propagating in the positive $\mathrm{x}$-direction at some non-zero positive velocity. The first-order linear wave equation is given by

$$
\frac{\partial u}{\partial t}=c \frac{\partial u}{\partial x}
$$

The exact solution to Equation 3.3.2 is written as

$$
u(x, t)=F(x-c t)
$$

which provides the platform by which the discretized algebraic equations can be written that solve the travelling of some initial function $F$ containing information at a velocity $c$. Numerous differencing schemes are available that solve the wave equation (Equation 3.3.1), however limitations apply depending of the desired accuracy and complexity of the problem. To evaluate which method better suited the problem at hand, three of the common differencing schemes were created and studied. These methods included the upstream or first-order upwind differencing scheme, the Lax method and the reformed Lax-Wedroff Method [40, 41]. 


\subsubsection{Study of Explicit Numerical Differencing Schemes}

\section{The First-Oder Upwind Differencing Scheme}

The first scheme studied was a first-order accurate discretized method that solved the spatial differences in the domain grid in the "upwind" direction. It was assumed that the ventilation air at the longwall face only travels in the positive $\mathrm{x}$-direction (HG to TG), therefore the associated upwind term will remain constant and the equation for the time step $j$ following the initial condition will be given as

$$
u_{i}^{j+1}=u_{i}^{j}-\frac{c \Delta t}{\Delta x}\left(u_{i}^{j}-u_{i-1}^{j}\right), \quad(c>0)
$$

The notation used to construct the methane profile $u(x, t)$ is defined as $u_{i}^{j+1}:=u\left(x_{i}, t_{j}\right)$. The stability criterion of the upwind scheme (3.3.4) is consistent with of the Courant-Friedrich-Lewy (CFL) condition. The CFL condition states that the differencing method is conditionally stable if and only if the models transport velocity $c$ is not bigger that the spreading velocity $\Delta x / \Delta$ t. This criterion is shown as

$$
\frac{c \Delta t}{\Delta x} \leq 1 \leftrightarrow c \leq \frac{\Delta x}{\Delta t}
$$

Truncation Errors (T.E.) associated with the first order differencing scheme are of $O[\Delta \mathrm{t}, \Delta \mathrm{x}]$ and are typically not zero. Though the backward differencing scheme provides conditional stability for the upwind method, the presence of the odd derivate terms in the T.E. result in an artificial diffusion or "false" diffusion. This false diffusion dissipates sharp signals that would be introduced to the model. This feature of the upwind scheme may be beneficial in the reconstruction of the longwall mining environment however, as the fluid domain is quite large, and a reasonable amount of mixing can be present. An initial numerical study was conducted to evaluate the features of the upwind differencing scheme in a simple MATLAB program (see Appendix B). These studies were similar to that of [41]. Figures 3.3-1 and 3.3-2 below show the resulting transport of two initial input functions respectively. 


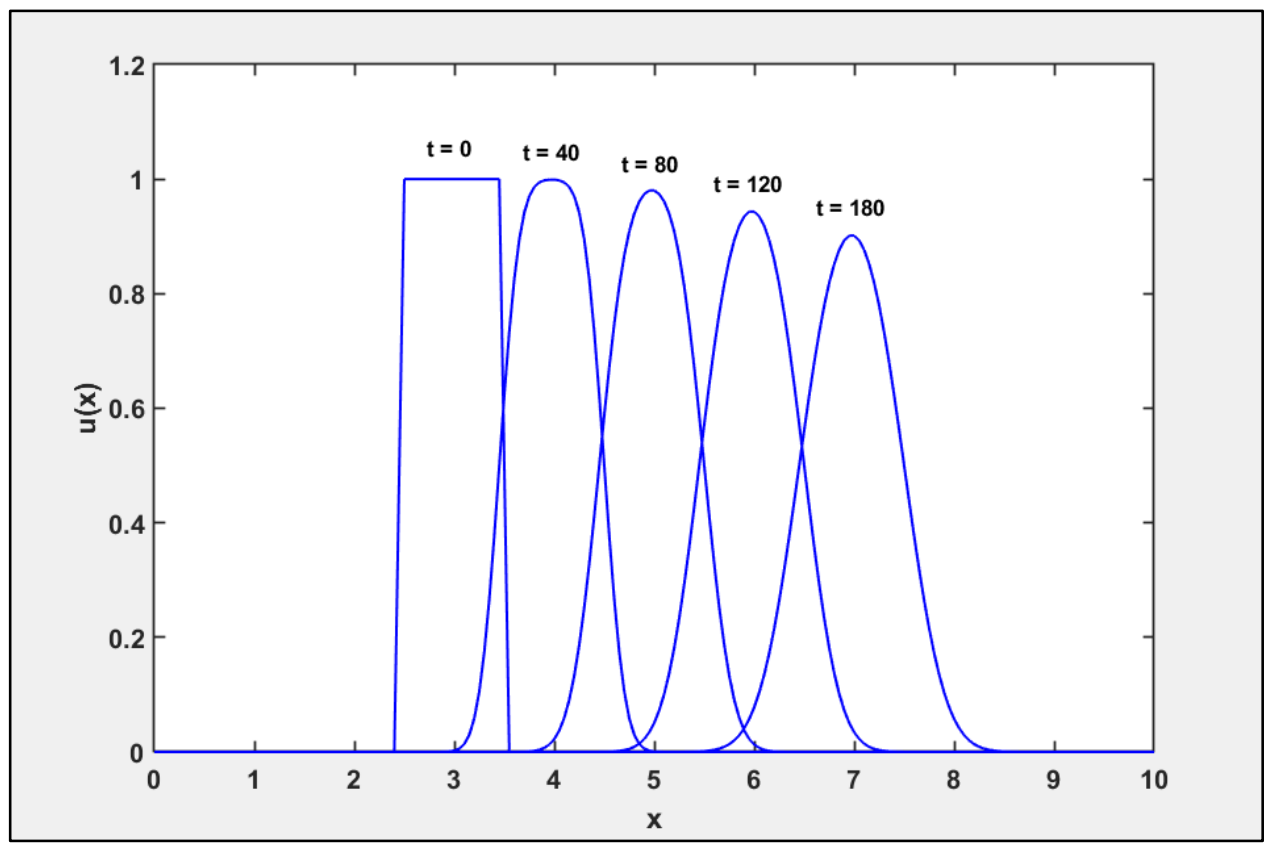

Figure 3.3-1 Advection of 1-D square function using the upwind differencing scheme. Simulation solved on the domain $\mathrm{x} \in[0,10]$ with $\mathrm{c}=0.5, \Delta \mathrm{t}=0.05, \Delta \mathrm{x}=0.05$. Solutions were obtained and plotted for $\mathrm{t}=0, \mathrm{t}=40, \mathrm{t}=80, \mathrm{t}=120, \mathrm{t}=180$.

From the initial square wave example (Figure 3.3-1), it can be seen that by $\mathrm{t}=180$ the function has taken a new form, losing its hard-edge features to a more continuous dispersed wave. Stability was maintained however, and the diffusion (loss of peak concentration) was minimal. A plume of this nature with no initial gradient in concentration would slowly mix with surrounding air. The result would be something very similar to this given the characteristic boundaries of the transported plume. Perhaps the characteristic boundaries of the system (MWS) possess some similarity to the diffused response of the methane analyzers. In this case, the diffused response can be characterized by the MWS design and can be used to reconstruct the output signal (the initial square wave). 


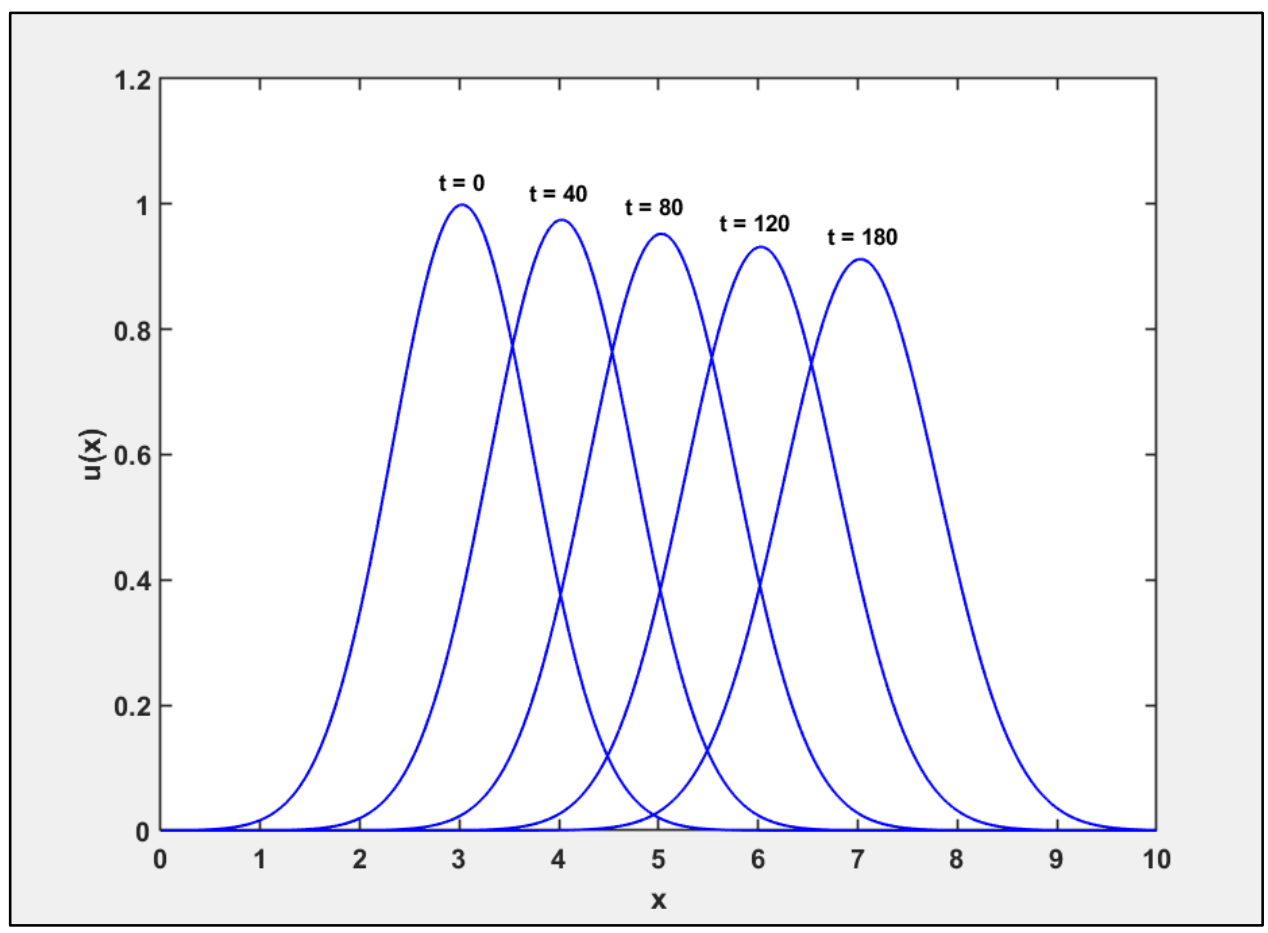

Figure 3.3-2 Advection of 1-D Gaussian distribution using the upwind differencing scheme. Simulation solved on the domain $\mathrm{x} \in[0,10]$ with $\mathrm{c}=0.5, \Delta \mathrm{t}=0.05, \Delta \mathrm{x}=0.05$. Solutions were obtained and plotted for $\mathrm{t}=0, \mathrm{t}=40, \mathrm{t}=80, \mathrm{t}=120, \mathrm{t}=180$.

With a Gaussian function defining the initial wave from, it is seen in Figure 3.3-2 that the advected results are stable and quite similar over time. Some diffusion is present; however, the function is still transported at the correct rate and possess no significant deformation. The effects of the false diffusion appear reasonable and representable of the mixing that would occur within the effective flow domain.

\section{The Lax Method}

The next explicit method used to model the advection equation is a variation of the FTCS (forward in time, centered in space) method. These methods consist of a forward temporal differencing scheme with a centered spatial differencing scheme which results in an unconditionally unstable system. The Lax method has slightly modified the FTCS scheme by replacing the $u_{i}^{j}$ term with the average over its two neighbors. The explicit first order accurate equation becomes:

$$
u_{i}^{j+1}=\frac{1}{2}\left(u_{i+1}^{j}+u_{i-1}^{j}\right)-\frac{c \Delta t}{2 \Delta x}\left(u_{i+1}^{j}-u_{i-1}^{j}\right)
$$


Like the upwind method, the Lax scheme is conditionally stable under the CFL stability criterion. To access the characteristics of this scheme, the same initial functions from the upwind method test were initialized into equation 3.3.6. Figure 3.3-3 contains the resulting profiles for the initial square wave input. Figure 3.3-4 displays the results from the initial normal distribution at the same time steps. The parameters of the model including wave speed and step sizes are consistent with that of the upwind model previously conducted (Figures 3.3-1 and 3.3-2).

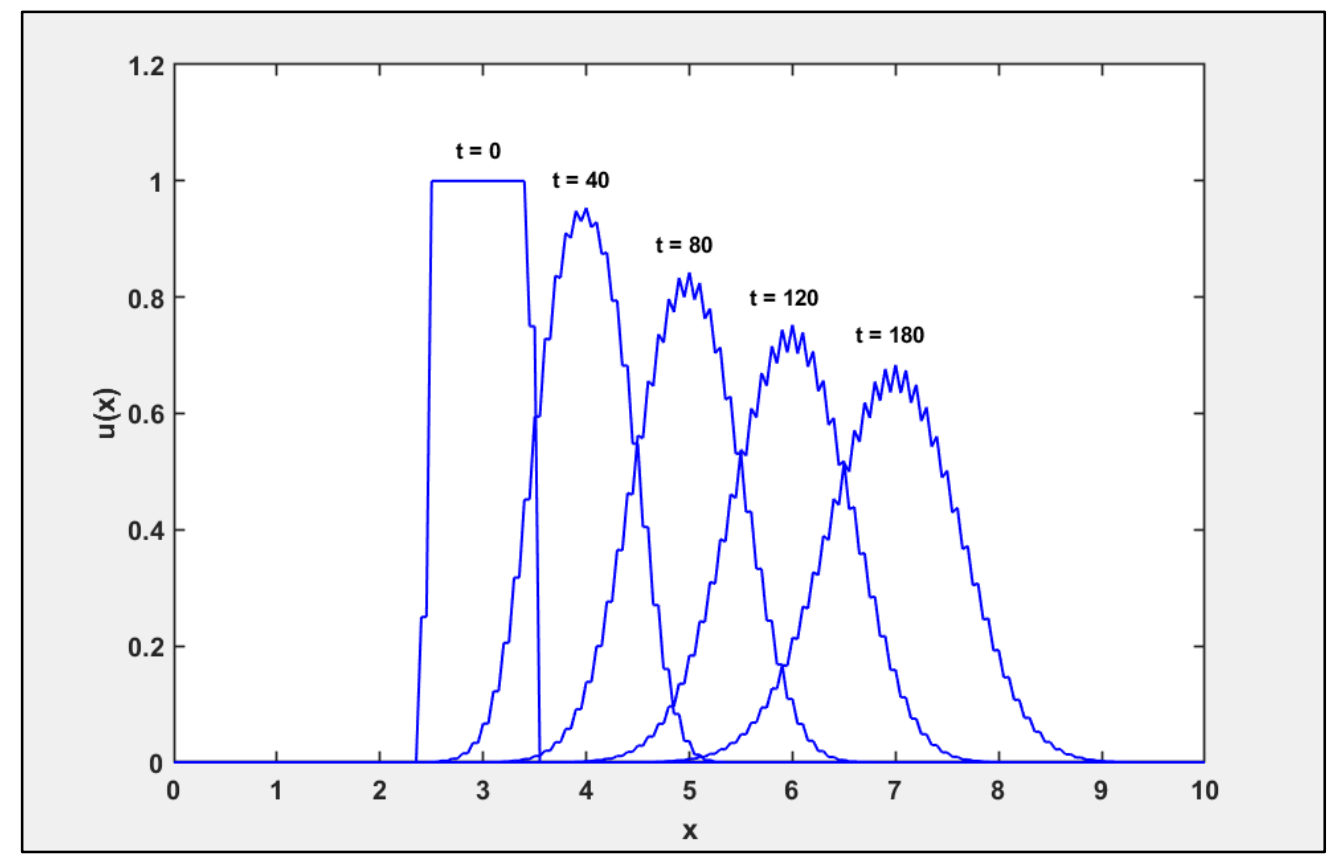

Figure 3.3-3 Advection of 1-D square wave using the Lax method. Simulation solved on the domain $\mathrm{x} \in[0,10]$ with $\mathrm{c}=0.5, \Delta \mathrm{t}=0.05, \Delta \mathrm{x}=0.05$. Solutions were obtained and plotted for $\mathrm{t}=$ $0, \mathrm{t}=40, \mathrm{t}=80, \mathrm{t}=120, \mathrm{t}=180$.

Unlike the results of the upwind method, it is apparent that some disturbances have propagated through the resulting profiles following the initial function $(t=0)$. Similar to the previous model however, the initial input has transitioned, becoming more characteristic to that of a normal distribution with a more continuous shape. The effects of false diffusion also appear to have a greater impact leading to the diminishing peaks. 


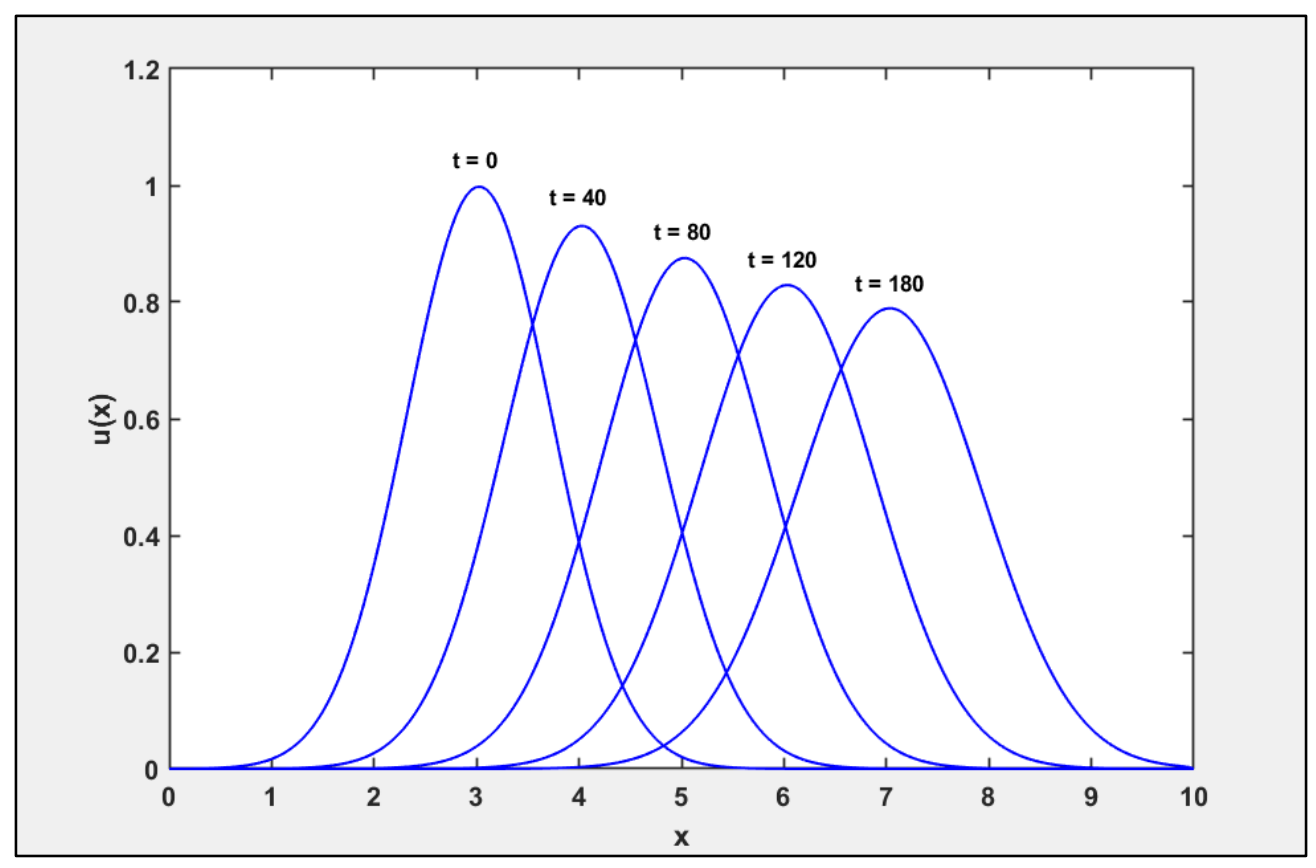

Figure 3.3-4 Advection of 1-D Gaussian distribution using the Lax method. Simulation solved on the domain $\mathrm{x} \in[0,10]$ with $\mathrm{c}=0.5, \Delta \mathrm{t}=0.05, \Delta \mathrm{x}=0.05$. Solutions were obtained and plotted for $\mathrm{t}=0, \mathrm{t}=40, \mathrm{t}=80, \mathrm{t}=120, \mathrm{t}=180$.

The results of the initial normal distribution appear stable with time; however, the deformation of the advected function appears greater than that of the upwind method (Figure 3.3-2). False diffusion may be a good initial assumption when capturing the mixing of methane in the rather large mixing volume of the longwall. However, substantial loss in concentration throughout time may lead to unrealistic resulting methane profiles.

\section{The Lax-Wendroff Method}

The final method that was examined for the 1-D modeling of the longwall mining environment was the Lax-Wendroff Method. This method employed a multistep method which was derived from the Taylor-series expansion which results in a second-order accurate model with a T.E. of $O\left[(\Delta \mathrm{t})^{2},(\Delta \mathrm{x})^{2}\right]$. Information calculated on the half time step is used in a central differencing scheme to approximate the derivative $u_{i}^{j+1}$. The multi-step scheme containing the half-time step equations is as follows

$$
u_{i-\frac{1}{2}}^{j+\frac{1}{2}}=\frac{1}{2}\left(u_{i}^{j}+u_{i-1}^{j}\right)-\frac{c \Delta t}{2 \Delta x}\left(u_{i}^{j}-u_{i-1}^{j}\right)
$$




$$
\begin{aligned}
& u_{i+\frac{1}{2}}^{j+\frac{1}{2}}=\frac{1}{2}\left(u_{i}^{j}+u_{i+1}^{j}\right)-\frac{c \Delta t}{2 \Delta x}\left(u_{i+1}^{j}-u_{i}^{j}\right) \\
& u_{i}^{j+1}=u_{i}^{j}-\frac{c \Delta t}{\Delta x}\left(u_{i+\frac{1}{2}}^{j+\frac{1}{2}}-u_{i-\frac{1}{2}}^{j+\frac{1}{2}}\right)
\end{aligned}
$$

The equations from (3.3.7) can be rewritten and reduced into a single approximate scheme as

$$
u_{i}^{j+1}=b_{-1} u_{i-1}^{j}+b_{0} u_{i}^{j}+b_{1} u_{i+1}^{j}
$$

Constants $b_{-1}, b_{0}$, and $b_{1}$ contain the Courant number defined as $\alpha$ and are given by

$$
\begin{gathered}
b_{-1}=\frac{\alpha}{2}(\alpha+1) \\
b_{0}=1-\alpha^{2} \\
b_{1}=\frac{\alpha}{2}(\alpha-1)
\end{gathered}
$$

Again, the numerical analysis of the advected square input Figure 3.3-5 and the normal distribution Figure 3.3-6 were conducted utilizing the Lax-Wendroff scheme.

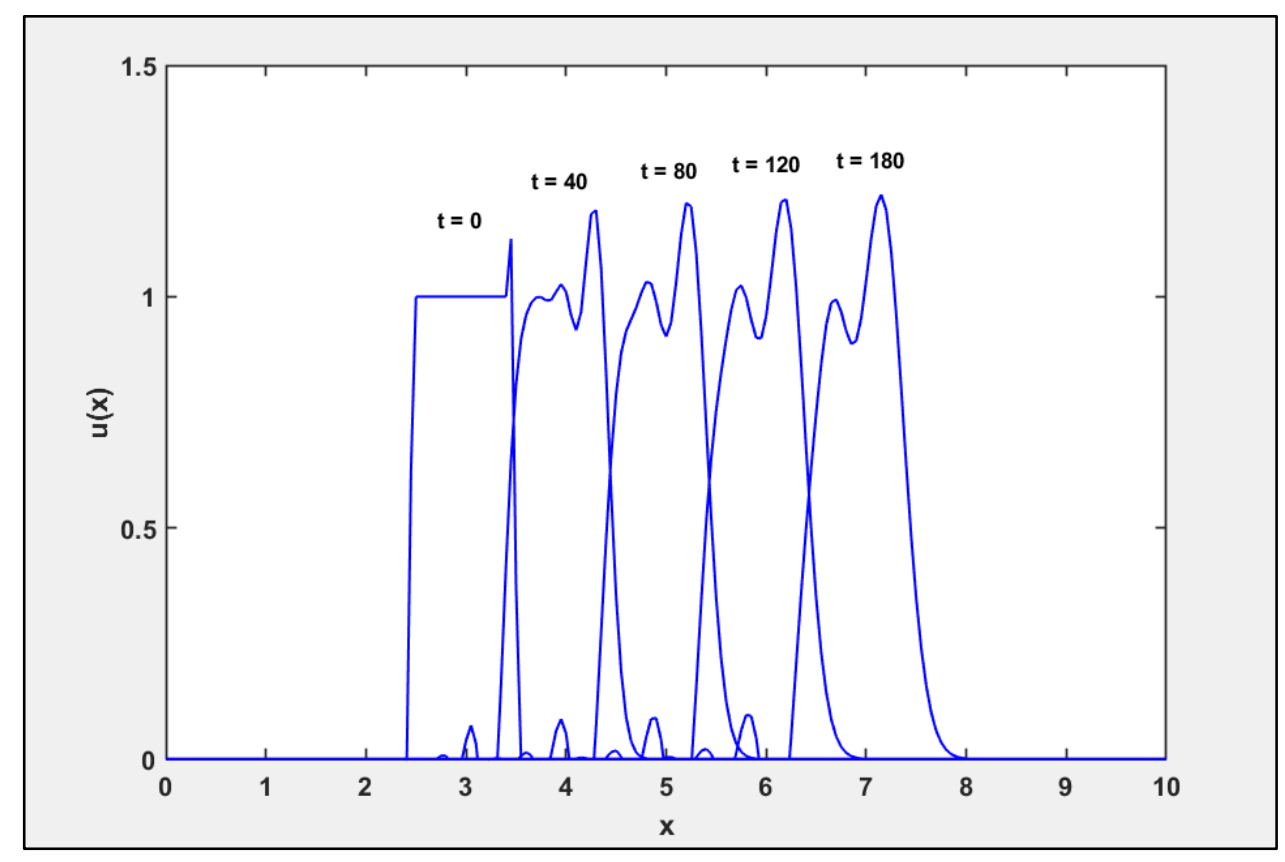

Figure 3.3-5 Advection of 1-D square wave using the Lax-Wendroff method. Simulation solved on the domain $\mathrm{x} \in[0,10]$ with $\mathrm{c}=0.5, \Delta \mathrm{t}=0.05, \Delta \mathrm{x}=0.05$. Solutions were obtained and plotted

$$
\text { for } \mathrm{t}=0, \mathrm{t}=40, \mathrm{t}=80, \mathrm{t}=120, \mathrm{t}=180 \text {. }
$$


Though the square wave function was again defined with the same model parameters of those in the first two methods, and meet the CFL stability criterion, distortion to the wave is quite significant downwind. The input does retain some initial characteristics however, as dispersion and diffusion effects are less apparent. The sensitive stability noticed at the edges of the wave are undesirable to the transient 1-D model of interest since transport velocity may always be changing effecting the CFL condition at each time step.

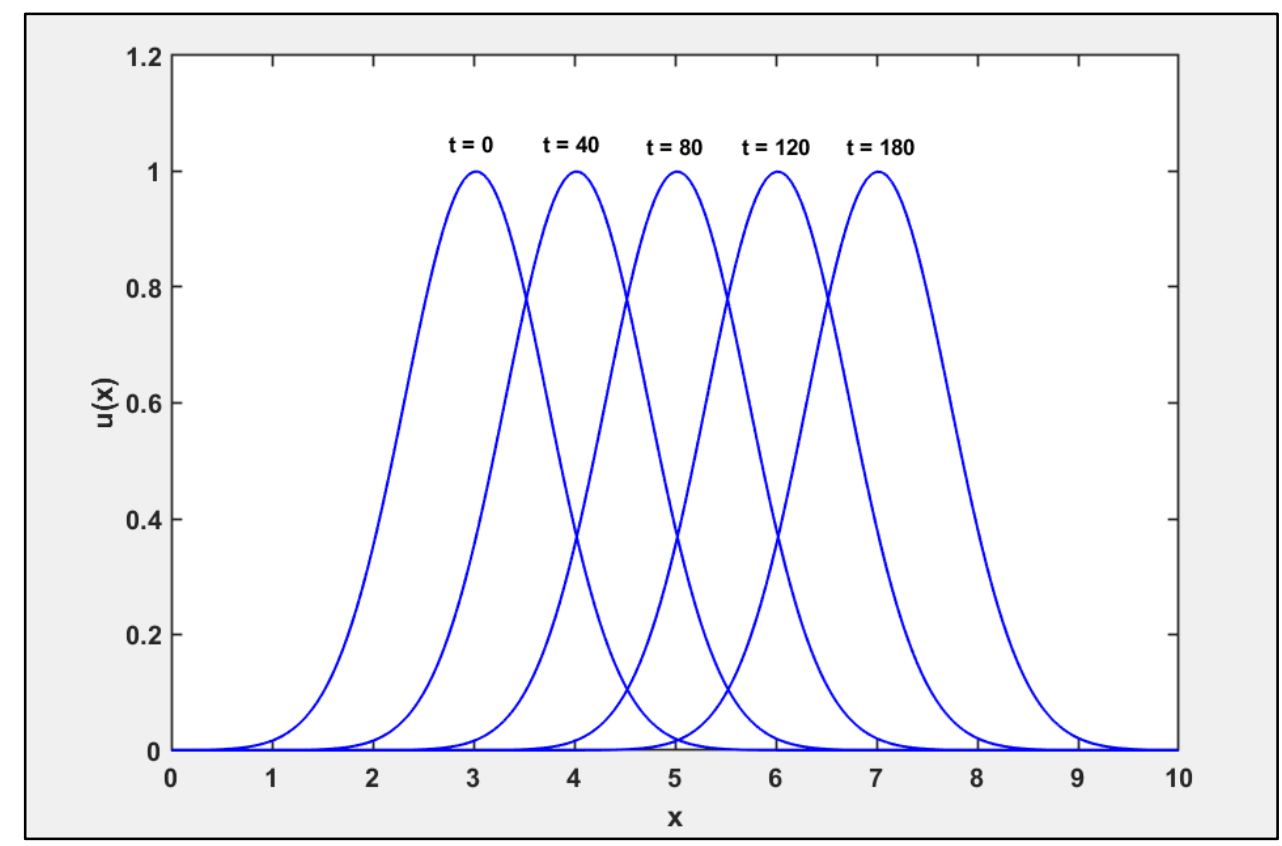

Figure 3.3-6 Advection of 1-D Gaussian distribution using the Lax-Wendroff method. Simulation solved on the domain $\mathrm{x} \in[0,10]$ with $\mathrm{c}=0.5, \Delta \mathrm{t}=0.05, \Delta \mathrm{x}=0.05$. Solutions were obtained and plotted for $\mathrm{t}=0, \mathrm{t}=40, \mathrm{t}=80, \mathrm{t}=120, \mathrm{t}=180$.

The numerical results of the normal distribution on the other hand, appear to maintain nearly perfect similarity at every time step downwind. The second-order accurate advected input possess little false diffusion, meaning that a concentration of methane emitted at any given time will remain that concentration for every instance downwind. This also means that an emitted concentration at any time will mix or diffuse very little with the surrounding concentration in the simulated spatial domain if emission rates are transient. Though this method does a very good job at advecting the initial input with little spatial and temporal deformation, it may not accurately capture the diffusion and mixing that would be expected in the large volume of the working area. The magnitude of turbulence and flow dynamics present along the face are not yet well understood; therefore, it will 
need to be assumed that some degree of mixing and diffusion occurs as the methane enters the flow domain and becomes diluted.

\subsubsection{Modeling the Longwall Environment}

From the study conducted, with the available numerical discretized models, the upwind scheme was selected to further develop the 1-D study of the longwall. The upwind scheme provided stability to accurately transport the resulting methane profiles while incorporating a degree of dispersion to couple the methane-air interactions. A second-order or even first-order accurate explicit finite difference method may be used to solve the advection-diffusion equation, however the accuracy of the solutions is still limited by the unknown variables associated with the mining environment [42]. Therefore, the characteristic "false" diffusion associated with the discretized solutions seemed most appropriate and stable for applying the desired transient boundary conditions. The boundary conditions are responsible for generating the resulting methane concentrations due to some act of the mining process at a given time. The advection model selected then transports the resulting methane profile downwind where it exits the mining section of interest.

\section{Boundary Conditions}

The 1-D study of the longwall section included two sources of methane and a single source of fresh ventilation air responsible for controlling methane emissions. From the review of relative literature on methane emissions, it was determined that there were two characteristic features of the methane profiles that resulted from shearing the coal. A baseline profile that was a result of the naturally desorbing methane from past activity, and the immediate release of methane that occurred directly at the cutting head of the shearer. The baseline emission profiles were typically well under the regularity limits and were nearly constant (linear) across the entire longwall face (HG to TG). Once production started however, methane profiles became very transient and ranged from the baseline profile to exceeding regulatory limits which lead to reported shutdowns. Methane emissions would begin to return to the baseline profile once production was halted. The baseline emission was incorporated into the 1-D advection model simply by a linear function that obtained some value at the HG and increased to some greater value at the TG. The baseline emission profile was also the initial condition for the model by which the methane emissions from shearing coal were constructed. It is important to note that the fresh ventilation air responsible for 
diluting the methane can only enter the HG of the working section. This typically means that emissions will increase towards the TG since "fresh" ventilation air containing no methane is only available at the entry of the face before it begins to acquire methane.

The methane emissions that were a function of shearer operation were then derived at every time step and added to the baseline emissions. The shearer cuts coal at some rate $(\sim 0.1 \mathrm{~m} / \mathrm{s})$ releasing methane into the ventilation air that transports it at some other rate $(\sim 2 \mathrm{~m} / \mathrm{s})$. Therefore, the model must keep track of the shearers location based on its production rate. The production rate defines the amount of coal that is being cut for every time step. The amount of coal cut will also relate to the amount of methane that was released as a result. Extensive data consisting of local CBM content provides the basis by which the amount of methane within a unit of coal was defined [11]. The resulting local methane concentration was then a function of the production rate and ventilation rate for that given instance in time. Because the upwind model is conditionally stable, the program included a section where the CFL stability criterion would check the boundary conditions at every time step before proceeding with the solution.

A ventilation "loss" term was also incorporated into the 1-D model to account for the ventilation loss from HG to TG noticed in literature. From the ventilation rates presented in Table 2.4-1, rates measured at the TG were consistently less than those at the HG. An average loss was found to be $0.51 \mathrm{~m} / \mathrm{s}(101 \mathrm{fpm})$ across the length of the working section. This may be a result of dynamic flow patterns characteristic to the voids present in the gob [18]. Given the nature of the 1-D advection model, the composition of air/methane cannot be directly controlled downwind of the source for a given solution of the simulation. Therefore, the "loss" term inversely added methane to the resulting concentration from the shearer. The magnitude of additional methane was dependent on the shearer's location along the face, capturing the linear loss of ventilation from HG to TG.

\section{Simulated Scenarios}

Due to the transient nature of the system being modeled; a number of scenarios were conceived to assess expected outcomes. Furthermore, simulated outcomes provided useful data needed to help test and develop the expected effectiveness and performance of the MWS. Since complete field data sets were limited and deployment of the MWS was unavailable at this time, simulated data provided an alternative method that can be easily employed and repeated in the laboratory. 


\section{Sensitivity Analysis for MWS Performance}

Ventilation rate and shearer operation parameters were altered to study their effects on emission profiles. The magnitude of variance in these parameters on the time scale of interest (minutes) is not well known. The variance or lack of steady state of these paraments are what define the resulting true methane concentration profiles which were of interest for testing the MWS performance. Sample transport and sensor response times have resulted in a shift and "diffused" output from the MWS, depending on the fluctuation in methane concentration. These effects have been noted among other areas of research and are further discussed in the later sections of Developing Reconstruction Techniques.

The 1-D model constructed a matrix $[t, x]$ with the nodal solutions at every time step. The matrix was also reduced to include only the results near the proposed MWS nodal locations along the longwall section. These particular solutions represent the expected methane concentrations that would be swept by the respective MWS sampling units. These methane profiles also represent the true methane concentrations that defined the input function to the MWS to evaluate performance and accuracy.

\section{Laboratory Setup}

Once a simulated scenario was constructed with the 1-D advection model, results were processed and formatted to be inputs for an active sampling MWS unit in the laboratory. Result data from the 1-D model were represented as percent methane $\left[\% \mathrm{CH}_{4}\right]$. With no way of administering a scheduled (constantly varying) methane concentration sample directly to the MWS; data were converted into flowrates that diluted methane down with laboratory air to the respective desired concentration. A $1 \%$ or $2 \%$ methane gas bottle was connected to an MFC which controlled the flowrate of the sample being released directly into the filter of the MWS [33, 34]. The sampling rate was held constant during the experiment to ensure respective flowrates matched concentration setpoints to its best ability. Refer to Figure 3.2-1 for visualization. The MFC controlling methane flowrates was controlled through the laboratory data acquisition software Scimitar. The MFC's built in setpoint control feature (which was controlled from Scimitar) was overridden with a program that contained the converted simulated methane concentrations. Converted setpoints were defined on a $1 \mathrm{~Hz}$ basis where a new flowrate (concentration) value was executed every second. 


\section{Production Studies}

It was initially considered that if the MWS provides near real time information on methane emissions along the entire longwall face then a possible "ideal" shearer rate exists. Meaning that emissions will never exceed the regulatory limits because the shearer is traveling just fast enough. The production rate would be less than typical; however, the tradeoff would be in the degree of utilization. In other words, less time would be spent having to stop and start production after an official methane check was completed.

Due to the lack of available field data that contained complete and accurate sets of concurrent ventilation and shearer rate measurements, two approached were taken to assess the impact of shearer rate on production utilization with the developed 1-D model. The first approach follows the assumption that fresh ventilation air is always available and is supplied to the face at a constant rate of $2 \mathrm{~m} / \mathrm{s}$. The model then simulates the shearer making a single pass from HG to TG and records the resulting duration and maximal methane concentration. The shearer rate was increased from $0.04 \mathrm{~m} / \mathrm{s}$ up to $0.12 \mathrm{~m} / \mathrm{s}$ in increments of $0.02 \mathrm{~m} / \mathrm{s}$ to construct a correlation between production rate and resulting emissions. This approach represents a near ideal case but provides a baseline impact measurement given the assumptions made in the model.

The second approach then replaces the constant ventilation rate with transient data consistent with values found in literature $(0.5-2.5 \mathrm{~m} / \mathrm{s})$. Unable to accurately represent the time lost during a shutdown and start-up procedure from a methane related delay in the coal mine, all instances throughout the simulated pass where methane concentrations exceed the regulatory threshold (1\% $\mathrm{CH}_{4}$ ) at a MWS node were simply recorded as a running time spent above the threshold. The total time spent above the threshold is represented as a percentage of the time it took to complete the pass for the given shearer rate. Results were evaluated near the HG, midway, and TG (Nodes 1, 5, and 10) of the modeled environment. Consistent with the first method, constant shearer rates were evaluated on the order of 0.04 to $0.12 \mathrm{~m} / \mathrm{s}$ throughout a pass from HG to TG.

\subsection{2-D Modeling Studies}

\subsubsection{Overview of 2-D Longwall Model}

CFD studies of the longwall section in the 2-D domain were constructed in Ansys Fluent ${ }^{\circledR}$ from data collected in the literature review of longwall mining. The working area of the longwall section was simplified to include: an entry way by which fresh air would enter the face at the HG, a shearer 
that created a flow restriction point and source of methane, and an exit region similar to that of the entry way. The resulting geometry that defined the flow domain and boundaries of the model is shown in Figure 3.4-1. The general dimensions of the model are summarized in Table 3.4-1 and were derived from average values obtained from literature.

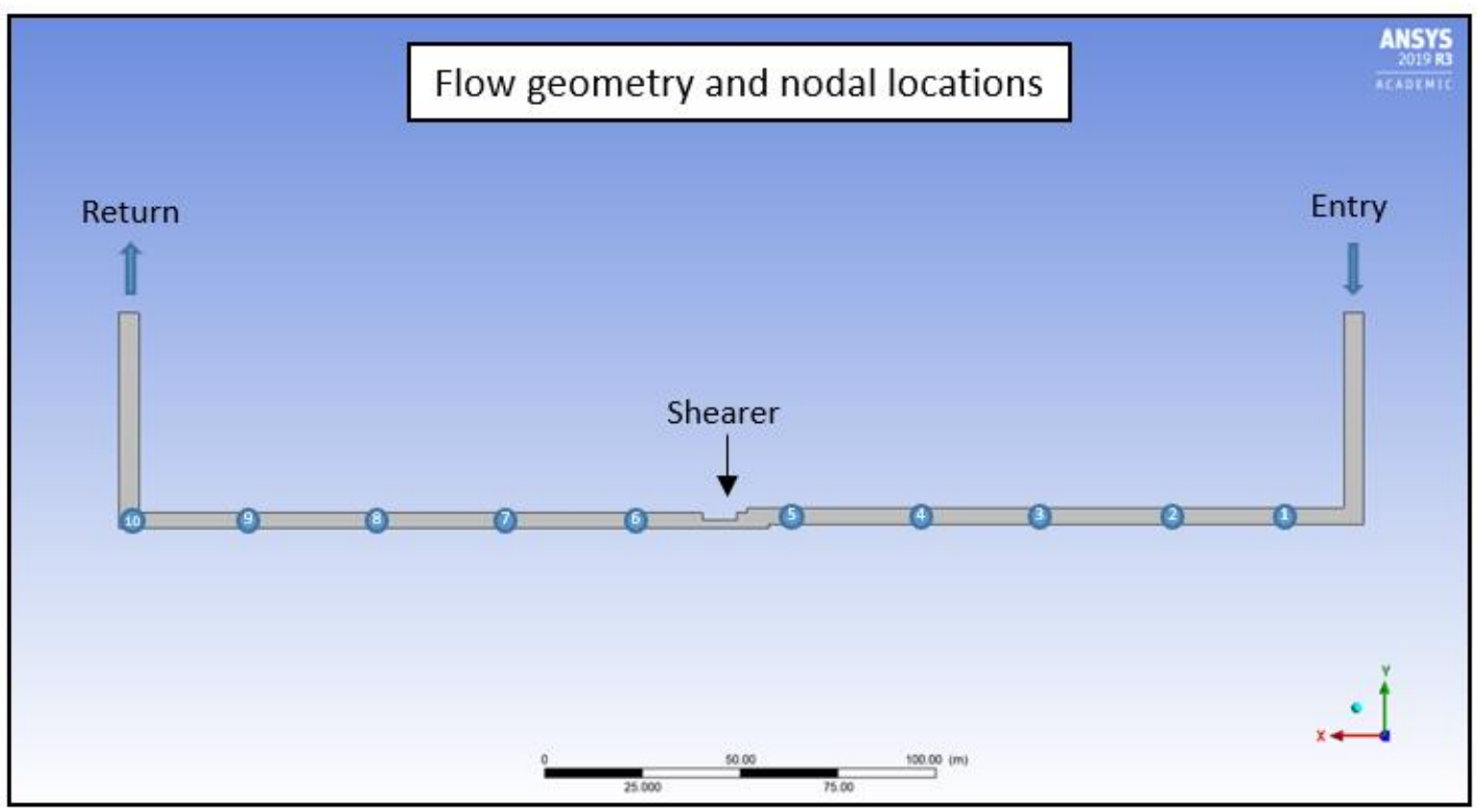

Figure 3.4-1 Layout of 2-D model flow domain with shearer located in the middle of a cutting sequence cutting from HG to TG. Numbered circles represent the locations of the 10 proposed MWS nodes.

Table 3.4-1 General dimensions of 2-D longwall model.

\begin{tabular}{cc}
\hline \hline Parameter & Dimensions [m] \\
\hline Face Length & 300 \\
Face Width & 4.12 \\
Depth of Cut & 1.01 \\
Entry/Return Length & 50 \\
Entry/Return Width & 5 \\
\hline \hline
\end{tabular}

Due to the large scale and meshing of the flow geometry, the flow domain was kept static to reduce computational complexities. Therefore, the analysis consisted of three geometrical scenarios where the shearer was located near the HG, the middle, and at the TG. Transient boundary conditions were also defined for the entry inlet representing fresh air and for the methane being 
emitted at the cutting edge of the shearer. These conditions are further discussed in the 'boundary conditions' section of the model setup.

\subsubsection{Model Setup}

The following details include the CFD models and governing equations used to simulate the transport of methane through the mine. For all cases, the solutions were solved under transient and pressure-based conditions. The standard k-epsilon turbulence model was used to promote the mixing and transport of methane as it would enter the flow domain. This model consisted of two transport equations, one for the turbulent kinetic energy $(k)$ and the other for viscous dissipation rate $(\varepsilon)$ and are given as [43], [38].

$$
\begin{array}{r}
\frac{\partial(\rho k)}{\partial t}+\operatorname{div}(\rho k \mathrm{U})=\operatorname{div}\left[\frac{\mu_{t}}{\sigma_{k}} \operatorname{grad} k\right]+2 \mu_{t} S_{i j} \cdot S_{i j}-\rho \varepsilon \\
\frac{\partial(\rho \varepsilon)}{\partial t}+\operatorname{div}(\rho \varepsilon \mathrm{U})=\operatorname{div}\left[\frac{\mu_{t}}{\sigma_{\varepsilon}} \operatorname{grad} \varepsilon\right]+C_{1 \varepsilon} \frac{\varepsilon}{k} 2 \mu_{t} S_{i j} \cdot S_{i j}-C_{2 \varepsilon} \frac{\rho \varepsilon^{2}}{k}
\end{array}
$$

\section{Species}

A Species Transport model was then enabled to define the active species that would be interacting within the domain. For this analysis, only Air and Methane $\left(\mathrm{CH}_{4}\right)$ were the species of interest and were defined at the inlet boundary conditions. Reactions were turned off within the model setup and a mixture material of methane-air was selected from the predefined mixture material database. Ansys ${ }^{\circledR}$ included all species that will participate and result from a reaction involved within the mixture material selected by default. Therefore, it was important that only the species of interest (air and methane) were selected and will therefore only contribute to the resulting mass fraction of the resulting concentrations. An illustration of these selections can be seen in Figure 3.4-2. 


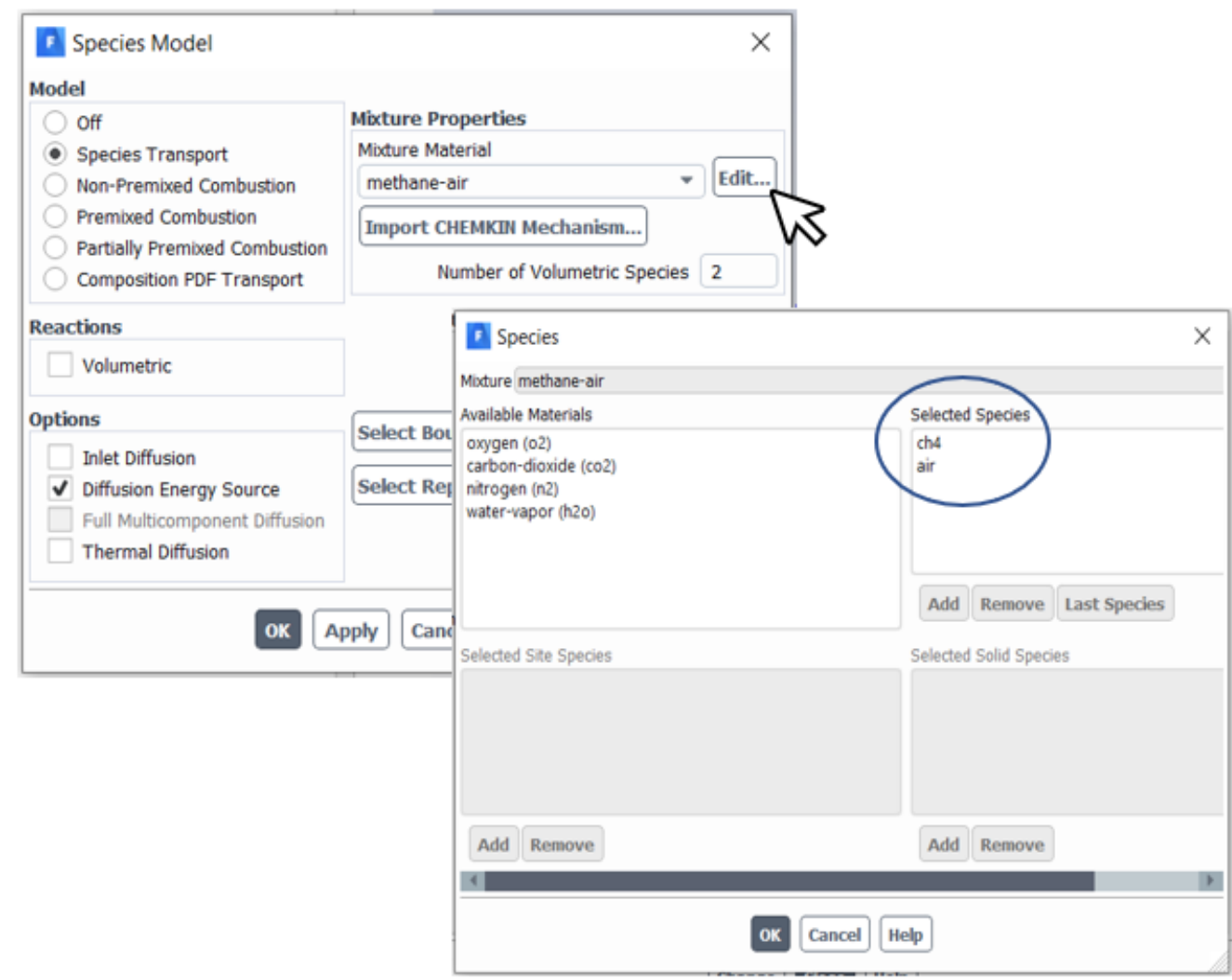

Figure 3.4-2 Defining active species within the species transport model definitions.

\section{Boundary Conditions}

The sources of air and methane and their respective emission rates were defined at the boundaries of the flow domain. Fresh ventilation air containing no methane was supplied to the entry of the longwall section (shown in Figure 3.4-1 above) as a mass flow rate $(\mathrm{kg} / \mathrm{s})$. It was assumed that the entry ways throughout the mine are adequately sealed and that no methane is accumulated prior to entering the longwall face. All boundary inlet conditions were defined on a mass flowrate basis which were consistent with emission rates calculated from previous studies. Methane inlet conditions were defined along all boundaries that represented coal within the main $300 \mathrm{~m} \mathrm{(984 \textrm {ft } )}$ length section of the model. The indentation in geometry that represents the shearer was defined as a wall and contributed no methane. The methane sources were defined on three criteria to more accurately represent an active mining process, since the 2-D model described here is static in nature.

The first classification of methane emissions within the working section represented the baseline emissions. These emissions were a result of the continuously desorbed methane from the exposed 
coal. The emission rate associated with this phenomenon will also define the methane that may escape from the gob region located behind the shields. The next classification of methane source represented the emitted gas from more recent activity. This region was defined as the boundary located behind the shearer that suggests that it had recently sheared coal away and is progressing forward. This can also be thought of as the beginning of the desorption process that defines the other boundaries representing a longer time scale (steady state). Lastly, a methane source with the highest emission rate was defined at the cutting edge of the shearer and represents the immediate release of methane from production.

Transient conditions were applied to both the air inlet and shearer cutting emissions to create unique scenarios. The transient condition consisted of a sinusoidal function applied to the emission rate and was of the form:

$$
y=A \sin (B(x+C))+D
$$

Where $\mathrm{A}$ is the amplitude that represents the maximum emission rate desired and $\mathrm{B}$ is the period or frequency of the high emission. $\mathrm{C}$ is the shift along the time axis (x-axis), and $\mathrm{D}$ is the vertical shift. The resulting expressions for the respective rates were uniquely constructed with the characteristic variables of Equation 3.4.3 to perturb emission profiles and access sensitively of boundary conditions.

\section{Solution and Report Definitions}

The pressure-based model was coupled with velocity using the Semi-Implicit Method for Pressure Linked Equations (SIMPLE). Spatial discretization of the transported species was solved with a second order upwind method. Solutions were calculated with a time step size of $0.1 \mathrm{~s}$ and a maximum iterations per time step of 20 .

A number of solution monitors and reports were constructed to capture resulting methane concentration profiles at the proposed nodal locations of the MWS. Since the MWS consist of 10 nodes, each with the ability to sample from both the face and gob region, 20 report monitors were defined at the respective locations (10 along the face and 10 along the gob). Monitors reported the average mass fractions of $\mathrm{CH}_{4}$ over the selected facet in the model's mesh. Contour graphs were also created for both the contour of $\mathrm{CH}_{4}$ mass fraction as well as the resulting velocity contour. Solutions to the simulation were obtained until a steady state was reached (time derivatives of methane concentrations approached zero). 


\subsection{Results and Discussion}

\subsection{MWS Overview}

Figure 4.1-1 presents one of the completed MWS sampling units. Ten units were constructed in all. The sampling unit packages all the sensors and data acquisition hardware needed to analyze a sample and report information back to the $\mathrm{CPH}$. The sample from either the face or gob region is brought into the unit via the sampling lines, respectively. A three-way valve was included in each unit to make the bi-directional sampling method possible, though not simultaneously. The sevenfoot sampling line which connected the filter near the face and gob to the unit, as well as all internal connections were made of $6.4 \mathrm{~mm}$ (0.25 in) PTFE tubing. The $6.4 \mathrm{~mm}(0.25 \mathrm{in})$ tubing was selected to increase sample velocity in attempts to minimize transport delay time.

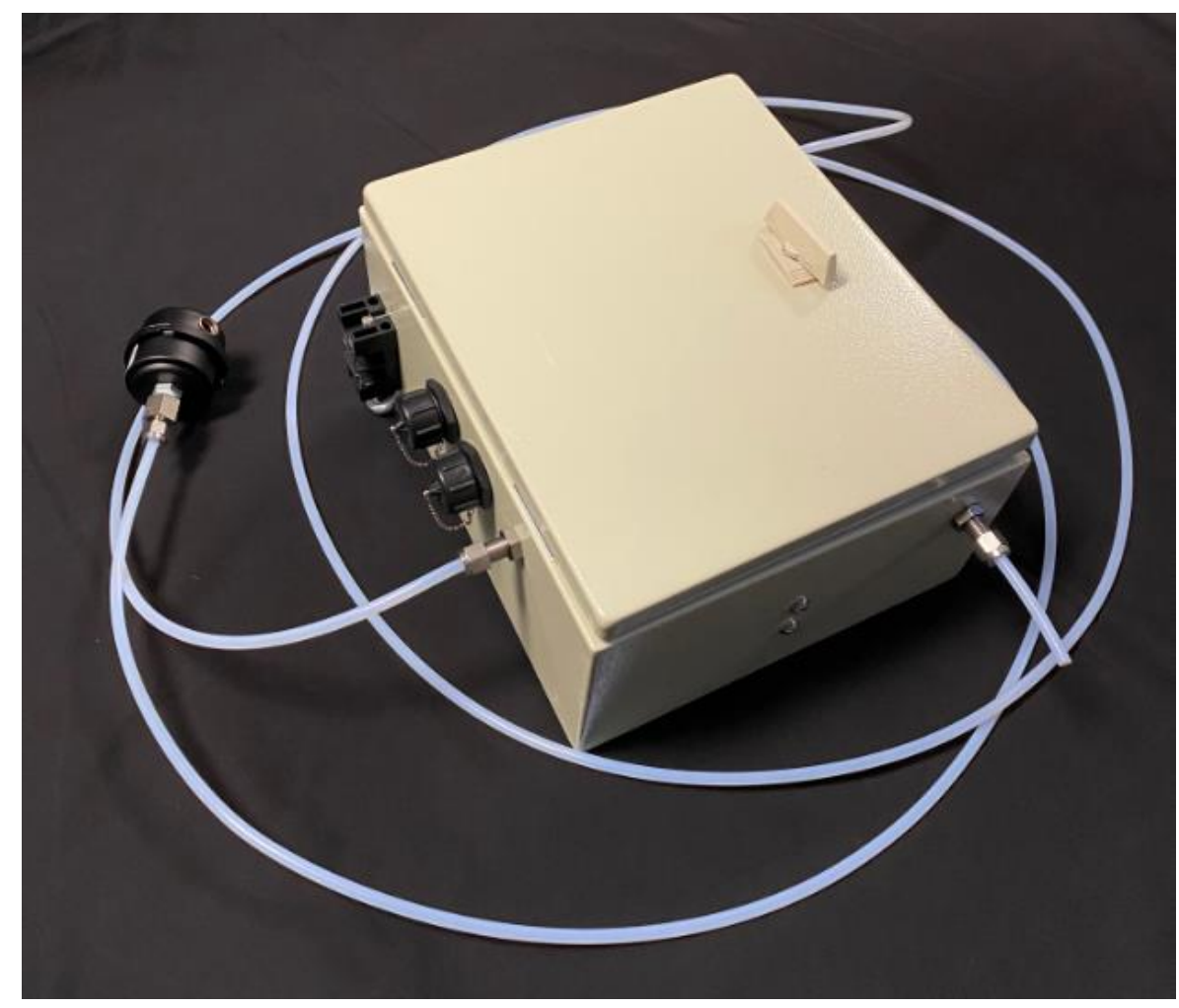

Figure 4.1-1 Completed MWS sampling unit with sampling line and filter.

\subsubsection{The Sensor Block}

The sensor block shown in Figure 4.1-2 was constructed from an aluminum billet to the specifications created in CAD. The block was designed in a way to include all sensors while minimizing dead volume and flow restrictions. A straightforward sample path with minimal 
volume were important design parameters to aid in reducing system response and delay times. Additional measures were also taken to ensure the block was leak proof when fitted with the respective sensors. The proposed motive force for sampling consists of a water driven vacuum system (water ejector) which means that any leak in the system could bring in air outside of the targeted area, diluting the sample. For example, a potted housing bung with an O-ring was constructed for the MQ-4 sensor to ensure no dilution occurred through the sensors original housing.

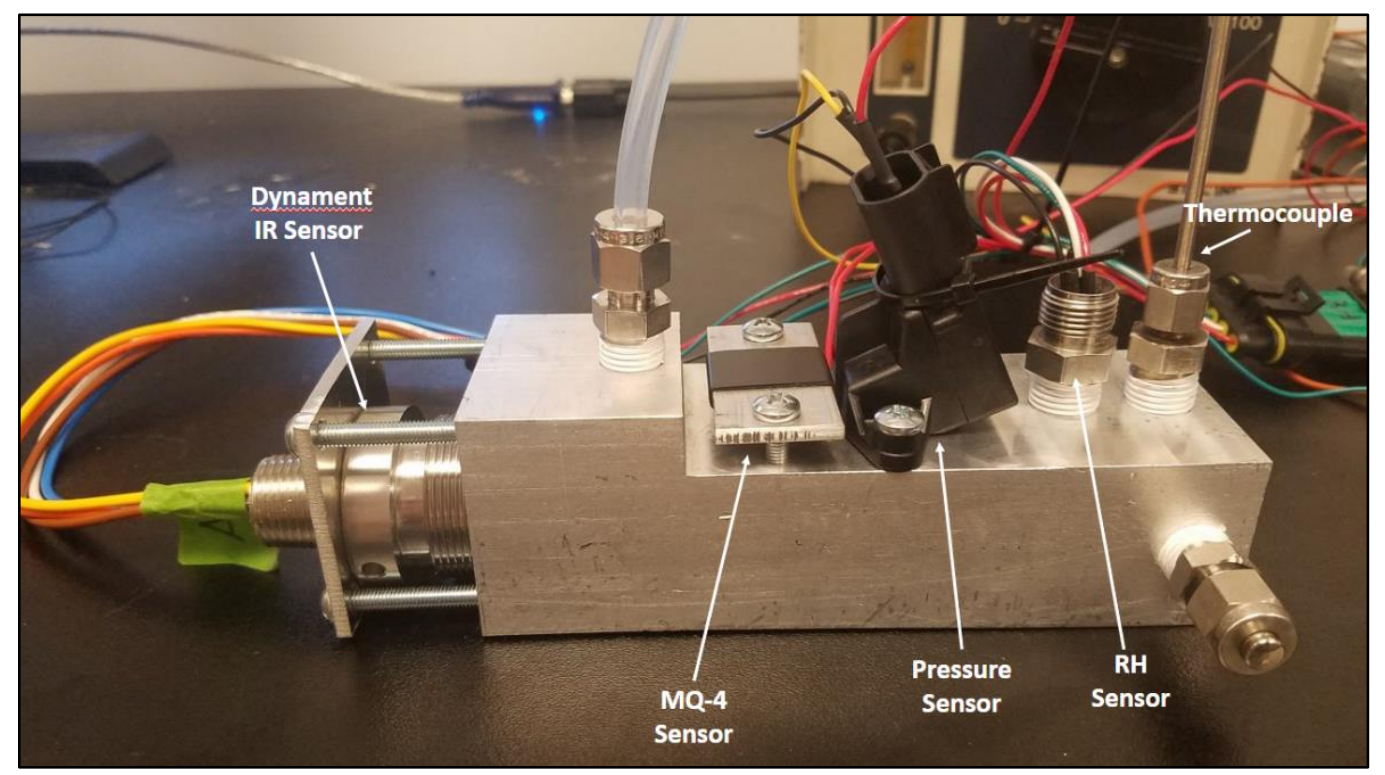

Figure 4.1-2 Completed sensor block containing the methane and climate sensors.

\subsubsection{Filtration}

Several tests were conducted on the three selected commercially available filters: Spectre, McMaster Carr, and Solberg. Experiments measured the effects design/material, dust loading and water saturation had on flow restriction.

\section{Sampling Flow Rate}

Table 4.1-1 contains the baseline measurements where air was sampled through each filter by a pump. A pressure measurement device (Heise) was used to measure the resulting pressure drop across the filter media at various flow rates. This test was performed at flowrates of 1, 2, 3, and 4 SLPM; which covers the proposed sampling rate of roughly 2 SLPM. The results can be found below in Table 4.1-1. 
Table 4.1-1 Examination of flow restriction across dry unloaded filter at various flow rates.

\begin{tabular}{lcccc}
\hline \hline & \multicolumn{4}{c}{ Pressure Loss Across Filter [in $\left.\mathbf{H}_{2} \mathbf{O}\right]$} \\
\cline { 2 - 5 } Filter & 4 SLPM & 3 SLPM & 2 SLPM & 1 SLPM \\
\hline Spectre & 1.041 & 0.655 & 0.341 & 0.126 \\
McMaster Carr & 0.012 & 0.008 & 0.006 & 0.004 \\
Solberg & 0.032 & 0.022 & 0.015 & 0.008 \\
\hline
\end{tabular}

Note: 1 in $\mathrm{H}_{2} \mathrm{O}=0.03609$ psi

\section{Coal Dust Loading}

To assess the effects of dust accumulation on the individual filters, a procedure to accelerate the cake formation on the filter media was used to simulate effective filtration life. This experiment aimed to correlate the amount of coal dust loaded to a resulting pressure drop that would ultimately lead to a reduction in sampling flow. To more accurately mimic the cake formation of coal dust on each of the filter's media, an apparatus was designed to effectively suspend coal dust within the proximity of the filter activity drawing air. This not only allowed for uniform dust loading but also allowed control of how much coal dust was added to the filter. From a review of literature, an average daily coal dust loading was found to be $0.144 \mathrm{~g} / \mathrm{day}$. This equated to 1.008 grams per week, which is the basis by which the analysis was made. The filter was initially weighed before entering the dust loading apparatus and weighed after to achieve a simulated 1 weeks' worth of coal dust. Tables 4.1-2, 4.1-3, and 4.1-4 contain the results of the coal dust loading simulation for the three filters.

Table 4.1-2 Spectre Filter coal dust loading results.

\begin{tabular}{lccccc}
\hline \hline & & \multicolumn{4}{c}{ Pressure Loss Across Filter [inH $\left.\mathbf{H}_{\mathbf{2}} \mathbf{O}\right]$} \\
\cline { 3 - 6 } Time & Loading [g] & 3.5 SLPM & 3 SLPM & 2 SLPM & 1 SLPM \\
\hline 1 day & 0.1 & 1.560 & 1.218 & 0.652 & 0.240 \\
1 week & 1 & 1.605 & 1.224 & 0.626 & 0.202 \\
2 weeks & 2 & 1.592 & 1.240 & 0.639 & 0.211 \\
3 weeks & 3 & 1.625 & 1.267 & 0.670 & 0.222 \\
4 weeks & 4 & 1.707 & 1.348 & 0.721 & 0.249 \\
\hline Note: Initial weight of filter was 53.7 g. Effective filtration area is $0.0102 \mathrm{~m}^{2}$ \\
\hline \hline
\end{tabular}


Table 4.1-3 Cylindrical Filter (white) coal dust loading results.

\begin{tabular}{lccccc}
\hline \hline & & \multicolumn{4}{c}{ Pressure Loss Across Filter [inH $\left.\mathbf{H}_{2} \mathbf{O}\right]$} \\
\cline { 3 - 6 } Time & Loading [g] & 3.5 SLPM & 3 SLPM & 2 SLPM & 1 SLPM \\
\hline 1 day & 0.1 & 0.010 & 0.008 & 0.005 & 0.003 \\
1 week & 1 & 0.012 & 0.010 & 0.006 & 0.003 \\
2 weeks & 2 & 0.013 & 0.011 & 0.007 & 0.003 \\
3 weeks & 3 & 0.027 & 0.023 & 0.015 & 0.007 \\
4 weeks & 4 & 0.037 & 0.031 & 0.020 & 0.010 \\
\hline Note: Initial weight of filter was 62.5 g. Effective filtration area is $0.0147 \mathrm{~m}^{2}$ \\
\hline \hline
\end{tabular}

Table 4.1-4 Solberg Filter (black) coal dust loading results.

\begin{tabular}{lccccc}
\hline \hline & & \multicolumn{4}{c}{ Pressure Loss Across Filter [inH $\left.\mathbf{H}_{2} \mathbf{O}\right]$} \\
\cline { 3 - 6 } Time & Loading [g] & 3.5 SLPM & 3 SLPM & 2 SLPM & 1 SLPM \\
\hline 1 day & 0.1 & 0.028 & 0.022 & 0.014 & 0.006 \\
1 week & 1 & 0.043 & 0.035 & 0.022 & 0.010 \\
2 weeks & 2 & 0.052 & 0.043 & 0.027 & 0.013 \\
3 weeks & 3 & 0.082 & 0.067 & 0.043 & 0.020 \\
4 weeks & 4 & 0.138 & 0.115 & 0.074 & 0.036 \\
\hline
\end{tabular}

Note: Initial weight of filter was $14.1 \mathrm{~g}$. Effective filtration area is $0.0185 \mathrm{~m}^{2}$

\section{Water Saturation}

Following the coal dust loading simulation, a similar procedure was conducted that assessed the flow restriction due to the presence of water on the filter media. The coal dust on the filter from the previous experiment was removed to the best of its ability. The remaining coal dust was accounted for and included in the initial weight of the filter before water was added. Similar to the dust loading procedure, water was incrementally added to the filter and a new weight was recorded. Tables 4.1-5, 4.1-6, and 4.1-7 contain the results of the water loading simulation for the three filters. 
Table 4.1-5 Spectre Filter (Blue) water loading results.

\begin{tabular}{ccccc}
\hline \hline & \multicolumn{4}{c}{ Pressure Loss Across Filter [inH $\mathbf{H}_{\mathbf{2}}$ ] ] } \\
\cline { 2 - 5 } Loading [g] & 3.5 SLPM & 3 SLPM & 2 SLPM & 1 SLPM \\
\hline 0 & 1.543 & 1.218 & 0.624 & 0.196 \\
0.1 & 1.607 & 1.216 & 0.644 & 0.199 \\
0.4 & 1.616 & 1.219 & 0.633 & 0.208 \\
1.8 & 1.643 & 1.231 & 0.639 & 0.206 \\
\hline Note: Zero loading represents a dry filter \\
\hline \hline
\end{tabular}

Table 4.1-6 Cylindrical Filter (White) water loading results.

\begin{tabular}{ccccc}
\hline \hline & \multicolumn{4}{c}{ Pressure Loss Across Filter [inH $\mathbf{H}_{2}$ O] } \\
\cline { 2 - 5 } Loading [g] & 3.5 SLPM & 3 SLPM & 2 SLPM & 1 SLPM \\
\hline 0 & 0.010 & 0.008 & 0.005 & 0.002 \\
0.10 & 0.010 & 0.008 & 0.005 & 0.002 \\
0.50 & 0.010 & 0.008 & 0.005 & 0.002 \\
1.80 & 0.011 & 0.009 & 0.006 & 0.002 \\
11.6 & 0.023 & 0.019 & 0.011 & 0.005 \\
\hline Note: Zero loading represents a dry filter \\
\hline \hline
\end{tabular}

Table 4.1-7 Solberg (Black) water loading results.

\begin{tabular}{ccccc}
\hline \hline & \multicolumn{4}{c}{ Pressure Loss Across Filter [inH $\left.{ }_{2} \mathbf{O}\right]$} \\
\cline { 2 - 5 } Loading [g] & 3.5 SLPM & 3 SLPM & 2 SLPM & 1 SLPM \\
\hline 0 & 0.057 & 0.047 & 0.030 & 0.014 \\
0.1 & 0.056 & 0.046 & 0.029 & 0.013 \\
0.4 & 0.055 & 0.046 & 0.030 & 0.014 \\
1.8 & 0.068 & 0.056 & 0.036 & 0.017 \\
\hline Note: Zero loading represents a dry filter \\
\hline
\end{tabular}

\section{Filter Selection}

From the data collected, all three filters performed within desired limitations. No significant contribution to flow restriction was detected throughout both the dust and water loading simulations. From the three filters initially evaluated, the Solberg filter was selected for the final design of stage 2 for the MWS prototype that would be deployed for full scale data collection. Figure 4.1-3 presents the Solberg filter with its internal filter cassette. This filter was of particular interest because of its design and construction. The flat pleated filter cassette is housed in a 
protective metal two-piece construction that allows for easy removal. The design also incorporates an inlet that functions as an added impact or drop out layer of protection for the larger particles and inhibits the direct contact of airborne water on the filter material. These design features coupled with the satisfactory performance from the coal mine simulation tests made this filter a favorable option.

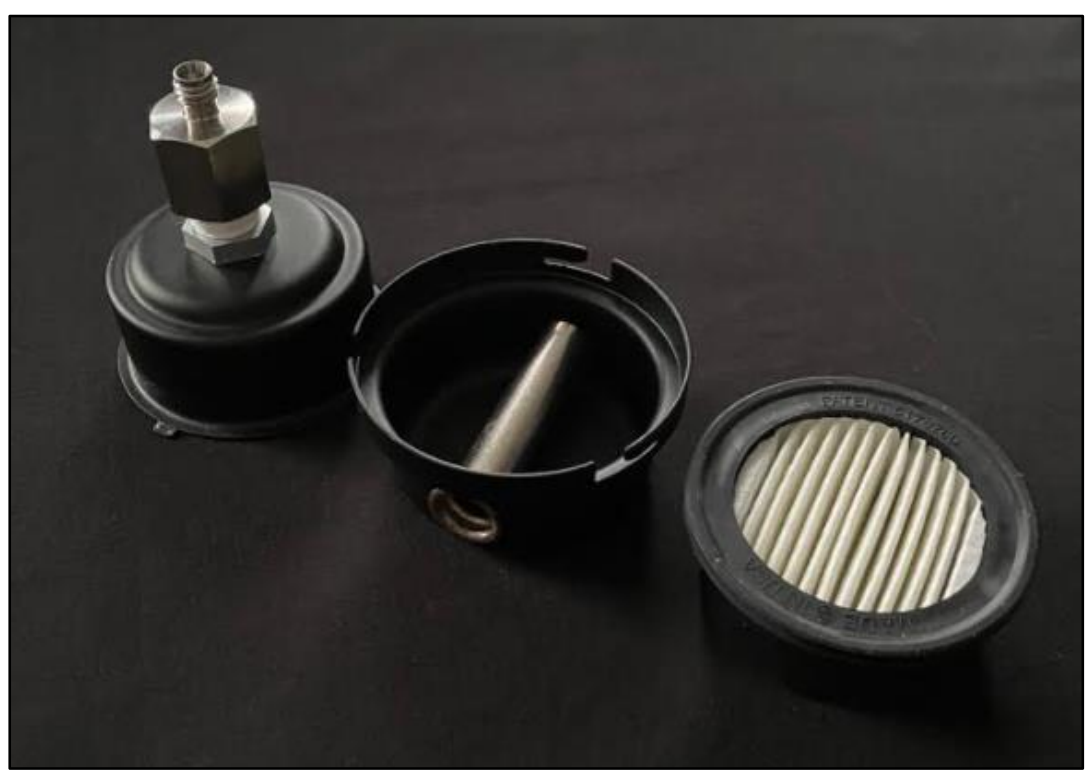

Figure 4.1-3 Solberg filter selected for final design of MWS prototype.

\subsubsection{Proposed Sampling Mode (The Water Ejector)}

Multiple designs of the water ejector backed by laboratory testing and CFD studies were completed by Ms. Amber Barr [35]. Figure 4.1-4 presents an initial design of the ejector that was 3-D printed for laboratory use. 


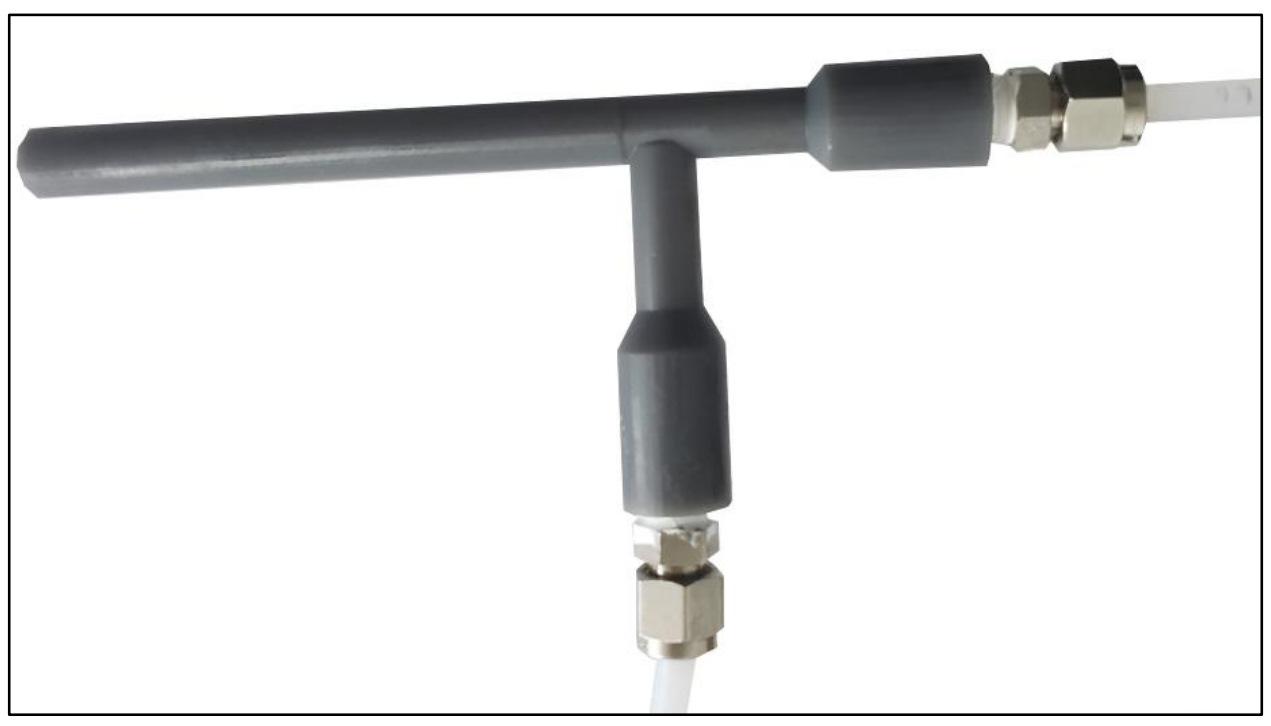

Figure 4.1-4 Initial design of 3-D printed water ejector.

Tests were constructed for the initial ejector to access the effective operational performance. The performance indicators include parameters such as suction flow rate (MWS sampling rate) and the ability to maintain desired flowrates while overcoming system losses. It was determined that the pressure differential across one completed MWS sampling unit was around $1.4 \mathrm{kPa}(0.2 \mathrm{psig}$ or $\left.5.55 \mathrm{inH}_{2} \mathrm{O}\right)$ at a desired sampling rate of $2 \operatorname{SLPM}(0.071 \mathrm{scfm})$. Figure 4.1-4 presents the ejectors performance at eight different data points representing operational suction pressures. Two distinct trends resulted across the eight pressure points; therefore, a classification of a "low" and "high" pressure curve was established. Table 4.1-8 then presents the results for the test where suction pressure was held constant while inlet water pressure was varied from 40 to 70 psig in increments of 10 psig. 


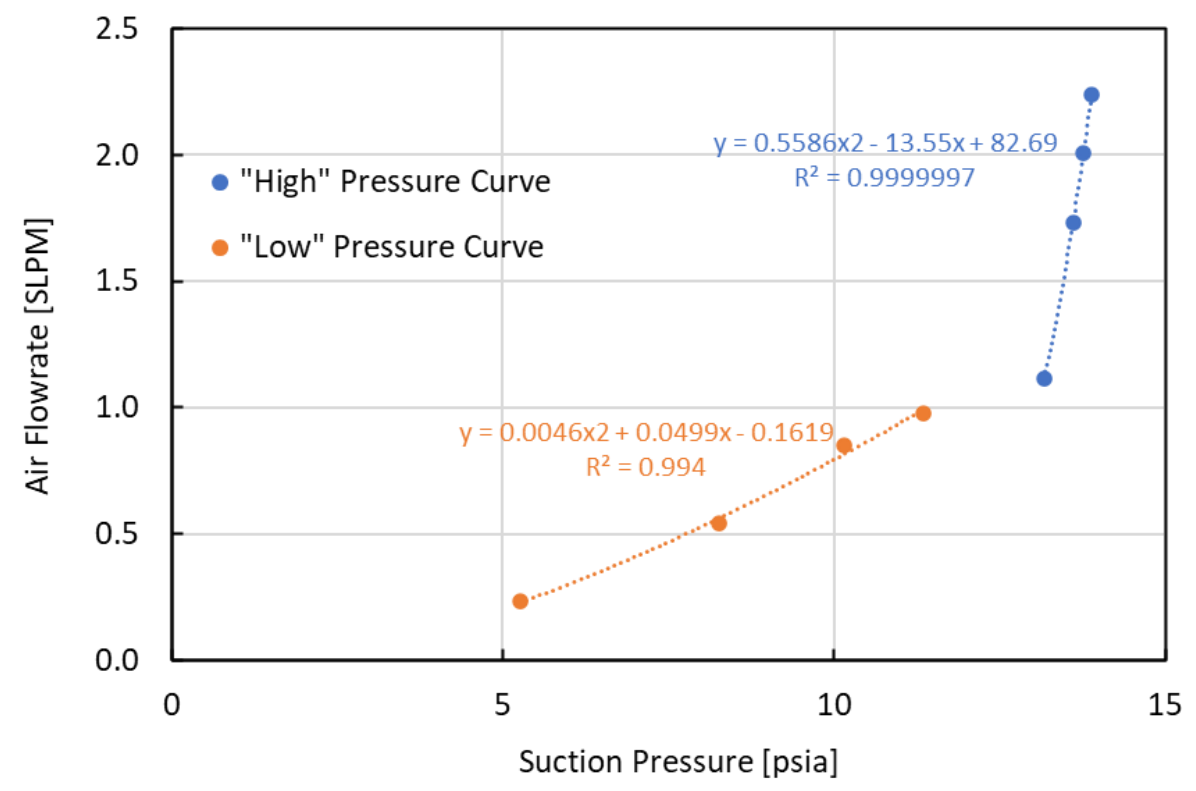

Figure 4.1-4 Ejectors performance curve as a function of operational suction pressure [35].

Table 4.1-8 Performance of initial ejector design at constant air suction pressure.

\begin{tabular}{cccccc}
\hline $\begin{array}{c}\text { Water } \\
\text { Pressure }\end{array}$ & $\begin{array}{c}\text { Air Mass } \\
\text { Flowrate }\end{array}$ & $\begin{array}{c}\text { Air } \\
\text { Volumetric } \\
\text { Flowrate }\end{array}$ & $\begin{array}{c}\text { Water } \\
\text { Flowrate }\end{array}$ & $\begin{array}{c}\text { Outlet } \\
\text { Pressure }\end{array}$ & Flow Ratio \\
\hline$[$ psig] & {$[$ SLPM] } & {$[$ LPM] } & {$[\mathbf{L P M}]$} & [psia] & \\
\hline 40 & 0.5 & 0.7 & 0.69 & 13.47 & 1.01 \\
50 & 0.68 & 0.95 & 0.76 & 13.55 & 1.24 \\
60 & 0.91 & 1.27 & 0.83 & 13.65 & 1.52 \\
70 & 1.04 & 1.44 & 0.89 & 13.69 & 1.63 \\
\hline Note: Constants include: Air suction pressure $\sim 11$ psia, Air temperature $\sim 24^{\circ} \mathrm{C}$, Water temperature $\sim 24{ }^{\circ} \mathrm{C}$ \\
\hline \hline
\end{tabular}

A multi-nozzle ejector design was then created in attempts to achieve a greater performance (higher flowrates at lower suction pressures). The design depicted in Figure 4.1-5 consisted of three pieces (3-D printed) which allowed for an interchangeable nozzle. The multi-nozzle design contained several holes similar to that of a shower head or gardening hose. This disrupts the water flow before it enters the diffusion section of the ejector allowing for better mixing of water to air. The dissimilar fluids possess a gradient in density which creates the uniqueness and challenge of this concept. 

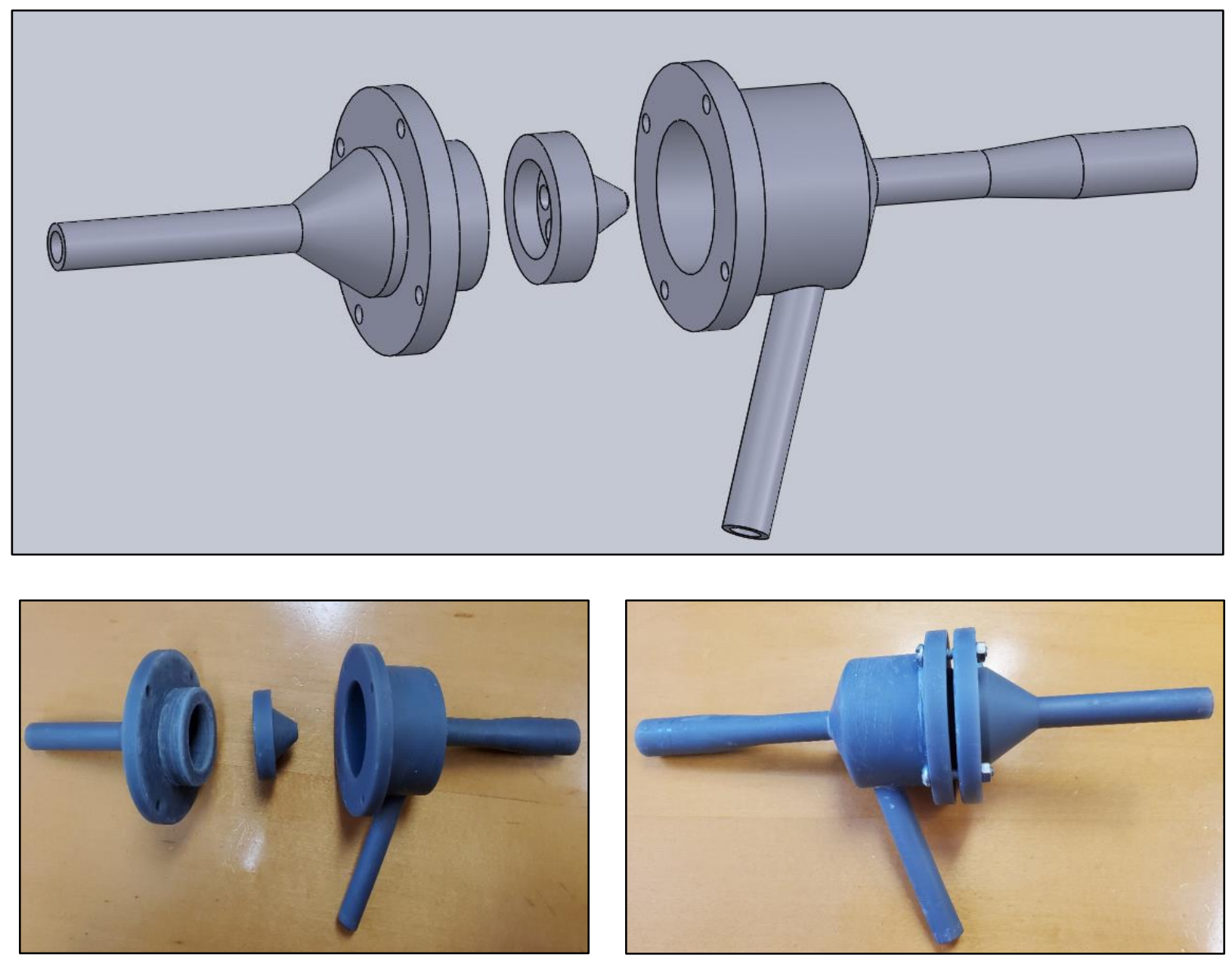

Figure 4.1-5 Images of 3-D printed multi-nozzle ejector.

Similar to the initial design, the multi-nozzle ejector presented a discontinuity in the performance curve when varying suction pressure. Figure 4.1-6 presents a resulting performance curve with a fixed water inlet pressure of $55 \mathrm{psig}$. Again, a low and high curve was established, however the multi-nozzle design did increase suction flowrate (sampling flowrate, air) performance. Table 4.19 contains the resulting performance when suction pressure was constant and inlet water pressure was varied. Consider referring to [35] for further information on the development and performance of the water-air ejector. 


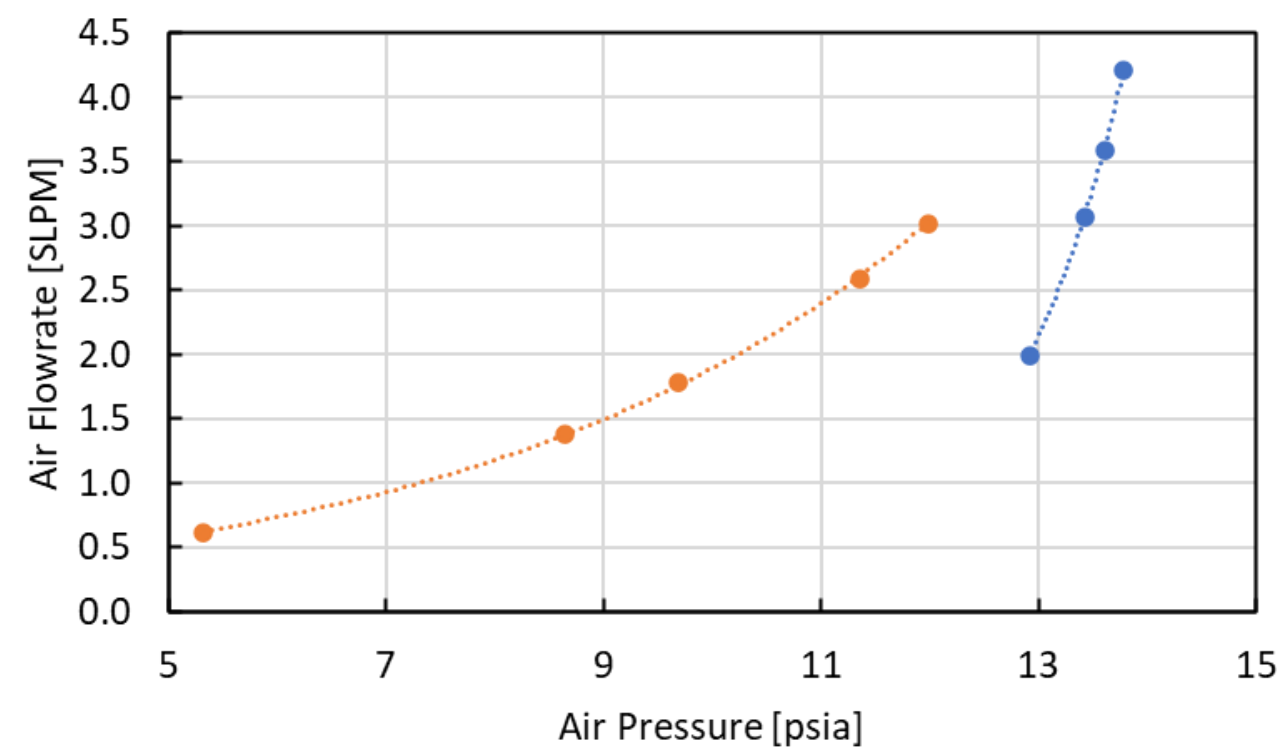

Figure 4.1-6 Multi-nozzle ejector performance curve at constant inlet pressure of 55 psig.

Table 4.1-9 Performance of multi-nozzle ejector with constant air suction pressure.

\begin{tabular}{cccccc}
\hline $\begin{array}{c}\text { Water } \\
\text { Pressure }\end{array}$ & $\begin{array}{c}\text { Air Mass } \\
\text { Flowrate }\end{array}$ & $\begin{array}{c}\text { Air } \\
\text { Volumetric } \\
\text { Flowrate }\end{array}$ & $\begin{array}{c}\text { Water } \\
\text { Flowrate }\end{array}$ & $\begin{array}{c}\text { Outlet } \\
\text { Pressure }\end{array}$ & Flow Ratio \\
\hline [psig] & [SLPM] & {$[$ LPM] } & [LPM] & [psia] & \\
\hline 10 & 0.04 & 0.06 & 0.56 & 13.81 & 0.11 \\
20 & 0.71 & 0.98 & 0.77 & 13.90 & 1.28 \\
30 & 1.20 & 1.65 & 0.91 & 13.91 & 1.81 \\
40 & 1.70 & 2.34 & 1.04 & 13.99 & 2.25 \\
50 & 2.13 & 2.94 & 1.15 & 14.11 & 2.56 \\
60 & 2.60 & 3.58 & 1.26 & 14.28 & 2.85 \\
70 & 2.89 & 3.98 & 1.33 & 14.50 & 3.00 \\
\hline
\end{tabular}

Note: Constants include: Air suction pressure $\sim 11 \mathrm{psia}$, Air temperature $\sim 30^{\circ} \mathrm{C}$, Water temperature $\sim 24^{\circ} \mathrm{C}$

\subsection{Sensor Response Characteristics}

The characteristics of the MWS's response to an input were a function of two things: physical transport of the sample through the system, and the sensors chemical/electrical response. Before the entire system was subjected to a series of controlled inputs, the sensors were individually calibrated and studied to build a baseline profile. 


\subsubsection{Defining Error and Non-dimensional Analysis}

The following analysis of the sensors' response to the various controlled inputs was completed on a non-dimensional basis. Equation 4.2.1 was used to normalize the collected data from the selected sensors

$$
y(t)_{\text {normalized }}=\frac{y(t)-y_{\min }}{y_{\max }-y_{\min }}
$$

where $y(t)$ is the original output at every collected data point, $y_{\min }$ was the sensors background output prior to an event, and $y_{\max }$ was the sensors full response (FR) to an input of sufficient length. An input of sufficient length means the sensor was able to reach a maximal steady response to a fixed concentration of methane. The sensors FR also provided the basis by which the sensors percent error was defined, which is presented in Equation 4.2.2. Due to the normalization, the "true" value is represented as 1 , which reduces the percent error equation to simply the difference between the two values.

$$
\% \text { Error }=(F R-\text { peak response }) * 100
$$

Figure 4.2-1 presents a sensors response to an input and the respective rise and decay criteria. The rise time was defined as the time required for the sensors output to reach $90 \%$ of the FR to a step input. The settling or decay time was broken down into two definitions for evaluation. The first evaluation $\left(\mathrm{T}_{-50}\right)$ was defined as the time required for sensors output to fall past $50 \%$ of the FR. The second evaluation $\left(\mathrm{T}_{\mathrm{s}}\right)$ defined the settling time as the time required for the sensor to settle within $+10 \%$ of the background output from the FR. Since speedy response to an input of potential danger $\left(\sim 5 \% \mathrm{CH}_{4}\right)$ is more critical for the application, the later decay definition holds less importance. 


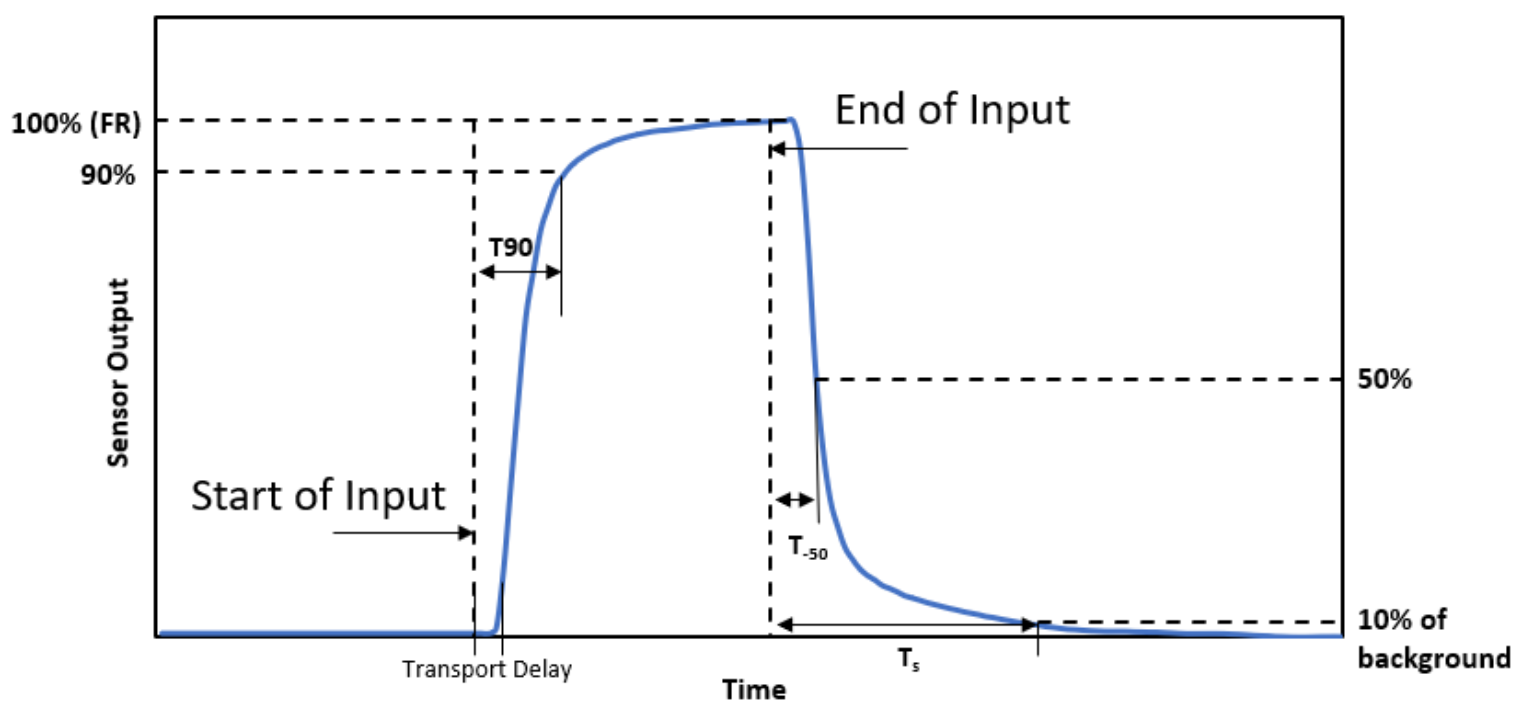

Figure 4.2-1 Rise and Decay time definitions for a sensor's response to a step input.

\subsubsection{Baseline Response Profiles}

\section{$M Q-4$}

Figure 4.2-2 displays the calibration curve of the MQ-4 sensor from 0 to $2 \%$ methane. The MOS type sensor in this case, displays a nonlinear calibration curve across its potential $(0-5 \mathrm{~V})$. Before diving into specifics, it may be noticed in Figure 4.2-3 that the rise time to a 1.01\% input is around 10 seconds, which is quite good, however once the input stops the decay is quite long (>1 min). As the sensor with the lowest price point, no additional compensation or signal processing was available. Additional studies were then performed to understand the adverse effects on the sensor's response to other parameters such as temperature and humidity. These effects are not discussed here, however correction factors and multiple calibrations were constructed to achieve a response of reasonable accuracy [35]. 


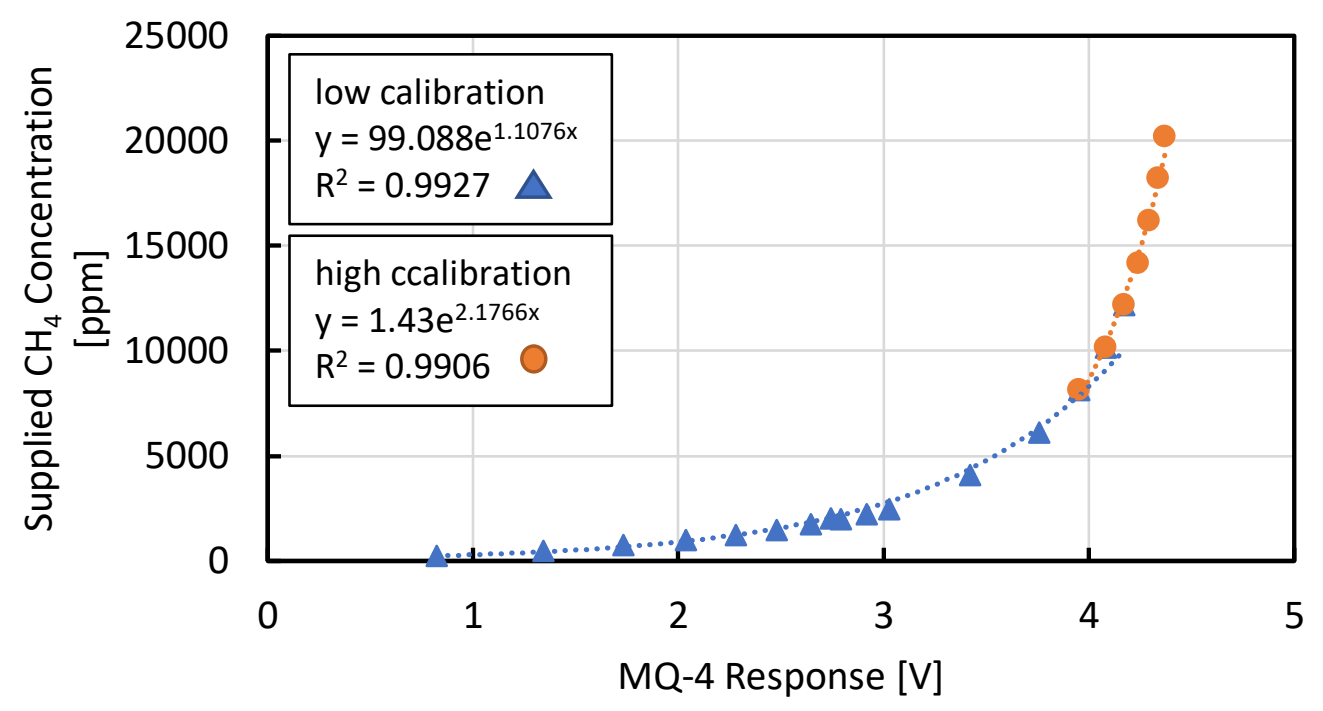

Figure 4.2-2 Non-linear calibration curve of the MQ-4 Sensor.

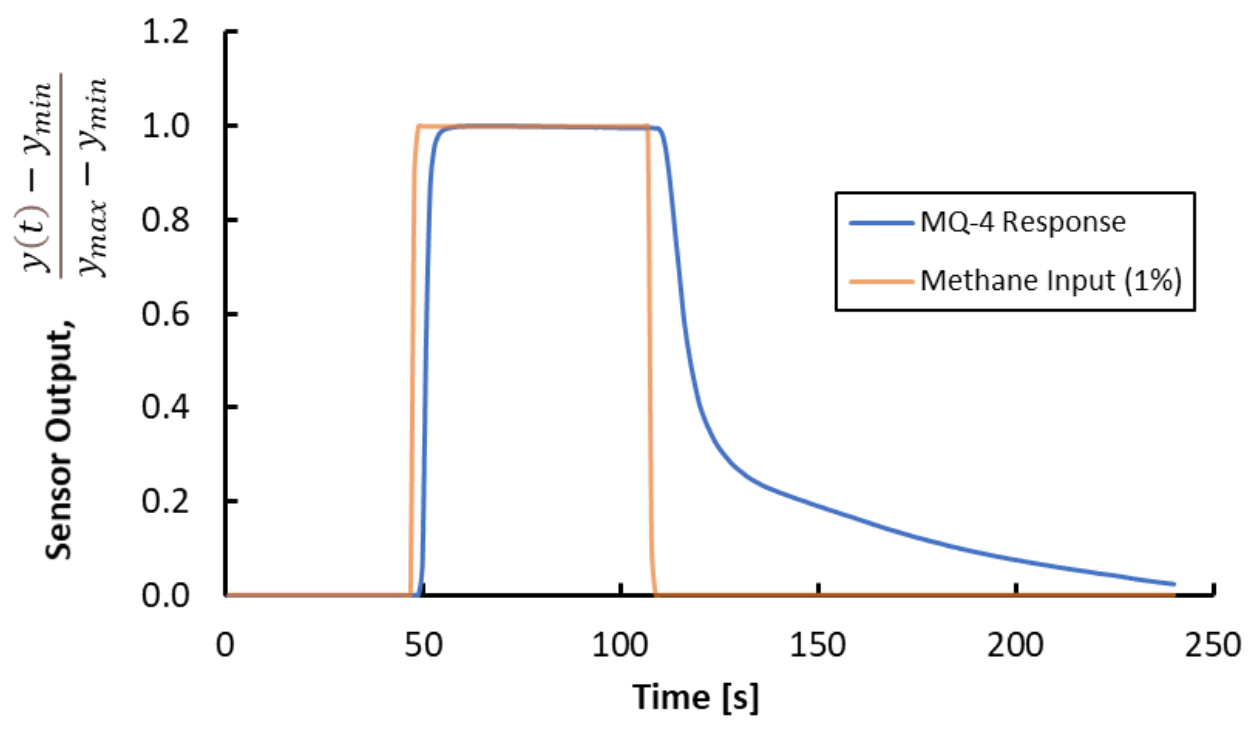

Figure 4.2-3 MQ-4 response to $1.01 \%$ methane input.

\section{Dynament}

Similar to the MQ-4 sensor, the Dynament was subjected to an input of methane to observe its characteristic response. Figure 4.2-4 presents the calibration curve of the Dynament sensor, while Figure 4.2-5 displays its characteristic response and decay profile from the presence of methane $(0-1.01 \%)$. The rise response to the input was around three times slower than that of the MQ-4, however significant improvement was gained on the decay time. Unlike the MOS operating principle of the MQ-4 sensor exhibiting a nonlinear calibration, the Dynament's IRS calibration is 
linear. The Dynament was factory tuned to measure methane within the range of $0-5 \%$ on the scaled linear output of $0-2.5 \mathrm{~V}$. Impact on measurement accuracy due to temperature and humidity was less than that of the MQ-4; however, correction factors were still applied to the reported concentration.

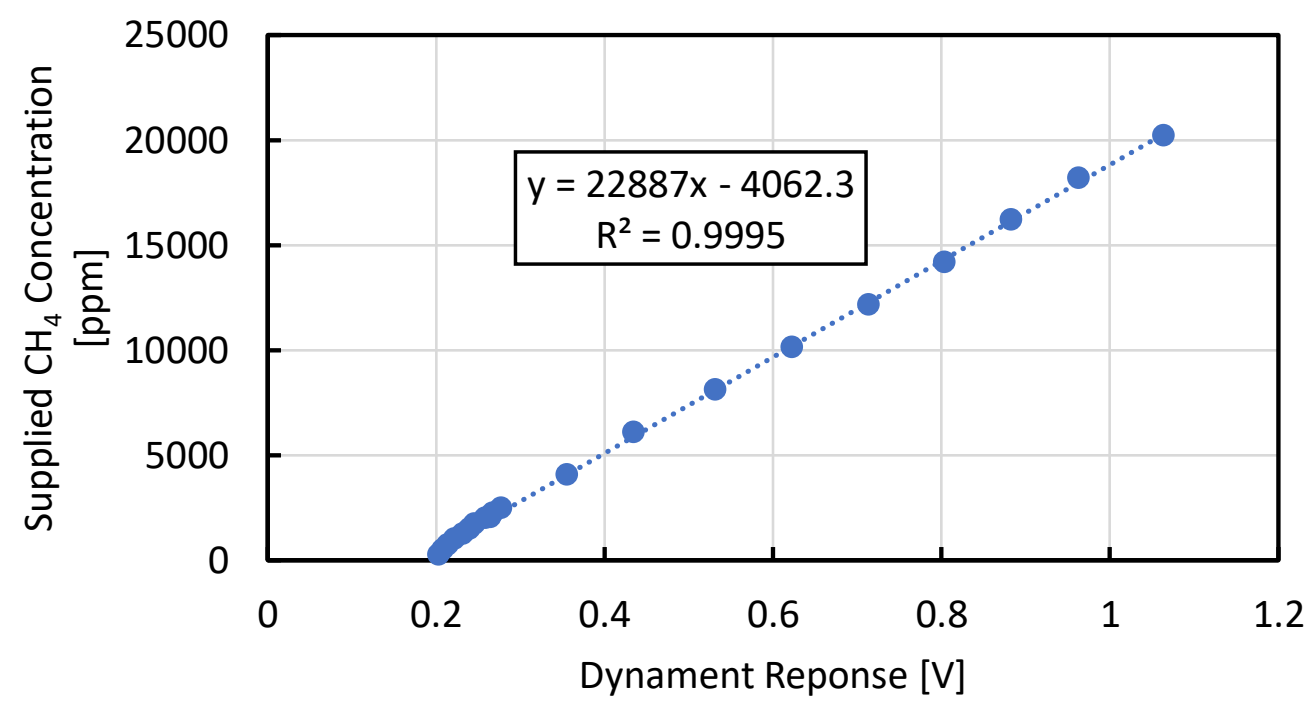

Figure 4.2-4 Linear calibration curve of the Dynament sensor.

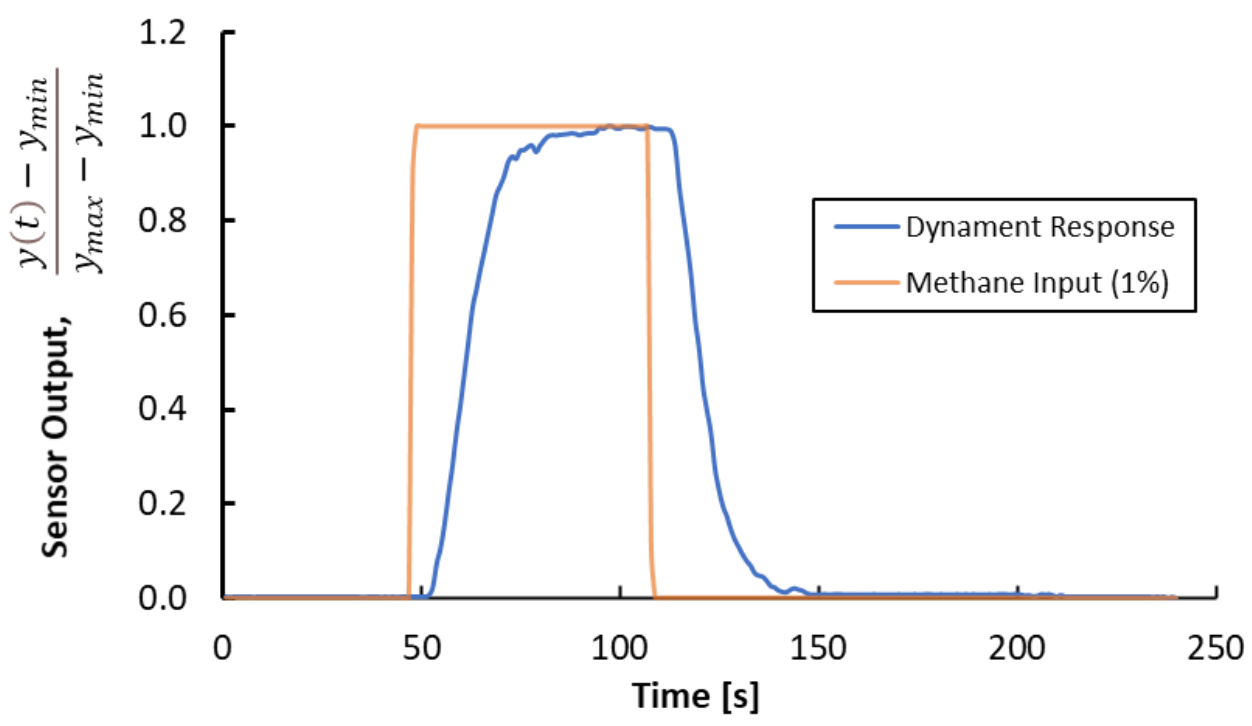

Figure 4.2-5 Dynament response to $1.01 \%$ methane input.

\section{Gasmitter}

The Gasmitter possesses a similar NDIR operational principle to that of the Dynament. As such, the Gasmitter provided a linear calibration from $0-2 \%$ methane on the output of $4-20 \mathrm{~mA}$. The 
smaller detection range over the output of 4-20mA provides the Gasmitter with a lower detection limit of $0.01 \% \mathrm{CH}_{4}(100 \mathrm{ppm})$. A marked improvement over the Dynament's poor performance under $0.2 \% \mathrm{CH}_{4}$ exhibited in the first-generation system. At the highest price point $(\$ 800)$ the sensor provided superior accuracy and response characteristics. Figure 4.2-6 displays the linear calibration profile as well as the performance at lower methane concentrations $(<0.1 \%$ or 1000 ppm). Shown in Figure 4.2-7, both the rise and decay responses to the presence of methane embody the speedy rise time of the MQ-4 while possessing the decay characteristics of the Dynament. Due to the Gasmitter's satisfactory performance and selection for second-generation system, a particular interest was placed on the sensor in the rest of the studies.
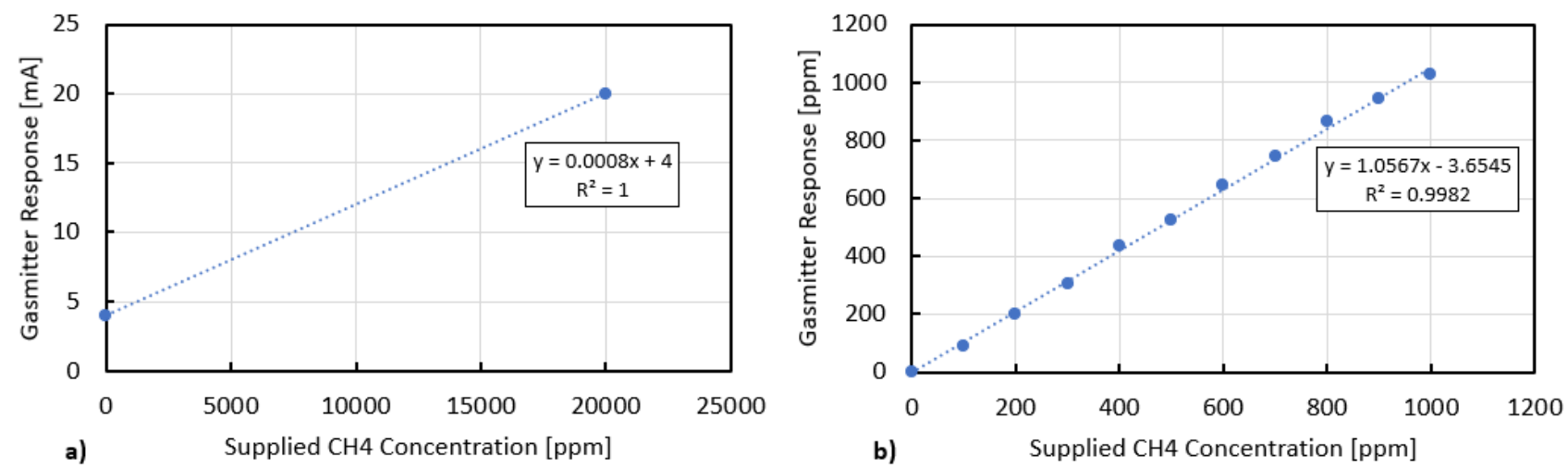

Figure 4.2-6 a) Linear span calibration for Gasmitter sensor. b) Performance at lower detection limit.

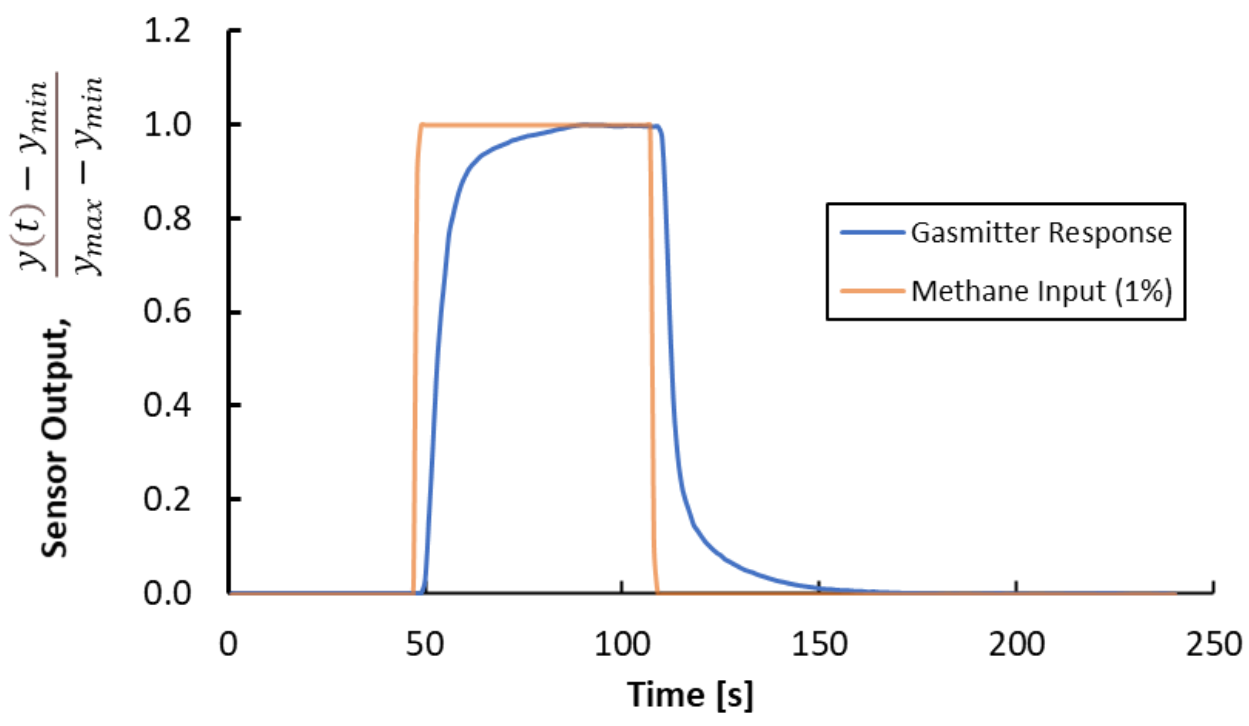

Figure 4.2-7 Gasmitter response to $1.01 \%$ methane. 
Table 4.2-1 presents the response characteristic results for the three sensors under the definitions mentioned above.

Table 4.2-1 Rise and Decay times for the MQ-4, Dynament, and Gasmitter sensors.

\begin{tabular}{|c|c|c|c|c|c|c|}
\hline \multirow[b]{2}{*}{ Sensor } & \multicolumn{3}{|c|}{ Step Input of $1.01 \% \mathrm{CH}_{4}$} & \multicolumn{3}{|c|}{ Step Input of $2.01 \% \mathrm{CH}_{4}$} \\
\hline & T90 [s] & $\mathbf{T}_{-50}[\mathrm{~s}]$ & $\mathbf{T}_{\mathrm{s}}[\mathbf{s}]$ & T90 [s] & $\mathbf{T}_{-50}[\mathrm{~s}]$ & $\mathbf{T}_{\mathrm{s}}[\mathbf{s}]$ \\
\hline MQ-4 & 6 & 12 & $>120$ & 5 & 14 & $>120$ \\
\hline Dynament & 22 & 17 & 28 & 24 & 14 & 31 \\
\hline Gasmitter & 17 & 5 & 59 & 20 & 5 & 72 \\
\hline
\end{tabular}

Two magnitudes of step inputs $\left(1.01 \%\right.$ and $\left.2.01 \% \mathrm{CH}_{4}\right)$ were evaluated for the rise and decay time analysis; both of which presented similar results. These characteristic times of the individual sensors are further validated by the following analysis, where the step input to the system is reduced and periodic to access response limitations in a transient environment.

\section{A note on the Gasmitter Sensor}

Unlike the MQ-4 and Dynament sensors, the Gasmitter is equipped with its own data acquisition software GasVision [44]. In this software, sensor calibrations are performed, and factory settings are available for modification. The factory settings consist of sensor filter adjustments which control a sample averaging method to limit the noise or sensitivity of the sensor when jumps in concentration are detected. These settings provide an additional layer of tunning by which the sensor response can be optimized for the desired application.

Provided these capabilities, factory settings were adjusted to sharpen response times. As a result, the T90 response time of the Gasmitter sensor was reduced from 17 seconds to 10 seconds. Note this response time is for the entire MWS sampling at 2 SLPM, which included the transport delay time of $\sim 4$ seconds. Therefore, the tuned settings in GasVision produced a sensor response time of around 6 seconds. The operation manual provided from Sensors Inc. reports an expected sensor response time (T90) to be within 3 to 45 seconds [31]. Table 4.2-2 presents the re-evaluated rise and decay times for the criteria presented previously for the optimized Gasmitter sensor. 
Table 4.2-2 Rise and Decay times for tunned Gasmitter sensor.

\begin{tabular}{|c|c|c|c|c|c|c|}
\hline \multirow[b]{2}{*}{ Sensor } & \multicolumn{3}{|c|}{ Step Input of $1.01 \% \mathrm{CH}_{4}$} & \multicolumn{3}{|c|}{ Step Input of $2.01 \% \mathrm{CH}_{4}$} \\
\hline & T90 [s] & $\mathbf{T}_{-50}[\mathrm{~s}]$ & $\mathbf{T}_{\mathrm{s}}[\mathrm{s}]$ & T90 [s] & $\mathbf{T}_{-50}[\mathrm{~s}]$ & $T_{s}[\mathrm{~s}]$ \\
\hline Gasmitter (optimized) & 10 & 6 & 17 & 10 & 5 & 16 \\
\hline
\end{tabular}

Though response times were significantly reduced without any additional postprocessing or reconstruction techniques, the subsequent results were consistent with the factory tunned settings. As a result of sharpening the response with the filter settings, the response became more characteristic of a second-order system. This second-order behavior created a more complex system to model and over defined the characteristic response. As a result, signal reconstruction techniques developed in the following sections are not consistent with the first-order system present with the factory settings.

\subsubsection{Controlled Burst Tests}

\section{Step Inputs (Square Wave)}

Controlled duration tests consisted of "on/off" events where methane of a fixed concentration was injected into the MWS's filter. For the initial tests, the sensor was allowed to return to its baseline output value (no methane) before a successive input was executed. Figures a), b) and, c) of 4.2-8 presents the response profiles at the various durations for the MQ-4, Dynament, and Gasmitter sensors. Table 4.2-3 presents the highest recorded output for the respective input duration and resulting error. Error was conditionally evaluated where green cells represent a percent error within $10 \%$, yellow cells represent an error between $10-20 \%$, and cells with a percent error greater than $20 \%$ are red. 

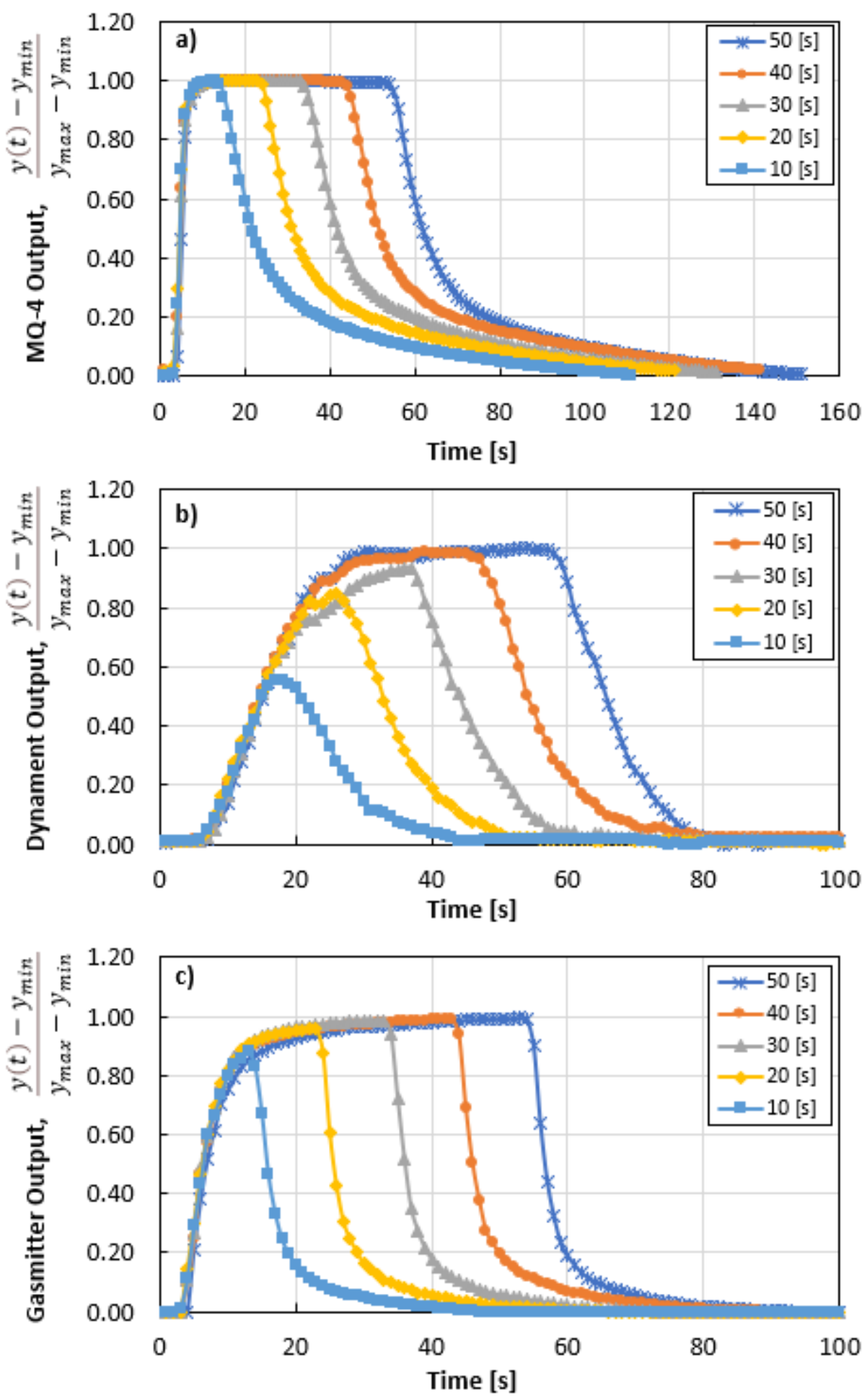

Figure 4.2-8 Evaluation to system response to step inputs of $1.01 \% \mathrm{CH}_{4}$ for durations of: 50, 40, 30, 20, and 10 seconds. a) MQ-4 Sensor, b) Dynament Sensor, c) Gasmitter Sensor 
Table 4.2-3 Collective results of the various duration tests with errors of the three sensors.

\begin{tabular}{cccc}
\hline \hline Step Input Duration & MQ-4 Response & Dynament Response & Gasmitter Response \\
\hline$[\mathbf{s}]$ & {$\left[\mathbf{y} / \mathbf{y}_{\mathbf{m a x}}\right]$} & {$\left[\mathbf{y} / \mathbf{y}_{\mathbf{m a x}}\right]$} & {$\left[\mathbf{y} / \mathbf{y}_{\mathbf{m a x}}\right]$} \\
\hline 50 & 1.00 & 1.00 & 1.00 \\
40 & 1.00 & 0.99 & 0.99 \\
30 & 1.00 & 0.93 & 0.99 \\
20 & 1.00 & 0.85 & 0.96 \\
10 & 1.00 & 0.56 & 0.89 \\
\hline \hline
\end{tabular}

The thresholds of the sensors ability to detect and report a step input of methane with $10 \%$ error were evaluated from the studies above. The MQ-4 possessed a very fast rise time of 5 seconds, making it the only sensor to reach a FR for all five input durations. However, its complicated calibration and inability to rapidly decay made the MQ-4 an unfavorable candidate. The Dynament had the slowest rise time of approximately 22 seconds. The low response performance resulted in a failure to accurately detect an input of $1.01 \% \mathrm{CH}_{4}$ for any duration less than 30 seconds. The Dynament also performed poorly at lower concentrations of methane $(<0.2 \%)$, due to a high lower detection limit. This can be seen in the non-linearity present at the lower part of the calibration curve presented above in Figure 4.2-3. The Gasmitter sensor displayed the all-around best performance. With a respectable rise time of 17 seconds (10 seconds if tuned) and superior ability to decay within $50 \%$ of the FR in 5 seconds, the Gasmitter was selected to further evaluate in a dynamic environment.

\section{Successive Bursts (Periodic Input) - Dynamic Responses}

Periodic burst tests consisted of successive step inputs of $1 \% \mathrm{CH}_{4}$. Input bursts were of fixed and equal duration of time spent "on" and "off". For example, a test where methane was released for 20 seconds would wait 20 seconds before releasing another event. Laboratory air containing no methane was sampled in between events. These tests differ from the previous set of experiments because the sensor was not allowed to return to its baseline output before a successive event was released. Figure 4.2-9 presents the response of the Gasmitter sensor where the duration of the successive burst is reduced from 40 to 5 seconds. 

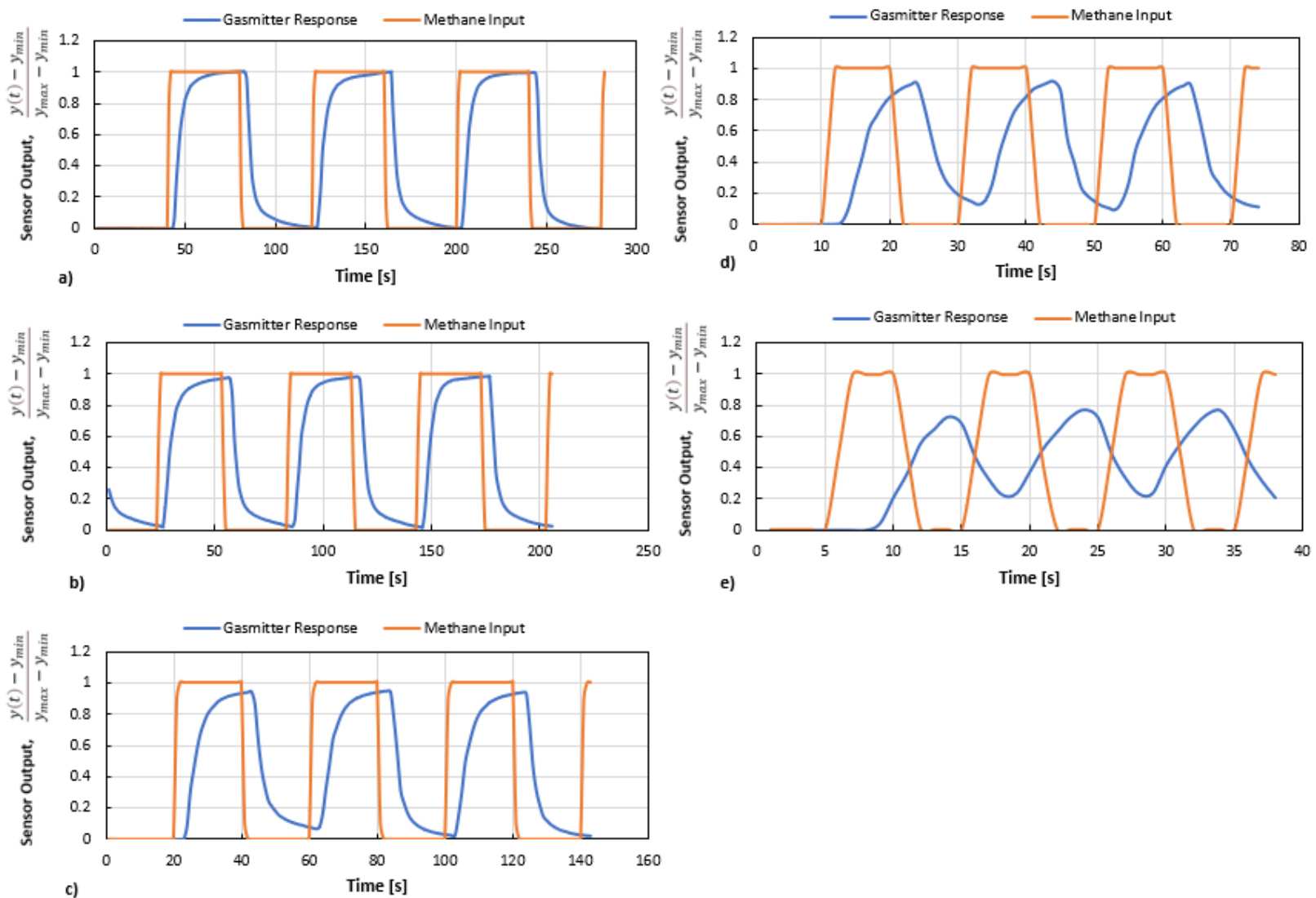

Figure 4.2-9 Dynamic response of Gasmitter sensor to periodic step inputs at durations (frequencies) of: a) 40, b) 30, c) 20, d) 10, and e) 5 seconds

The results from the periodic inputs were then compiled to form a trend that was associated with the frequency. Figure 4.2-10 presents the projected error or expected response of the Gasmitter sensor to a periodic input of any duration. The periodicity of the input function mimicked the transient nature of the expected methane profiles within the longwall mine. From here, the sensors ability to rise to an input and return is challenged, which resulted in a diffused output of the MWS system. In reality, methane may diffuse quickly in the longwall section and present a more continuous function. Therefore, ramp inputs and simulated data were also created to further understand the expected performance of the MWS in the longwall domain. 


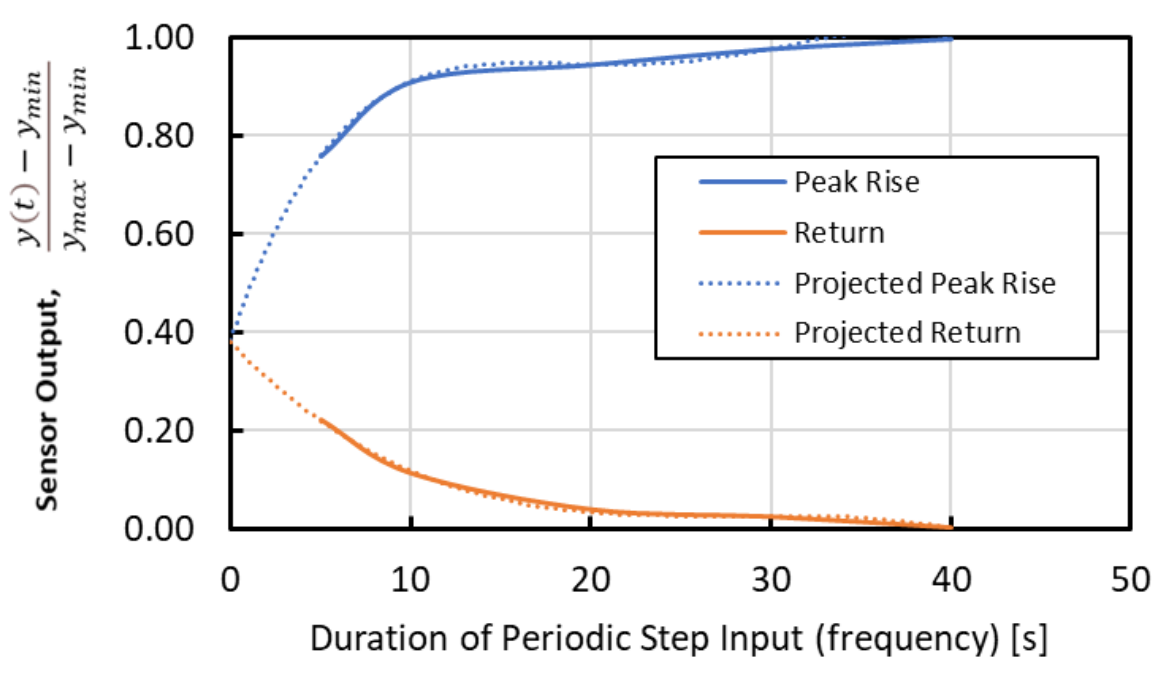

Figure 4.2-10 Projected Gasmitter dynamic response characteristics to periodic step inputs of $1 \% \mathrm{CH}_{4}$. Equivalent to the amplitude ratio and dynamic error.

\section{Ramp Inputs}

A ramp input was then introduced to the MWS for further evaluation of the response characteristics. The ramp input provided an additional method for measuring the systems response time, which was previously found to be around 17 seconds with the Gasmitter sensor. Figure 4.211 presents the criteria used for evaluating the systems response to the ramp input. Equation 4.2.3 was used to calculate the system response time from the two resulting functions, where error is the deviation to the true value at a given instance and the slope is the ramp rate.

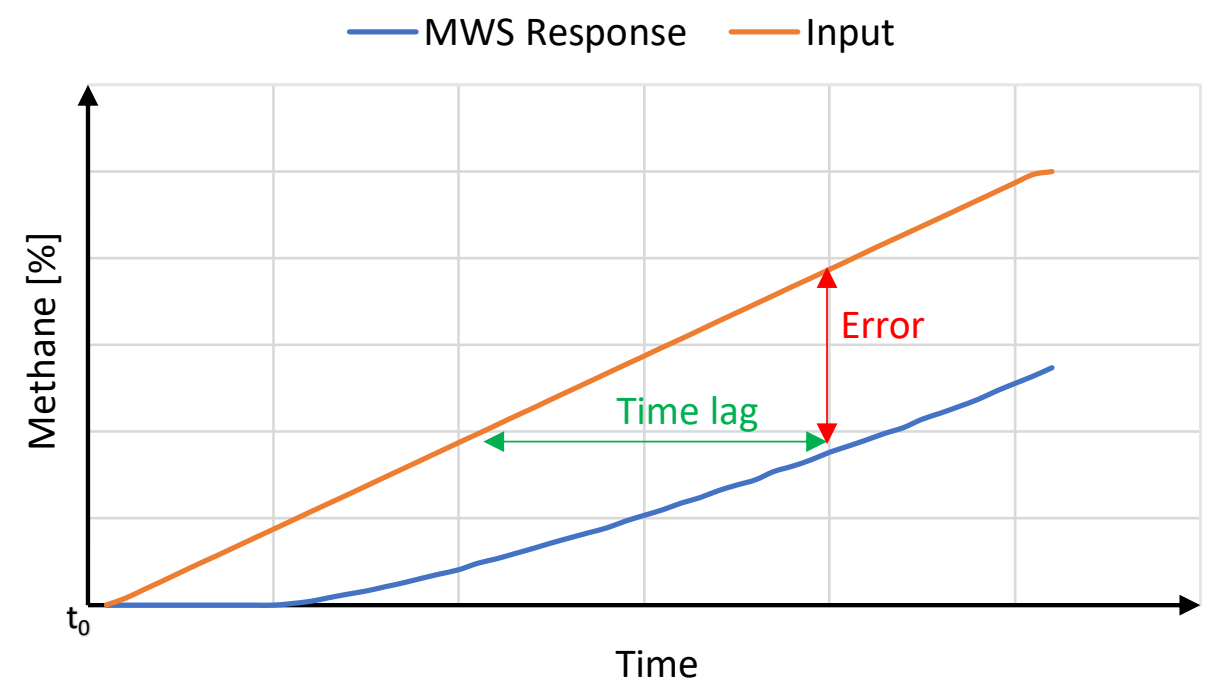

Figure 4.2-11 Definitions used to evaluate ramp input results. 


$$
\text { Response Time }=\frac{\text { error }}{\text { slope }}
$$

Unlike the sudden change in concentration provided by the step input tests, the ramp input created two unique linear response characteristics. The determined response time was a function of both the real time error and the shift in signal as a result of transport and sensor response delay. Figure 4.2-12 presents the resulting response to the ramp input. The input and output data were reduced to include only the range of data were the two curves were near parallel.

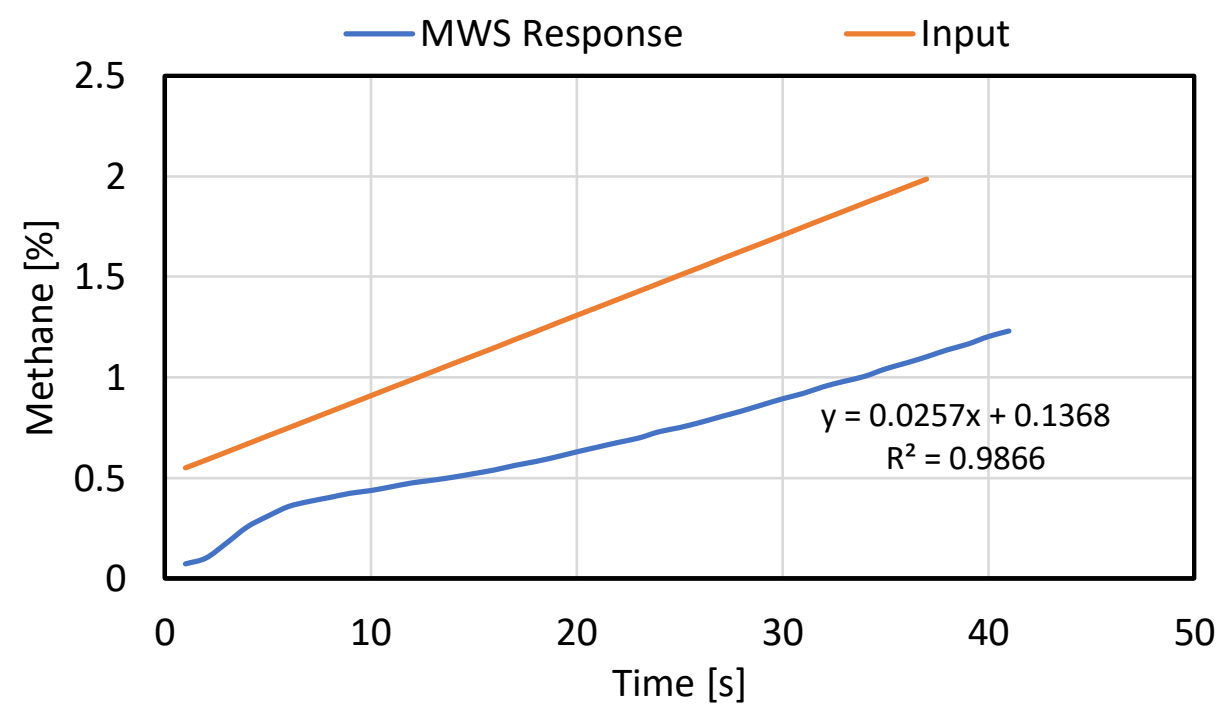

Figure 4.2-12 MWS Response to the ramp input.

A response time was found to be 16.5 seconds from the ramp input test, which validated the 17 seconds determined from the step input test. Due to limitations in sensing range and flow control in the laboratory, the MWS output data that made up the slope was averaged. With a ramp rate of 0.04 (\% $\mathrm{CH}_{4}$ per second), the resolution was quite low and would need to be lower to achieve a longer set of data before the maximum concentration is reached.

\subsection{1-D Model Results}

A 1-D model was created using the first-order upwind method and may be found in Appendix C. The model was taken from the Study of Explicit Numerical Differencing Schemes and expanded to define the spatial domain of the longwall coal mine. Tables 4.3-1 and 4.3-2 presents the models parameters and boundary conditions. Boundary conditions were varied to represent certain scenarios for the various studies within the modeled domain. 


\begin{tabular}{ll}
\hline \hline Parameter & Quantity \\
\hline Longwall Face Length & $300 \mathrm{~m}(984 \mathrm{ft})$ \\
Longwall Width & $5 \mathrm{~m}(16.4 \mathrm{ft})$ \\
Longwall Height & $2.5 \mathrm{~m}(8.2 \mathrm{ft})$ \\
Avg. Ventilation Rate & $2 \mathrm{~m} / \mathrm{s}(394 \mathrm{fpm})$ \\
Avg. Shearer Rate & $0.08 \mathrm{~m} / \mathrm{s}(16 \mathrm{fpm})$ \\
Depth of Cut & $1.02 \mathrm{~m}(40 \mathrm{in})$ \\
Ventilation Loss Term** & $0.0067 \mathrm{~kg} \mathrm{Ch} 4$ per meter \\
\hline Space Discretization Step & $0.8 \mathrm{~m}$ \\
Time Discretization Step & $0.3 \mathrm{~s}$ \\
\hline **Mimics loss or diminished flow rates by increasing CBM towards the TG. \\
\hline
\end{tabular}

Table 4.3-2 Average regional methane content of coal.

\begin{tabular}{ccc}
\hline \hline Region/State in the U.S. & Methane Content of Coal & Classification \\
\hline Pennsylvania & $3.59 \mathrm{~m}^{3} /$ ton & HV-A \\
West Virginia & $4.90 \mathrm{~m}^{3} / \mathrm{ton}$ & $\mathrm{HV}-\mathrm{A}$ \\
Western (CO, NM, OK) & $3.88 \mathrm{~m}^{3} /$ ton & HV-A \\
\hline \hline
\end{tabular}

\subsubsection{Baseline Emission Profile}

Figure 4.3-1 represents the baseline emission profile that is a result of the naturally desorbed methane only. Note the range of the y-axis is from 0 to $2 \% \mathrm{CH}_{4}$ so that a comparison can be made in subsequent graphs as methane is added from production activities. The baseline methane emissions are what would be expected prior to production and remain relatively constant with time. A maximum concentration of $0.05 \% \mathrm{CH}_{4}$ was resulted at the TG. 


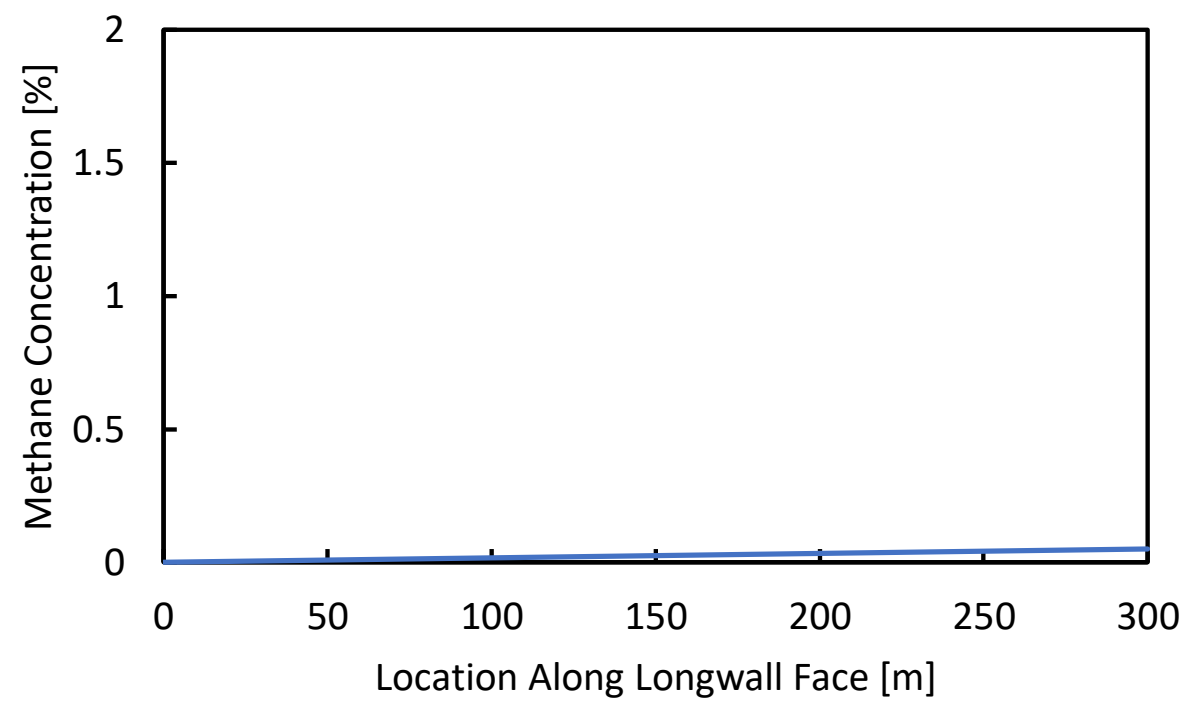

Figure 4.3-1 Linear Baseline Emission Profile.

A constant shearer rate of $0.08 \mathrm{~m} / \mathrm{s}$ was then applied as well as the ventilation rate fixed to $2 \mathrm{~m} / \mathrm{s}$ with a loss coefficient of $0.0067 \% \mathrm{~kg} \mathrm{Ch}_{4}$ per meter. Figure 4.3-2 presents a snapshot of the resulting profile. The shearer rate defined the production rate (tons/s) which was then used to calculate the amount of methane released.

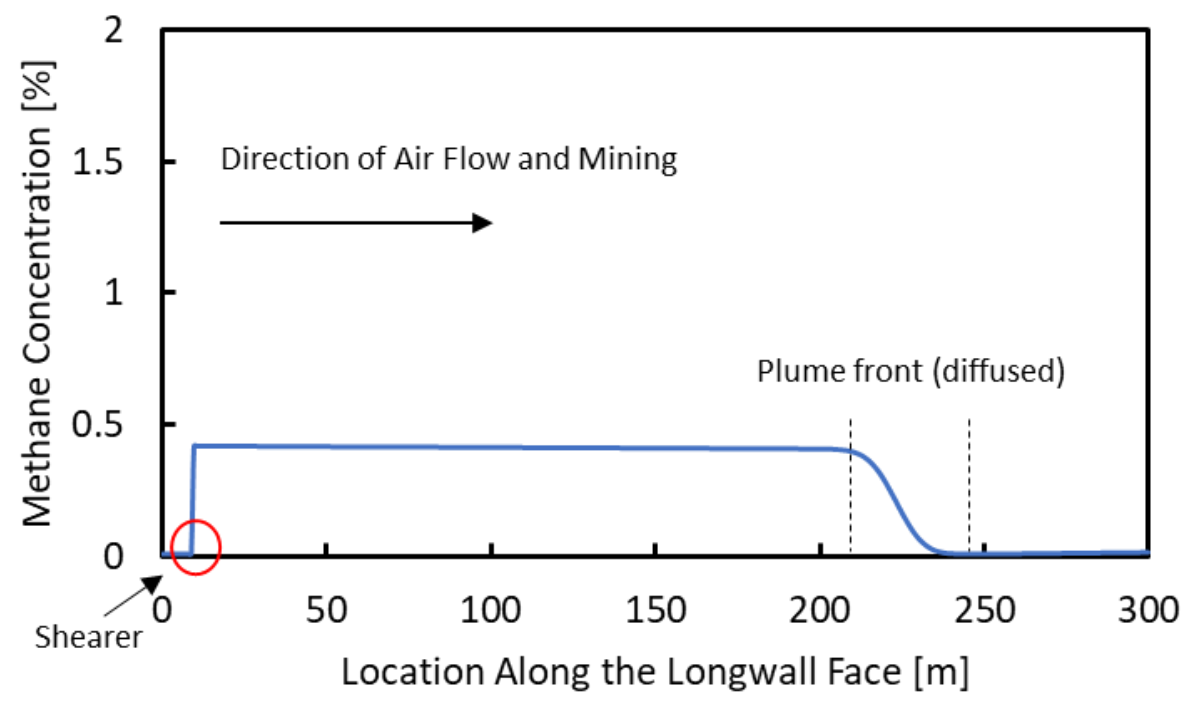

Figure 4.3-2 Constant shearer rate and constant ventilation rate profile.

From Figure 4.3-2, it may be seen that the resulting profile reaches a near steady state. Since the shearer is a moving point source, the rate of production (which is constant here) will equate to some concentration as it is diluted with the constantly supplied fresh air. The resulting 
concentration is a function of the volumetric domain and the rate of fresh dilution air. Diffusion and mixing are assumed to be rapid in this scenario, however the false diffusion of the upwind differencing scheme mimics the expected physical effects to some degree.

\subsubsection{Sensitivity of Boundary Conditions (Transient Cases)}

Shearer rate and ventilation were then altered to achieve transient scenarios. The results of these simulations more accurately represent the expected emissions profiles that would be a result of a production environment.

\section{Ventilation Rate}

Due to the lack of immediate control of ventilation air supplied to the longwall face, rates are expected to fluctuate as mining progresses. To simulate this, ventilation data were created to include fluctuation of airflow within the minimal and maximal rates consistent with previous studies. In addition, the ventilation loss coefficient increases the methane content of coal $\left(\mathrm{kg} \mathrm{CH}_{4}\right.$ per meter of coal mined) along the length of the longwall to simulate flow lost to the porous gob region. Figure 4.3-3 presents the transient model, where ventilation rates varied with time while the shearer rate remained constant.

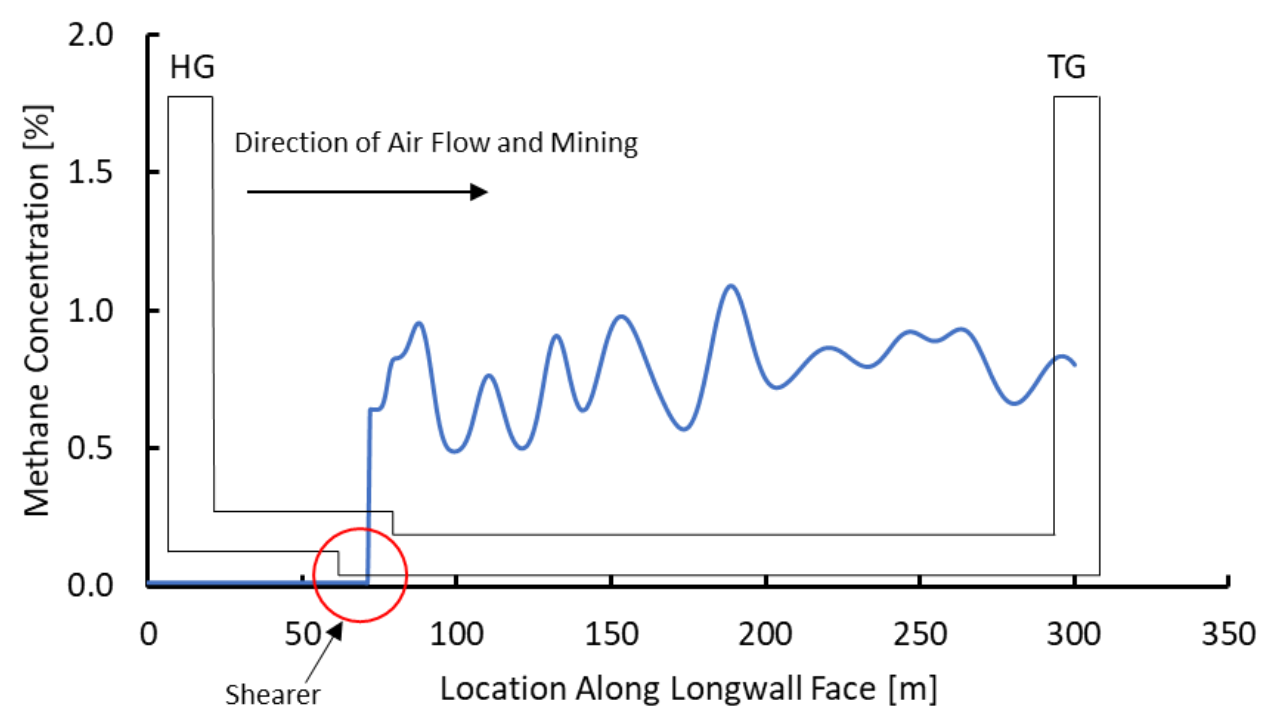

Figure 4.3-3 Resulting methane profile from fluctuations in ventilation rate while shearer rate remained constant at $0.08 \mathrm{~m} / \mathrm{s}$.

Numerical results were extracted from the proposed sampling locations of the 10 MWS units. These results represent the expected true methane concentrations that would be transported by the sampling unit in the mine from a single pass of the shearer. Figure 4.3-4 presents the recorded 
methane emission profile at Node 5 of the MWS; this is near the halfway point of the entire longwall face.

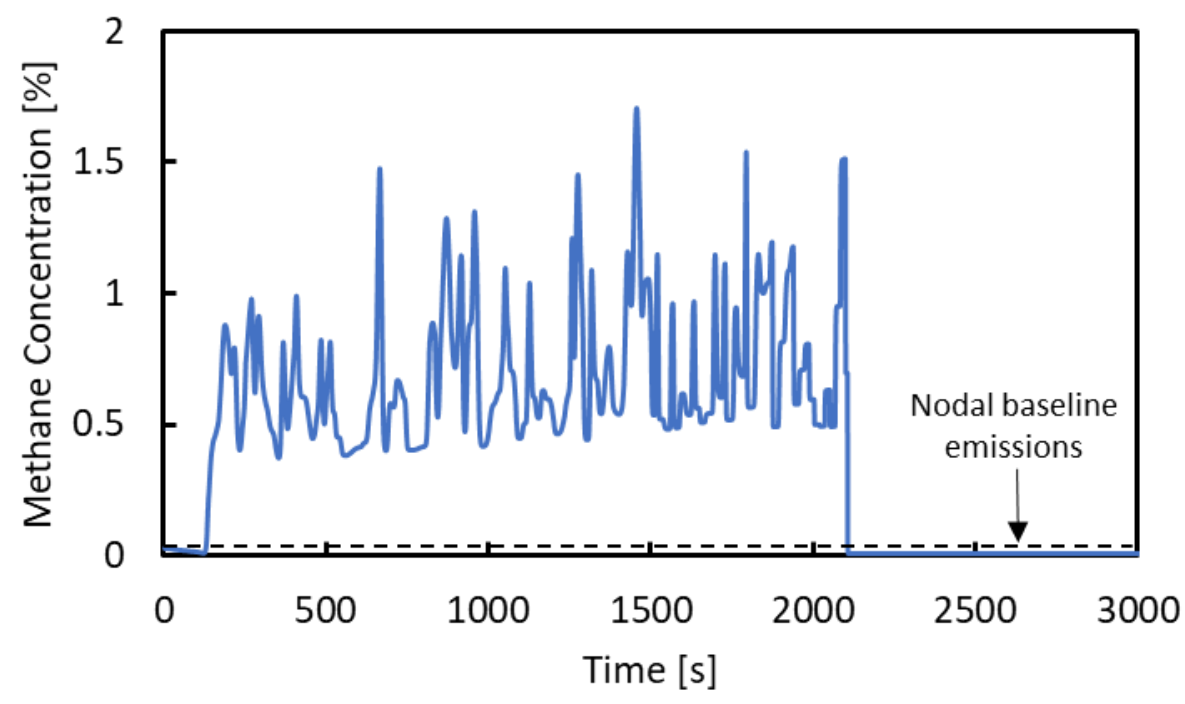

Figure 4.3-4 Nodal concentration profile of Node 5 from a single pass simulation.

The first 100 seconds, where no activity is present, represents the beginning of methane release that is occurring at the HG. Therefore, it has not yet been swept down to Node 5. Concentrations diminish shortly after 2000 seconds marking the time where the shearer has traveled past the node and fresh air has once again became available. Emissions measured at this node are temporally characteristic to what occurred upstream. With MWS nodes evenly spaced along the entire longwall face, each node will have the ability to monitor and evaluate these temporal trends as they evolve spatially.

\subsubsection{Evaluation of System Performance Through Simulation Data}

Nodal data sets extracted from the 1-D simulation represent temporal methane concentrations expected to occur at the respective MWS nodes deployed in a working mine. As such, these data sets were used to evaluate the performance of an MWS unit in the laboratory. The dynamics of the resulting methane profiles are characteristic to the fluctuations of fresh ventilated air supplied to the entry of the model. Therefore, the results due to the frequency of change in rate of the ventilation air were evaluated on the time scale of 6 to 21 seconds in increments of 3 seconds. Table 4.3-3 presents the scenarios that contains the evacuation points and boundary definitions. 
Nodal data were reduced to a 200 seconds data set that was used in the evaluation of the MWS performance.

Table 4.3-3 List of evaluation points and the resulting minimal and maximal methane concentrations recorded at Node 5.

\begin{tabular}{cccc}
\hline \hline Ventilation Data & Shearer Rate & \multicolumn{2}{c}{ MWS Node 5 Data } \\
\hline Time Scale of Change & Constant & Min Conc. & Max Conc. \\
\hline [Time steps (seconds)] & {$[\mathbf{m} / \mathbf{s}]$} & {$\left[\% \mathbf{C H}_{\mathbf{4}}\right]$} & {$\left[\% \mathbf{C H}_{\mathbf{4}}\right]$} \\
\hline $20(6)$ & 0.08 & 0.36 & 0.88 \\
$30(9)$ & 0.08 & 0.35 & 0.77 \\
$40(12)$ & 0.08 & 0.34 & 1.20 \\
$50(15)$ & 0.08 & 0.36 & 0.89 \\
$60(18)$ & 0.08 & 0.34 & 1.10 \\
$70(21)$ & 0.08 & 0.35 & 1.10 \\
\hline Note: Methane concentrations are from the reduced nodal data for performance evaluation (200 s). \\
Node 5 baseline emissions were $0.1 \% \mathrm{CH}_{4}$
\end{tabular}

The reduced data sets were loaded into Scimitar as volumetric flow rates for the MFC. This conversion is explained in the relevant section of the Methodology. The plots of Figure 4.3-5 present the simulated methane profiles and the MWS's response to the input data. 

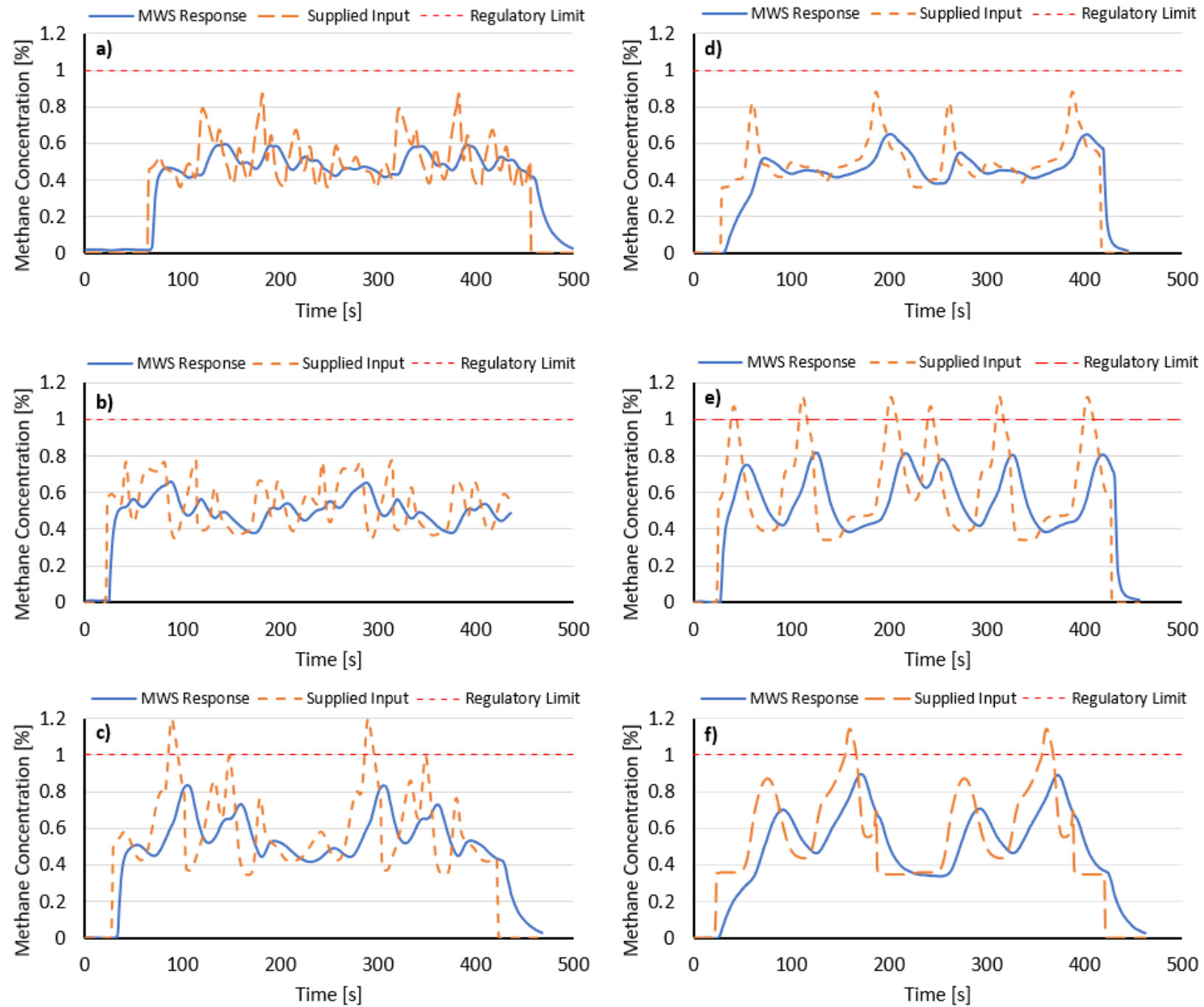

Figure 4.3-5 Laboratory evaluation of MWS performance using 'Node 5' simulation data. Fluctuation in ventilation rates at increments of: a) 6, b) 9, c) 12, d) 15, e) 18, and f) 21 seconds. The results from the simulation data were collected to evaluate two things: the MWS's expected performance to a scenario in the longwall environment, and the effects of downwind methane profiles as a result of fluctuation in fresh air supply at the longwall face. From Figure 4.3-5a), frequent disturbances were apparent from the supplied input due to the small-time scale of change imposed. The MWS's response is dampened and fails to capture all characteristics of the input signal, resulting in a $32 \%$ error reporting the highest peak in concentration and an average real time error of $18 \%$.

Figure 4.3-5c) presents the first case where the simulated data contained two events where methane concentrations quickly spike above the regulatory limit of $1 \% \mathrm{CH}_{4}$. The MWS failed to report the regulatory value of $1.2 \% \mathrm{CH}_{4}$ by $30 \%$. Again, the MWS output was diffused and shifted from the 
input signal, however all characteristic peaks of the input were retained. As the time scale fluctuation in air is increased, the opportunity for larger deviation in methane concentrations also increased. Figure 4.3-5e) displays a scenario where the resulting methane profile becomes quite sinusoidal, where plumes range from 0.34 and $1.1 \% \mathrm{CH}_{4}$ successively.

The final Figure 4.3-5f) presents the longest time scale evaluated, where ventilation data values were varied every 21 seconds. The MWS's performance resulted in an average real time error of $28 \%$ and a $22 \%$ error to report the highest peak of $1.1 \% \mathrm{CH}_{4}$. Though the resulting error is quite significant for all cases $(>10 \%)$, the MWS was able to capture most features of the characteristic profiles input to the system. As such, the opportunity to develop and employ advanced signal sharpening techniques is quite good. At this point in development, no full-scale field data were collected or present. Therefore, it is unknown to the certainty of expected spatial and temporal methane profiles.

\subsubsection{Production Analysis}

Various shearer rates were assessed with the 1-D model in attempt to reduce downtimes associated with increased levels of methane. Table 4.3-4 presents the highest methane concentration recorded at the various shearer rates for a single pass of mining. For these results, the ventilation rate remained constant at $2 \mathrm{~m} / \mathrm{s}$ with the addition of the loss coefficient across the length of the face.

Table 4.3-4 Various production rates and reported max concentration at TG for a single pass.

\begin{tabular}{ccc}
\hline \hline Constant Shearer Rate & Methane \% at TG & Single Pass Time \\
\hline$[\mathbf{m} / \mathbf{s}]$ & {$[\%]$} & {$[\mathbf{m i n}]$} \\
\hline 0.04 & 0.613 & 125 \\
0.06 & 0.918 & 83 \\
0.08 & 1.22 & 63 \\
0.10 & 1.53 & 50 \\
0.12 & 1.83 & 42 \\
\hline
\end{tabular}

Note: Shaded row is average production rate found from literature. Single pass length $=300 \mathrm{~m}$.

In reality, the majority of time lost during production is due to the starting and stopping from a methane related shutdown $[8,9]$. It may be difficult to predict an ideal production rate under the assumption that everything is constant, and ventilation is always adequately maintained. Therefore, a production analysis was conducted with a state flow model designed in Simulink. The state flow model takes in the nodal methane concentrations generated from the 1-D simulation and 
determines how much time was spent operating above the allowed threshold $\left(1 \% \mathrm{CH}_{4}\right)$. Figure 4.3-5 presents the state flow diagram created in Simulink. Table 4.3-5 then presents the results that were obtained from three general areas of the longwall face: the HG, midway, and the TG. Nodes 1, 5, and 10 of the MWS represent the three general areas of interest and provided the input data for the analysis. The Uninterrupted Time represents the time it takes for the shearer to make a full pass if there were no interruptions.

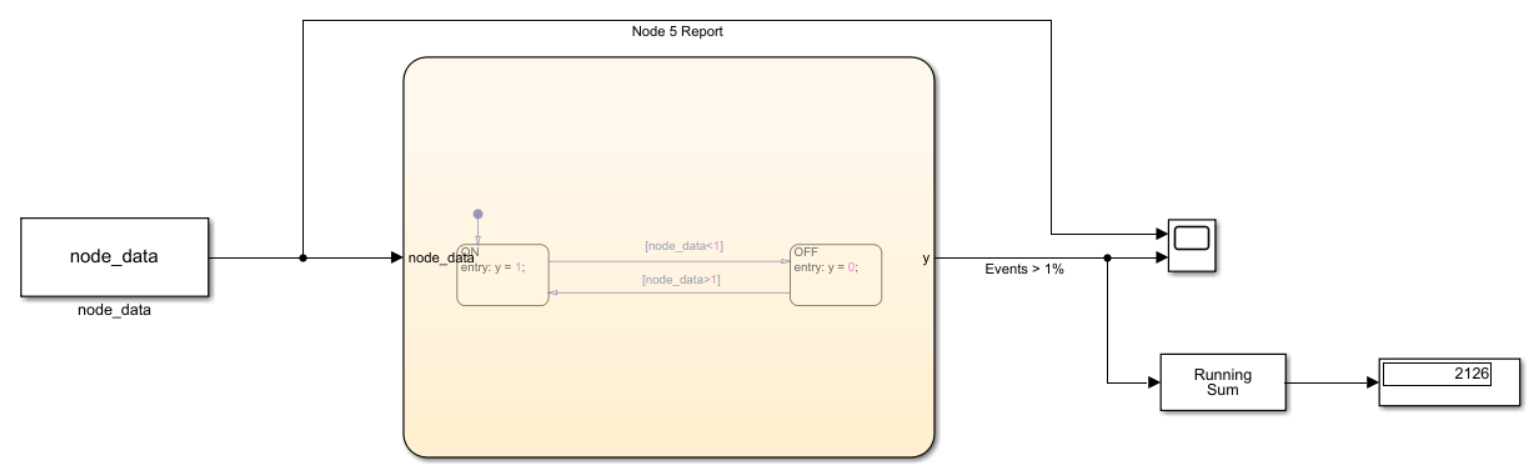

Figure 4.3-5 State flow diagram used in Simulink to complete production analysis.

Table 4.3-5 Production analysis with transient ventilation rates.

\begin{tabular}{ccccc}
\hline \hline $\begin{array}{c}\text { Production } \\
\text { Rate }\end{array}$ & $\begin{array}{c}\text { Uninterrupted } \\
\text { Time }\end{array}$ & \multicolumn{3}{c}{ Time spent above 1\% $\mathbf{C H}_{\mathbf{4}}$ [\% pass time] } \\
\hline$[\mathbf{m} / \mathbf{s}]$ & [min/pass] & Node 1 & Node 5 & Node 10 \\
\hline 0.04 & 125 & $<1$ & 1.1 & 5.5 \\
0.06 & 83 & $<1$ & 3.7 & 24 \\
0.08 & 63 & 1.2 & 12 & 50 \\
0.10 & 50 & 3.0 & 20 & 69 \\
0.12 & 42 & 3.8 & 32 & 84 \\
\hline
\end{tabular}

Note: Shaded row is average production rate found from literature. Single pass length $=300 \mathrm{~m}$.

Ventilation rate varied from $0.5-2.5 \mathrm{~m} / \mathrm{s}$

Location of Nodes 1, 5, and 10 with respect to HG: 30,150 , and $300 \mathrm{~m}$

Given the uncertainty of temporal ventilation patterns, it is difficult to justify if such an ideal production rate exists from this analysis. Rather a general study was conducted to construct an impact assessment on methane emissions from a production rate and selected ventilation data. The magnitude of time spent above the threshold $\left(1 \% \mathrm{CH}_{4}\right)$ provides a measure of how frequent production delays may be expected, given a constant production rate. 


\subsection{Developing the Reconstruction Technique}

Results collected from the 1-D models and system characterization were then used to build upon the usefulness and accuracy of the MWS through a simple signal reconstruction technique. Controlled step and ramp inputs including generated methane cycles provided useful information when characterizing the systems response to an input. Furthermore, it provided the information needed to construct a first order transfer function that described the expected behavior of the system in the presence of methane.

\subsubsection{Previous Relevant Studies}

Previous work had addressed the common issue that concerns the dampened and delayed output from analyzer measurements. Clark and Madireddy discussed two methods for reconstructing transient automotive emission measurements collected from a dilution tunnel within the laboratory setting $[45,46]$. Similarly, the collected data was delayed and diffused due to the transport of sample and the analyzers response. The Sequential Inversion Technique (SIT) and Differential Coefficients Method (DCM) [47] were compared against a "fast responding" analyzer [48]. Reconstructed data were then shifted back, or time aligned to match the peaks of the input data, since the reconstruction does not correct the delayed time due to the physical transport of the sample. More broadly, dynamic system responses have been well studied among controls and dynamical system modeling fields [49]. Sensor response characteristics can be constructed from simple step and ramp functions applied to the system of interest. The step and ramp input definitions are consistent with the studies conducted previously here to characterize the Gasmitter and MWS response. More complex structures of a sensor's response exist among second or multi-

order responses where overshoot and stabilization periods are present. The response from the MWS was characteristic of a first-order system however, where little to no overshoot or settling period was recognized. A second-order reconstruction was attempted but provided little addition advantage. Instead an averaging technique was employed.

\subsubsection{Defining the First-Order System}

Consider the first order ODE to be of the form

$$
\tau \frac{d y}{d t}+y=K x
$$


where $x$ is the measured input and $y$ is the systems output. $K$ is the static sensitivity and Tau $(\tau)$ is the first-order time constant. The time constant $\tau$ is equivalent to the horizontal component of the characteristic ramp input study and was found to be 16.5 seconds. This component being the Time lag which resulted from the MWS's inability to instantaneously respond to the input.

Equation 4.4.1 was then employed to measure the effectiveness and ability to reconstruct the diffused and delayed output data collected from the Evaluation of System Performance through Simulation Data studies. These effects were shown above in Figure 4.3-5. The derivative was computed from the backward difference of the $1 \mathrm{~Hz}$ data and $y$ consisted of the current uncorrected output value. The reconstructed output can be represented more generally as

$$
U(t)=y(t)+\frac{d y}{d t} C_{1}
$$

where $U(t)$ is the reconstructed output value and $C_{1}$ is the time constant obtained from the ramp response.

\subsubsection{Reconstructing the MWS Data}

At first, Equation 4.4.2 was used to reconstruct the original MWS data collected from the multicase simulation studies. A time constant $\left(C_{1}\right)$ obtained from the ramp input study of 16.5 was used. An error analyses was conducted with the reconstructed data time aligned to the peaks of the true input data. Therefore, the error was defined as the ability of the system to measure the correct magnitude of an event, though it may occur seconds later. The component of delay attributed to only the physical transport of the sample through the system was found to be around 4 seconds. If measurement error can be significantly reduced, then a 4-5 second delay time may be an acceptable tradeoff. Figure 4.4-1a) presents the reconstructed output of the MWS in comparison to the true input signal. The original diffused output signal is also included for reference. Figure 4.4-1b) then presents the time aligned signals which were used to measure the error or correctability of the firstorder ODE method. 

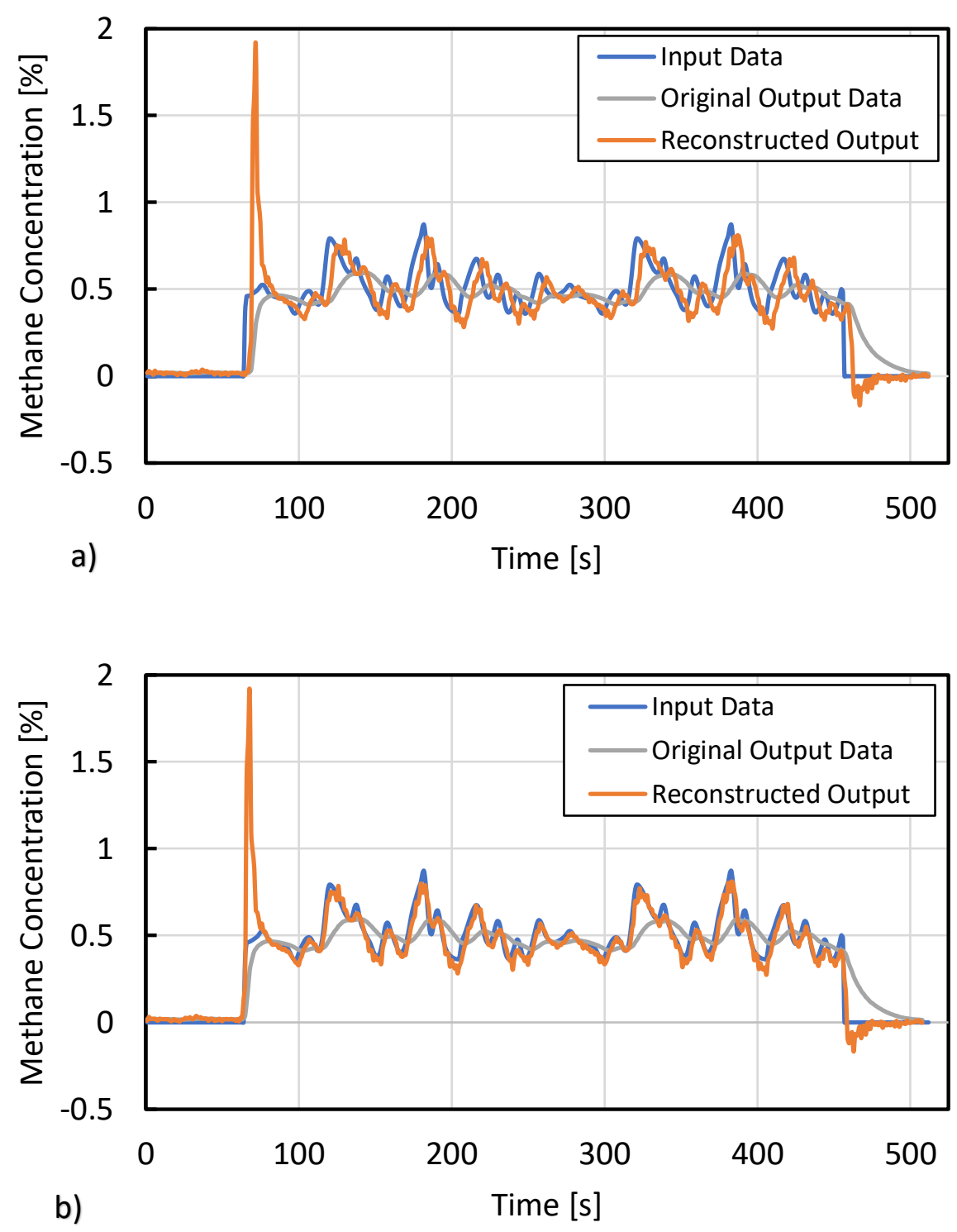

Figures 4.4-1 First-order reconstructed output of MWS with time constant of 16.5. a) Real-time delayed signal. b) Time aligned to input data.

Though the simple first-order method appears to have improved the diffused output signal, a large spike overshooting the initial input of methane is present. It is also noticed that a similar phenomenon occurs at the end of the test by the overshot noise when returning to zero. This phenomenon is consistent with the Gibbs phenomena commonly encountered in Fourier series of square wave reconstruction [50]. The discontinuity of the function presents noise as the immediate jump is not constructable by the first order ODE and time constant. In other words, the slope of the sensor's response becomes very steep momentarily and is not characteristic to the time constant 
obtained (16.5). This issue is also what causes the overshoot at the valleys of the signal. Discussed earlier, the Gasmitter embodies a very quick decay when a methane concentration is removed. This quick decay results in a characteristic response that is not consistent with the rise response, which forms the basis of the reconstruction technique.

With these characteristics now understood, an additional attempt was made to better fit the reconstructed data to the true input data through a conditional program. The program provided the control needed to alter the time constant when the derivative switched from being positive (rise response) to negative (decay response). In addition, a condition was used that eliminated the correctional time constant all together when a slope exceeded a threshold of $0.07 \% \mathrm{CH}_{4}$ per second. This would be the result of an immediate step input of methane seen at the beginning and end of the test presented above. Figure 4.4-2 presents the results of the program-controlled reconstruction technique. Again Figure 4.4-3 then presents the time aligned data as well as a parity plot showing the improved correlation. Each reconstructed datum was also averaged to its previously measured value in attempts to further smooth out noise at the peaks.

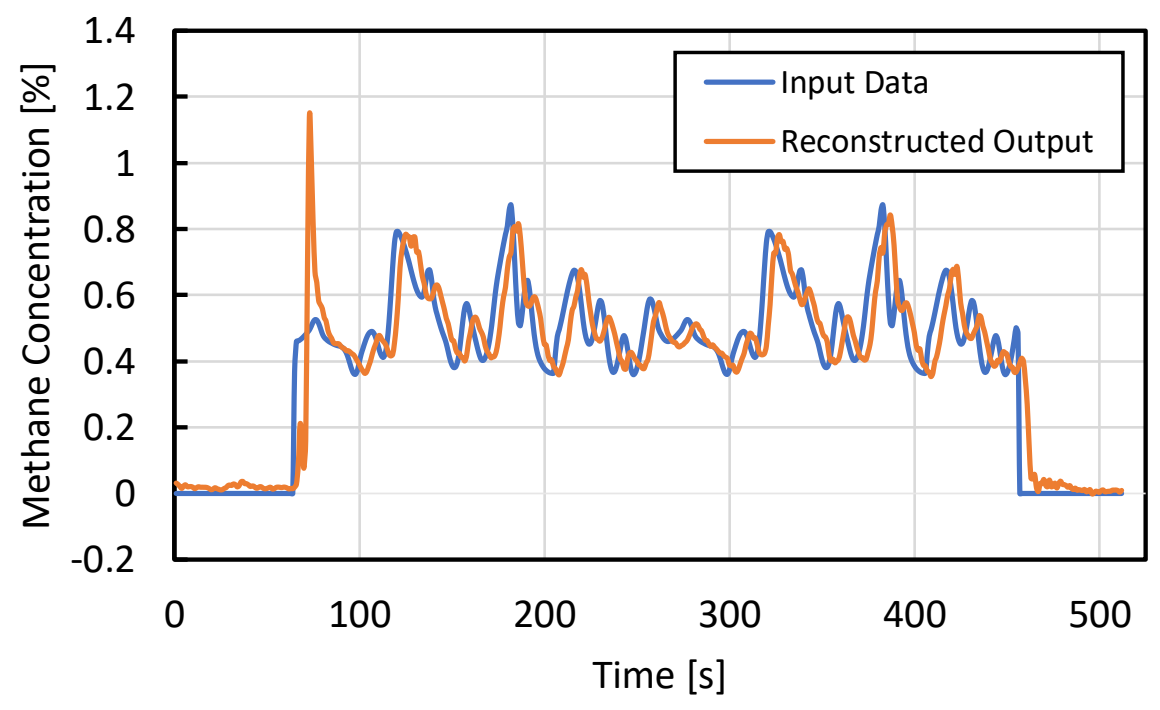

Figure 4.4-2 Program controlled reconstruction technique utilizing a rise constant of 20, decay constant of 12 , and a cancelation threshold of $0.07 \mathrm{CH}_{4} / \mathrm{s}$. 

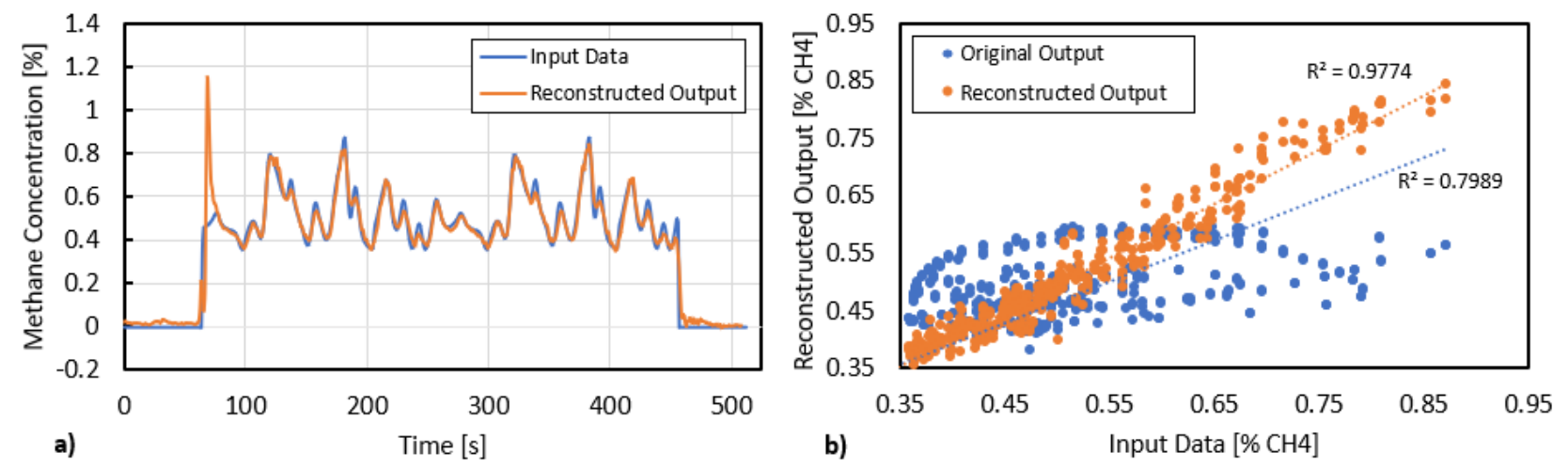

Figure 4.4-3 Time aligned reconstructed MWS output from program-controlled method. a) continuous data. b) Parity plot showing improved correlation.

By implementing a conditional program (Appendix D), the time constants were tuned to characterize the rise response and the decay response. The original time constant of 16.5 was increased to 20 to improve the peak responses and a new decay constant of 12 was defined to correct the low or valley concentrations. The discontinuity error was not eliminated at the start of the test; however, it was reduced by nearly $50 \%$. The averaging of two time-steps also noticeably reduced the noise without sacrificing any correctional benefits. Table 4.4-1 presents the results obtained when the reconstruction method is applied to all six simulation cases previously studied. The table contains the average original errors, after time alignment, and the new reduced errors achieved from the reconstruction method. The average error was taken over all continuous relative data in the simulation, omitting the discontinuity error at the beginning.

Table 4.4-1 Error analyses showing improved accuracy with the reconstructed technique.

\begin{tabular}{cccc}
\hline $\begin{array}{c}\text { Case } \\
{[\#]}\end{array}$ & $\begin{array}{c}\text { Original Output } \\
\text { [Error] }\end{array}$ & $\begin{array}{c}\text { Reconstructed } \\
\text { [Error] }\end{array}$ & $\begin{array}{c}\text { Improved Accuracy } \\
{[\%]}\end{array}$ \\
\hline 1 & $15 \%$ & $4.1 \%$ & $73 \%$ \\
2 & $18 \%$ & $4.4 \%$ & $76 \%$ \\
3 & $22 \%$ & $4.9 \%$ & $78 \%$ \\
4 & $12 \%$ & $3.4 \%$ & $72 \%$ \\
5 & $26 \%$ & $3.5 \%$ & $87 \%$ \\
6 & $23 \%$ & $3.6 \%$ & $84 \%$ \\
\hline Average & $19 \%$ & $4.0 \%$ & $78 \%$ \\
\hline \hline
\end{tabular}

The program-controlled reconstruction method worked on all six cases and improved measurement accuracy by $78 \%$ on average. Note that this is after time alignment. A 4-5 second delay due to 
sample transport and calculation will still be expected in real time measurements. As such, Case5 provides an example where fluctuations are less frequent but possess a larger deviation in concentration. In this case, six instances occurred where methane concentrations spiked just above the $1 \% \mathrm{CH}_{4}$ threshold (refer to Figure 4.3-5e). The MWS failed to record a single instance where methane concentrations went above the regulatory $1 \%$ limit. The highest concentration observed was $\sim 0.8 \% \mathrm{CH}_{4}$. Figure 4.4-4 now presents the reconstructed signal for Case-5, where all six instances that methane rose above the limit were recognized.

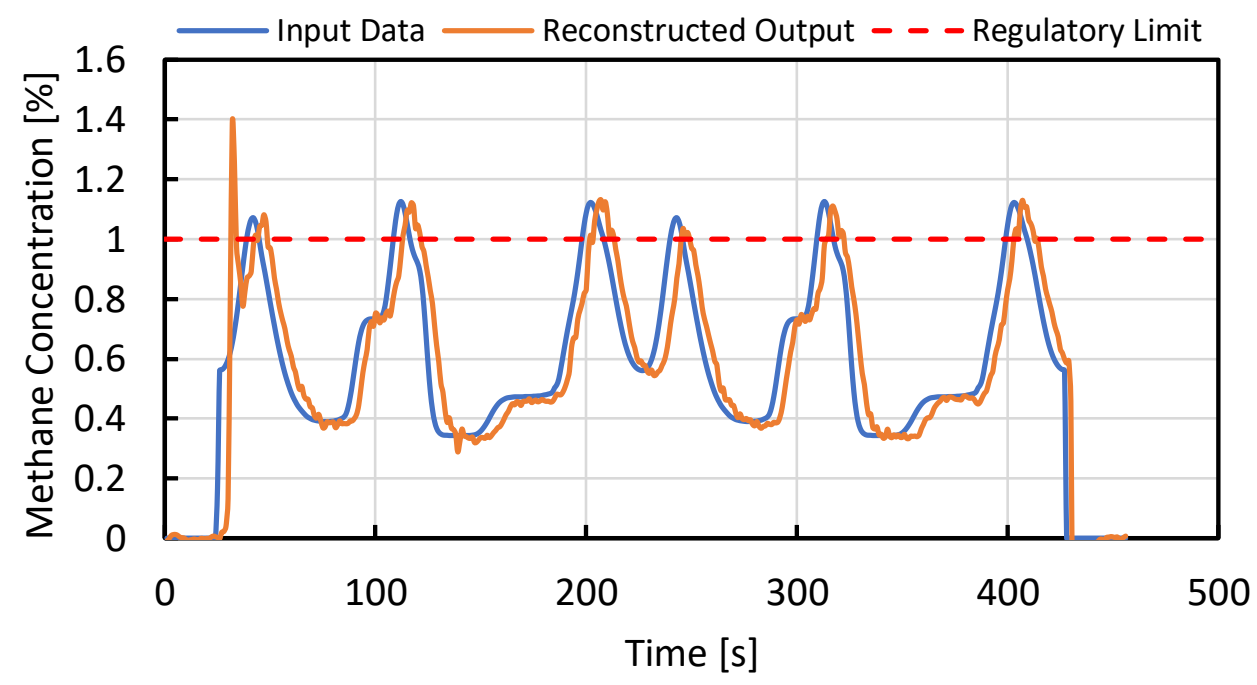

Figure 4.4-4 Reconstructed output capturing all six events where methane spikes above $1 \% \mathrm{CH}_{4}$.

\subsection{2-D Model Results}

A CFD model was constructed to more accurately define the effective flow domain of a typical longwall mining site. The aim of the CFD studies was to evaluate timescales of methane formation that were characteristic of the flow geometry, whereas the 1-D model was used to create methane profiles for the evaluation of the MWS's performance. Flow restrictions that the shearer impose were not a function of the 1-D studies, therefore the CFD model was used to couple these features with the MWS sampling locations to evaluate the dynamics of methane formation.

Three static geometries were assessed in the 2-D domain that consisted of a shearer actively cutting coal near the HG, midway, and TG of the longwall face. The boundary conditions for all three CFD models were consistent. Therefore, the resulting downwind methane profiles are only a direct result of the current mining operation configuration that was defined by the model's geometry. 
The simulations run time of 400 time steps (80 seconds) for the three models insured that the solutions reached a periodic steady-state, meaning that methane concentrations had reached their maximal value possible given the models geometry and boundary conditions. Table $4.5-1$ presents the maximum and average methane concentrations recorded at the 10 designated MWS sampling locations for the HG, Midway, and TG mining geometries.

Table 4.5-1 CFD nodal results of the HG, midway, and TG geometries.

\begin{tabular}{|c|c|c|c|c|c|c|}
\hline \multirow{2}{*}{$\begin{array}{c}\text { MWS } \\
\text { Node } \\
\#\end{array}$} & \multicolumn{3}{|c|}{ Peak Concentration [ $\left.\% \mathrm{CH}_{4}\right]$} & \multicolumn{3}{|c|}{ "Average Concentration [ $\left.\% \mathrm{CH}_{4}\right]$} \\
\hline & HG & Midway & TG & HG & Midway & TG \\
\hline 1 & 0.18 & 0.09 & 0.09 & 0.15 & 0.07 & 0.07 \\
\hline 2 & 0.21 & 0.14 & 0.14 & 0.19 & 0.12 & 0.12 \\
\hline 3 & 0.73 & 0.19 & 0.19 & 0.41 & 0.17 & 0.17 \\
\hline 4 & 0.50 & 0.25 & 0.25 & 0.33 & 0.21 & 0.21 \\
\hline 5 & 0.47 & 0.37 & 0.30 & 0.36 & 0.30 & 0.25 \\
\hline 6 & 0.51 & 0.88 & 0.35 & 0.37 & 0.55 & 0.28 \\
\hline 7 & 0.53 & 0.73 & 0.41 & 0.38 & 0.51 & 0.31 \\
\hline 8 & 0.57 & 0.68 & 1.22 & 0.39 & 0.47 & 0.78 \\
\hline 9 & 0.60 & 0.65 & 0.89 & 0.40 & 0.41 & 0.57 \\
\hline 10 & 0.63 & 0.63 & 0.81 & 0.40 & 0.38 & 0.52 \\
\hline
\end{tabular}

The TG mining model resulted in the highest recorded event of $1.22 \% \mathrm{CH}_{4}$. To better understand the dynamics of the results and the resulting profiles of the three modeled configurations, contour plots of methane concentration were created for the solutions of the flow domain. The plots are evaluated in the following section.

\subsubsection{Shearer Located Near HG}

In the HG model, the shearer was located $70 \mathrm{~m}$ from the entryway of the face. The shearer and shield advancements were arranged in a way that represented the shearer making a pass towards the TG. Figure 4.5-1 presents the models boundary assignments and outlines the flow domain arrangement for the HG study. 


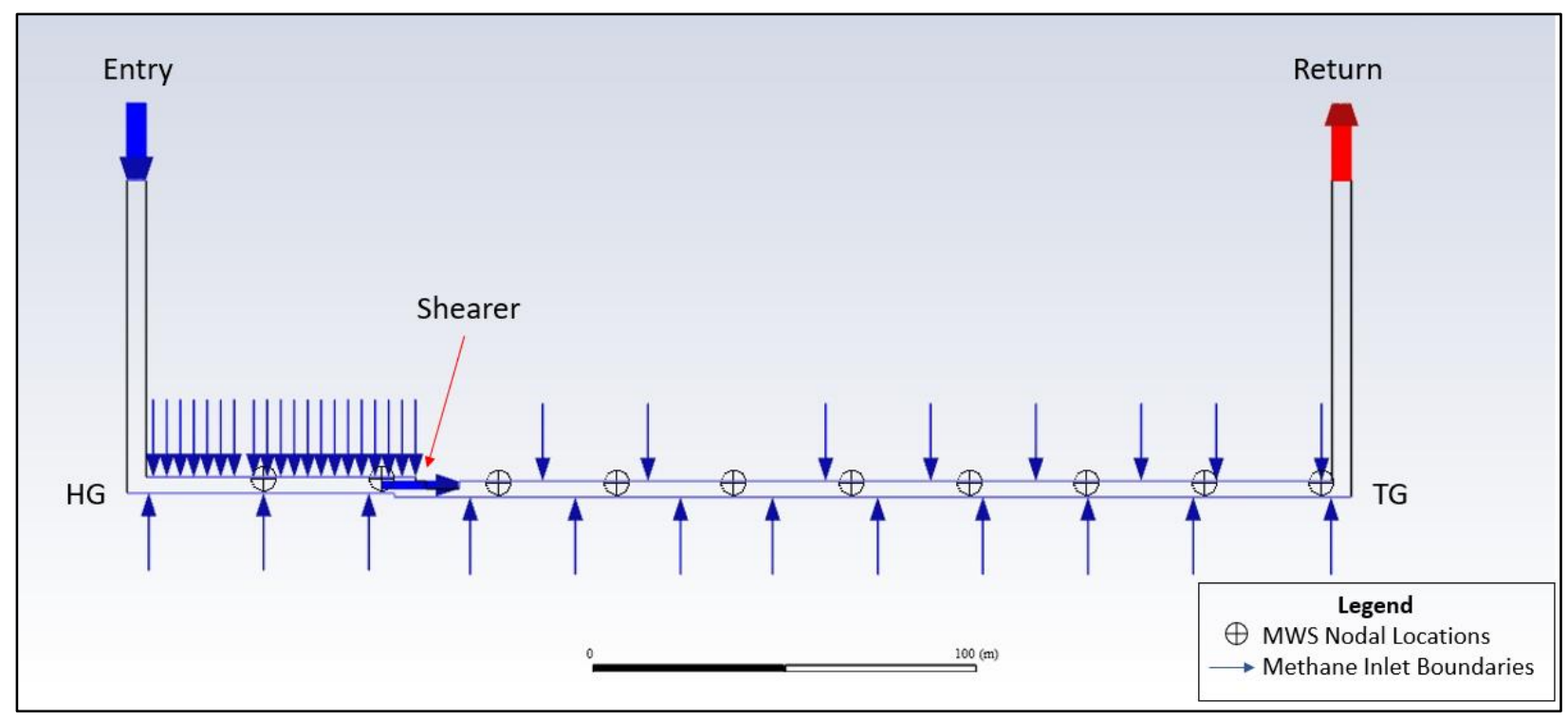

Figure 4.5-1 2D Model domain of longwall face during production where shearer is located near the start of a pass $(70 \mathrm{~m})$ from $\mathrm{HG}$ to $\mathrm{TG}$.

The $70 \mathrm{~m}$ in this scenario defined the region of coal that had just been recently exposed and therefore resulted in a higher emission rate than that of the baseline emissions defined ahead of the shearer. Figures a), b), and c) of 4.5-2 depict the development of the methane profile as a result of the shearer located at the HG. 
a) Initial distribution - start of simulation

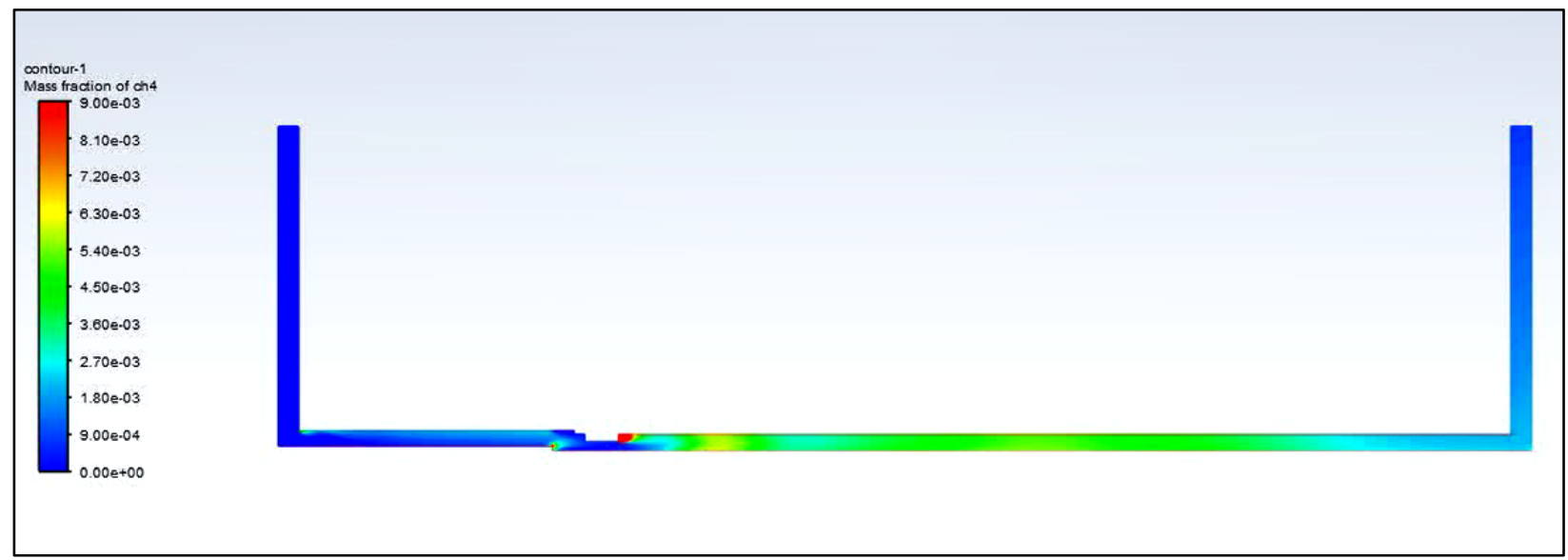

b) Boundary layer methane gradients and emissions begin to accumulate.

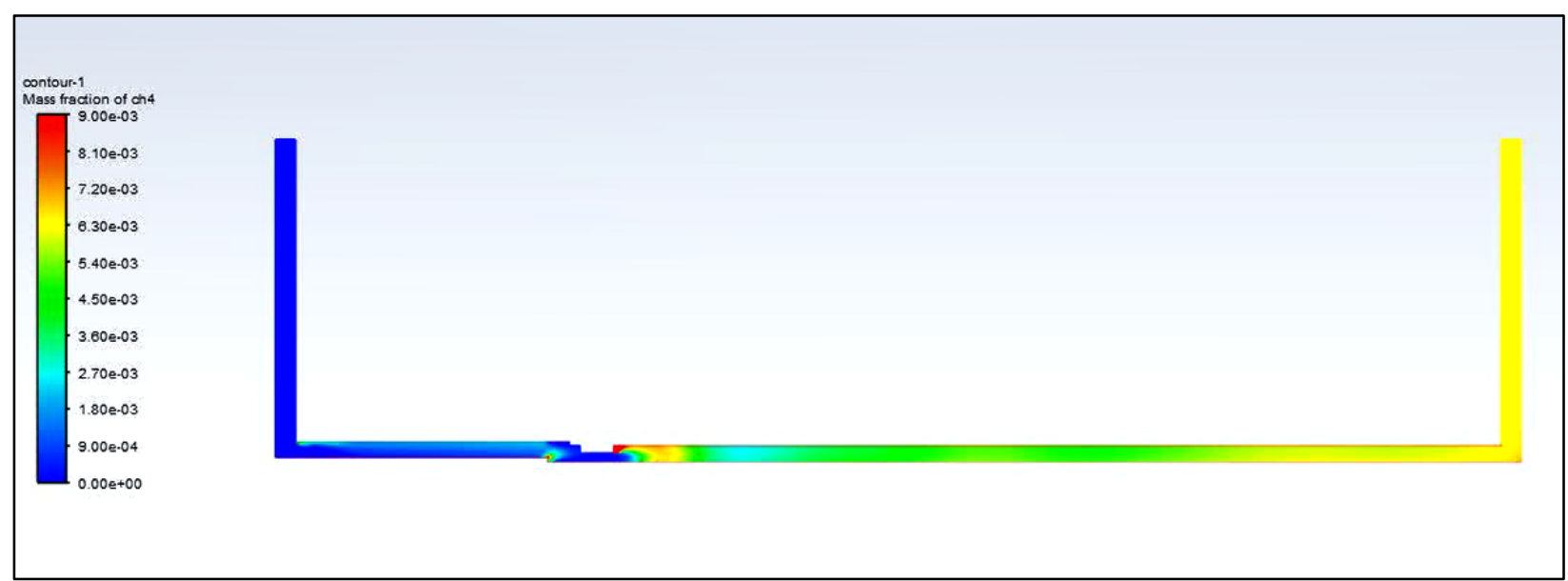

c) Maximal methane concentration profile reached

Figure 4.5-2 Development of methane distribution along the longwall face for the shearer cutting near the HG. 
Fluctuations in methane concentration where minimal along the entire length of the longwall face as a result of the shearer being located near the HG. With the shearer located closest to the fresh air source of the three scenarios, the high emitting methane at the cutting edge of the shearer was quickly diluted and diffused downwind methane concentrations. Only nodes 1 and 2 of the MWS resided upwind of the shearer in this scenario, while node 3 is the closest downwind unit to the shearer where high levels of released methane were expected. The results of this configuration present a low risk scenario where no excessively high concentration plumes developed early or accumulate at the TG; this would favor the monitoring strategy of the MWS.

It is important to note however that a high turbulent kinetic energy was experienced around the shearer which resulted in a large pressure difference. This is partly in turn of the walls being solid (nonporous) media that make up the boundaries of the model. However, this suggested that under real world conditions, the void and porous media of the fallen coal that makes up the gob provides an excellent sink for the flow to divert; consequently mixing with the methane that accumulated in the gob. This loss of flow to the gob creates the loss in ventilation air towards the TG which can increase emissions demonstrated in the 1-D model. This may also support the claims of emissions being higher in a HG to TG pass, similar to the simulation presented here.

\subsubsection{Shearer Located Midway}

In the midway model, the shearer was located at $152 \mathrm{~m}$ from the entryway of the face, halfway between the HG and TG. Again, the shearer and shield orientations were such that signified a HG to TG pass. Figure 4.5-3 presents the model geometry with the shearer located midway. 


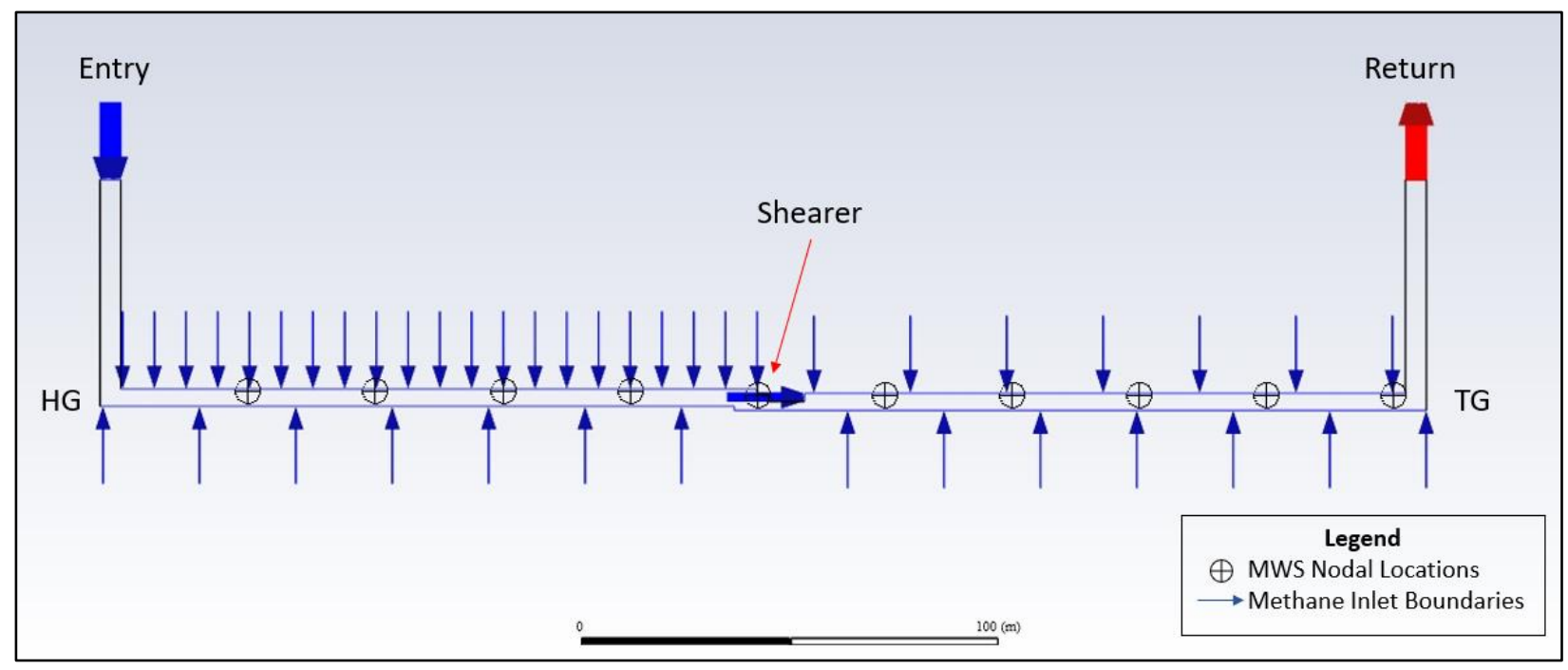

Figure 4.5-3 2D Model domain of longwall face during production where shearer is located hallway through a pass $(152 \mathrm{~m})$ from $\mathrm{HG}$ to $\mathrm{TG}$.

The additional $82 \mathrm{~m}$ of recently exposed coal redefined the methane boundary inlet to be 0.079 $\mathrm{kg} / \mathrm{s}$. All other boundary conditions including the ventilation air, baseline emissions, and shearer cutting emissions remained the same. Figures a), b), and c) of 4.5-4 depict the development of the methane profile as a result of the shearer located at the midway through a cutting sequence. 


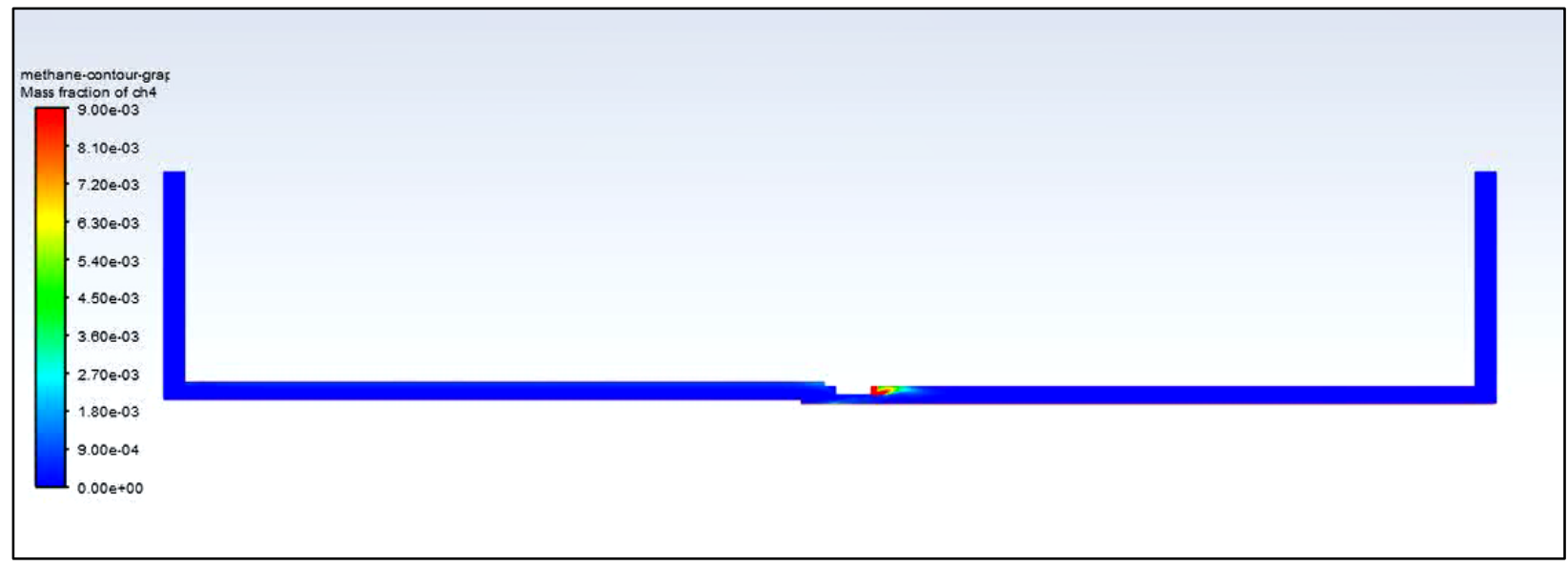

a) Initial distribution - start of simulation

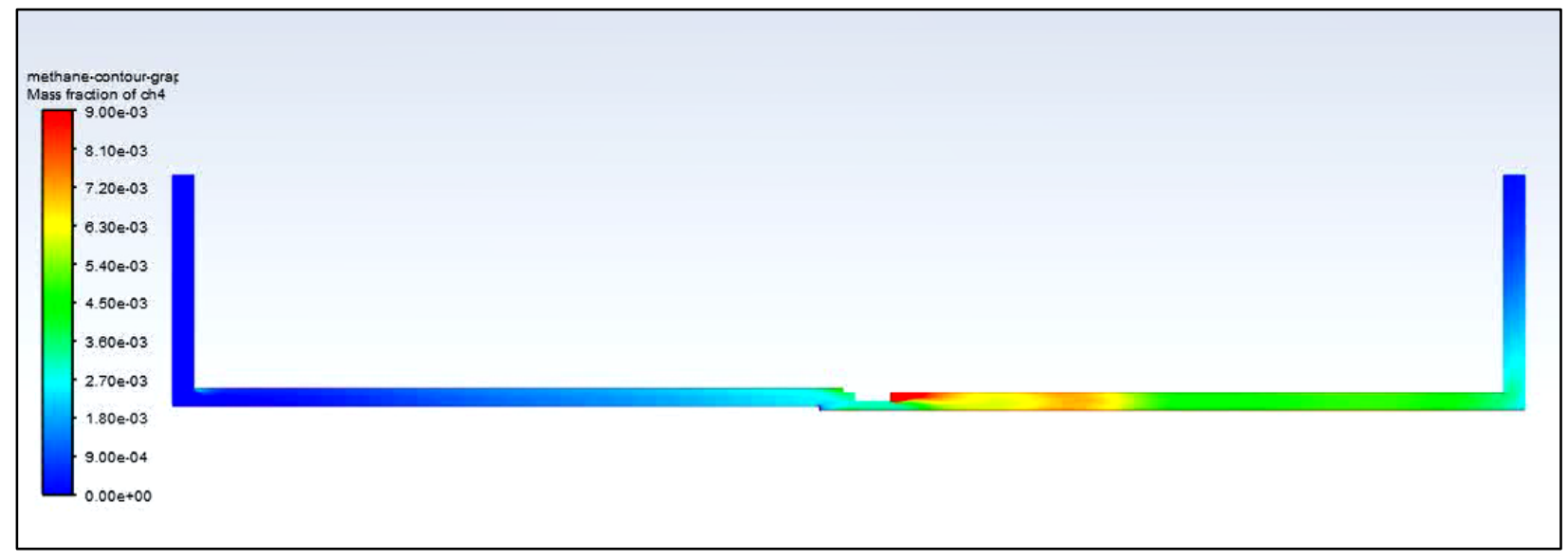

b) Methane emissions begin to increase behind the shearer due to its interference with flow.

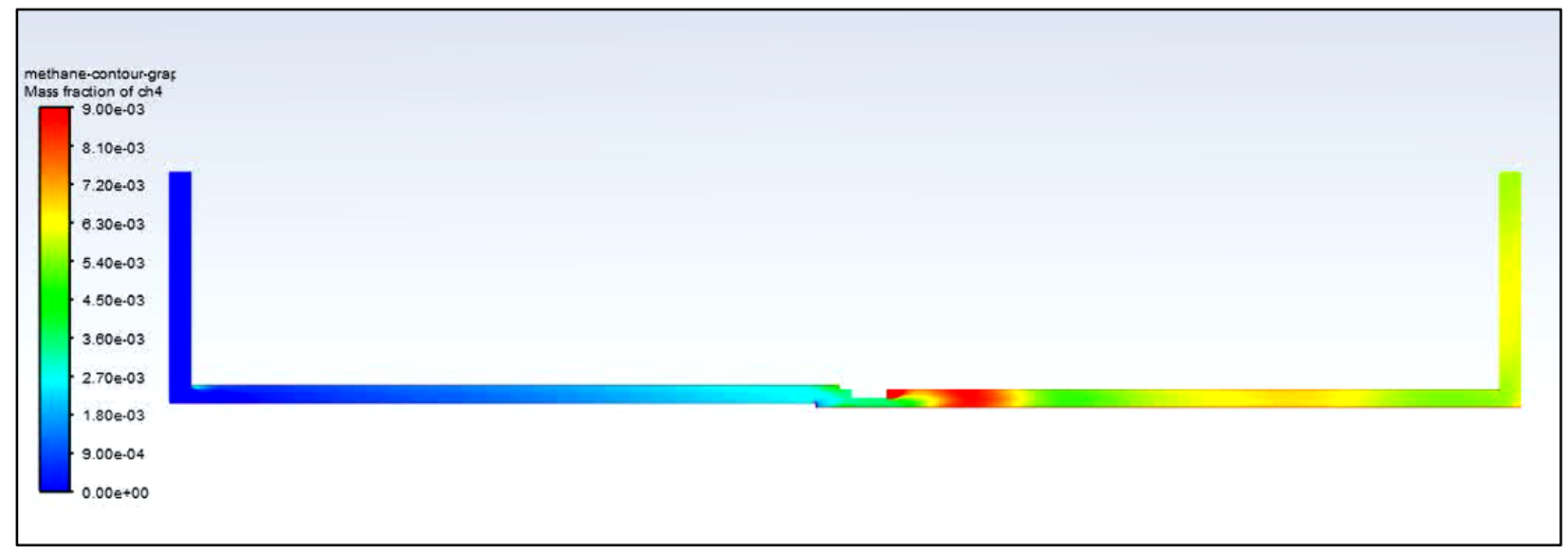

c) Maximal methane concentration profile reached

Figure 4.5-4 Development of methane distribution along the longwall face for the shearer cutting halfway through a cutting sequence. 
The midway model provided a scenario where half of the MWS units were located upstream of the shearer, while the second half were located downwind of the cutting emissions. Emissions accumulated behind the shearer at this point, diminishing the fresh air available to the cutting face of the shearer. As a result, higher concentration plumes $\left(\sim 0.90 \% \mathrm{CH}_{4}\right)$ began forming after the shearer and can be seen in Figure c.) above. Once diffused, the maximal resulting emissions recorded at the TG (node 10$)$ where similar to those of the $\mathrm{HG}$ model $\left(0.63 \% \mathrm{CH}_{4}\right)$.

The plume development of this model displayed a scenario where a "higher" emitting event may momentarily exist near the shearer but would ultimately go unnoticed downstream if regulatory emissions are monitored at a single predetermined location. With only 5 MWS units available at this point in the cutting sequence, time scales and control strategies begin to become more crucial if the true concentration is to be recognized and exemplifies a moderate threat level.

\subsubsection{Shearer Located Near TG}

Finally, the TG model represents a cutting scenario where the shearer is located near the TG, 224 $\mathrm{m}$ from the entryway. The $224 \mathrm{~m}$ section increased the emissions from recently exposed coal to $0.116 \mathrm{~kg} / \mathrm{s}$. Again, all other boundary conditions remained unchanged. Figure $4.5-5$ presents the geometry with the shearer near the TG. Following, Figures a), b), and c) of 4.5-6 depicts the development of the methane profile as a result of the shearer located near the TG.

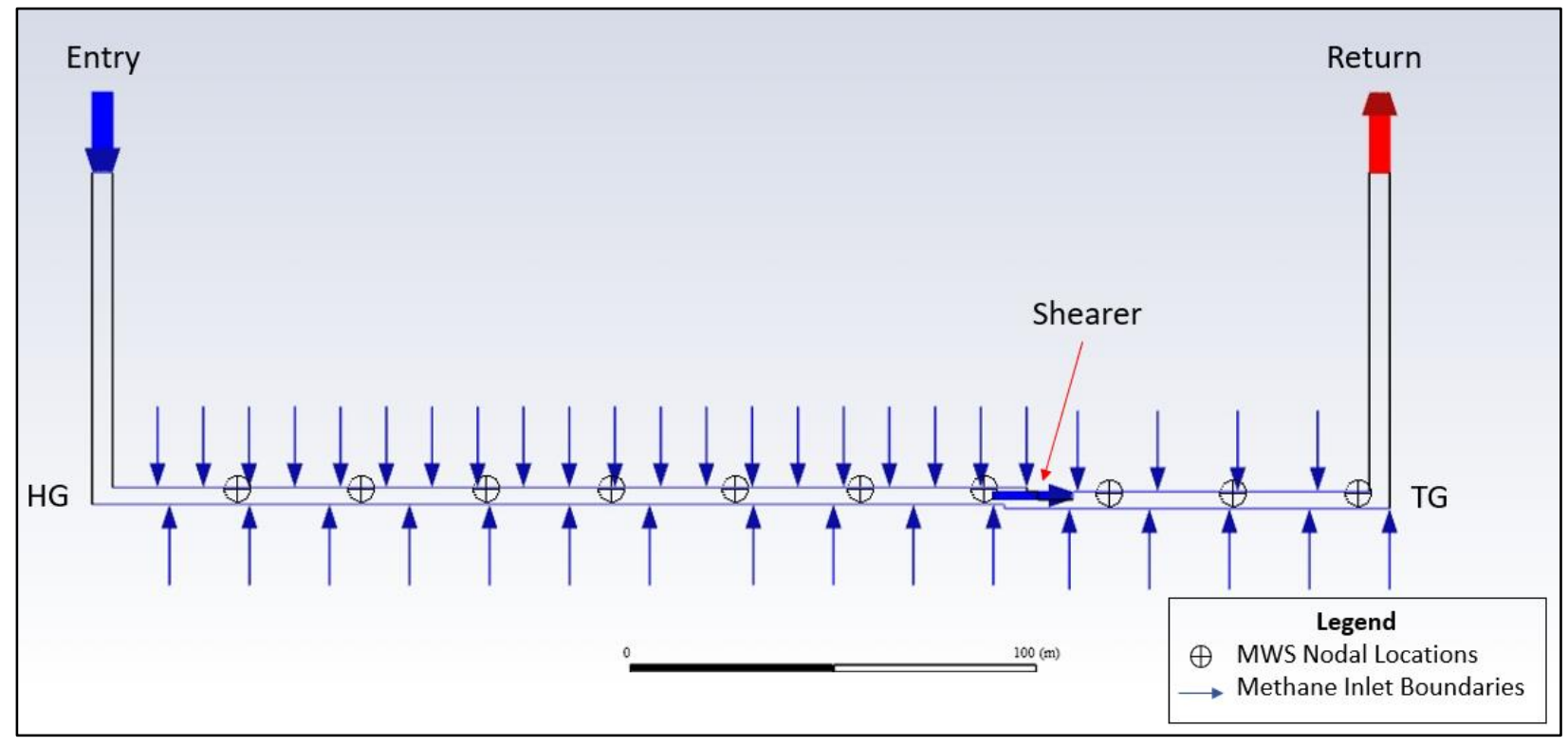

Figure 4.5-5 2D Model domain of longwall face during production where shearer is located near the end of a pass (224 m) from HG to TG. 


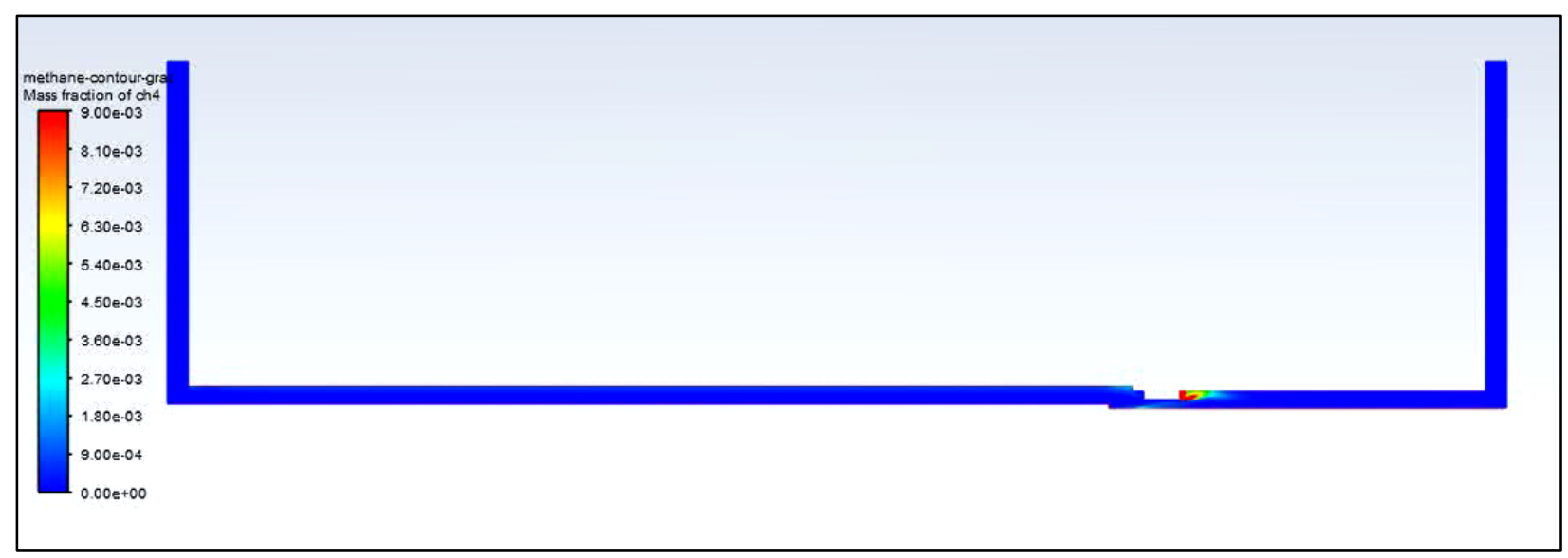

a) Initial distribution - start of simulation

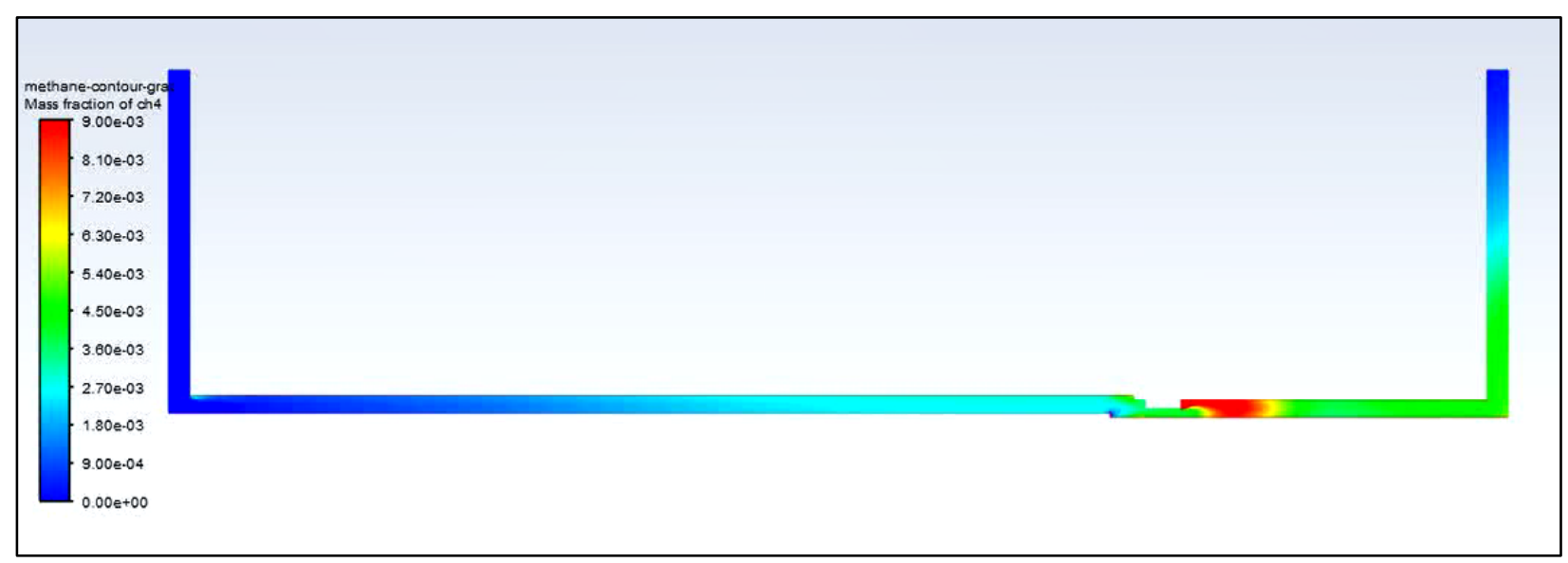

b) Methane emissions begin to increase behind the shearer due to its interference with flow.

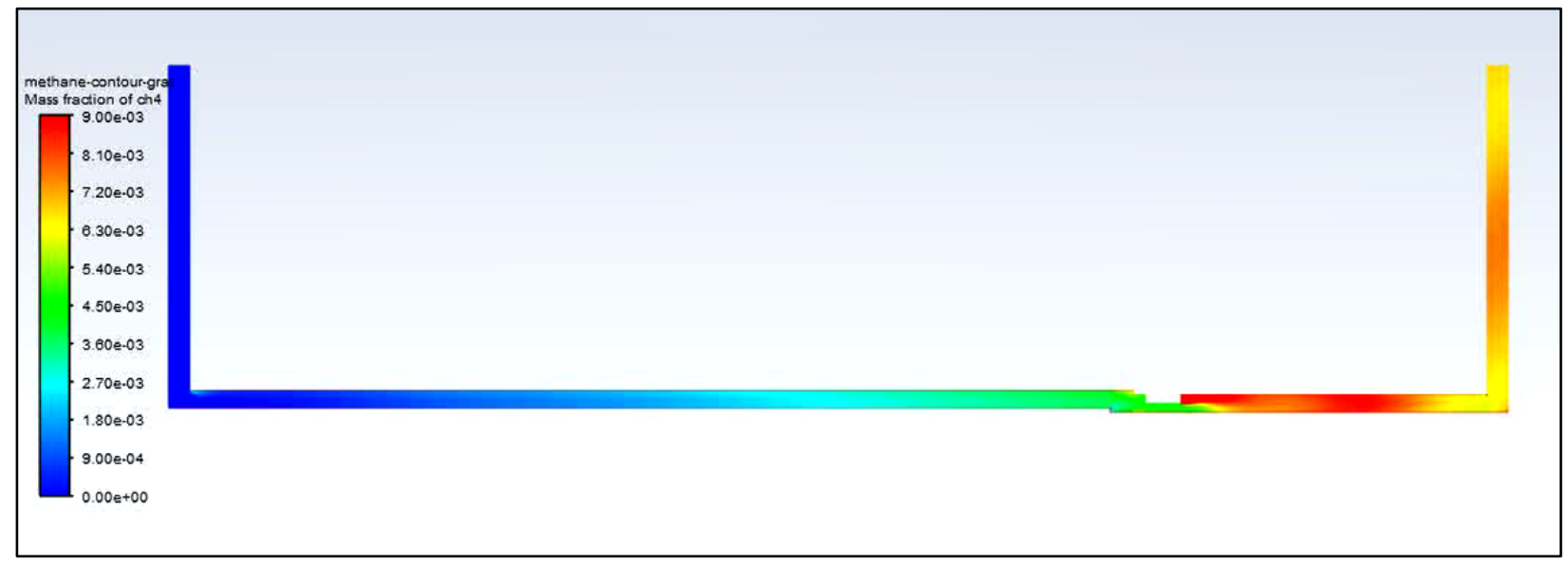

c) High emitting events from the shearer cutting produce elongated high concentration plumes downwind of shearer.

Figure 4.5-6 Development of methane distribution along the longwall face for the shearer cutting near the TG. 
The TG model demonstrated the highest threat level of the three scenarios modeled here. Higher emissions of $\sim 0.90 \% \mathrm{CH}_{4}$ downwind of the shearer became increasingly dispersed. These events where unable to be reduced due to the lack of fresh air. Constant emissions of around $0.50 \% \mathrm{CH}_{4}$ were present upwind of the shearer. With now only 3 MWS units downwind of the shearer, timescales become rather small as the 3 can actively reference each other. However, the resulting emissions experienced at the final nodes (9 and 10) showed a positive trend in emissions as the geometries progressed towards the TG, marking the end of a single pass. If this is true, then a decision may be made earlier on to reduce the production rate of the shearer in attempts to reduce emission rates as the shearer approaches the TG.

\subsection{Conclusions}

A multi-nodal methane detection system for improving safety among the longwall coal mines was designed, developed, and tested for effectiveness through experimental and modeling approaches. System response characterization and sensor selection reduced baseline response times from 17 seconds to approximately 5 seconds. The average time aligned measurement error of the MWS was also reduced from $19 \%$ to $4 \%$, demonstrating a $78 \%$ improvement in measurement accuracy. The MWS system consisted of 10 sampling units, each containing a suite of sensors to monitor the environment climate and methane concentration. Three methane sensors of various price points and operational principles were evaluated within the completed MWS unit. The Gasmitter methane sensor was ultimately selected the second generation MWS prototype. At the highest price point of $\$ 800$, the Gasmitter sensor provided superior performance among the various laboratory tests that simulated conditions and scenarios expected in an actual mining environment.

A 1-D model was created to generate scenarios that consisted of temporal methane profiles that may result from the spatial domain and longwall mining operations. The 1-D advection equation provided the solutions of the numerical analysis. More specifically, the first-order upwind differencing scheme modeled the transport of methane plumes along the 1-D domain of the longwall face. The upwind scheme provided stability and diffusion over the range of transient boundary conditions. A boundary sensitivity analysis was completed with the 1-D model to generate temporal data sets. The data sets consisted of transient methane data that were administered to one of the MWS units to measure its effectiveness and performance. Due to sample transport delay and sensor response times of around 17 seconds, the resulting outputs were diffused 
and shifted when compared to the original input. A failure to report a spike in concentration above the regulatory threshold of $1 \% \mathrm{CH}_{4}$ resulted in a $30 \%$ error when administered one of the simulated data sets.

Controlled step inputs aided in characterizing the response profile of the MWS. From the resulting profile, a time constant along with the first derivative provided a useful first-order transfer function which defined the reconstruction method developed. This method may be used in real time measurements and sacrifices only the previous measurement value (one second) for the first derivative. The reconstruction method was then validated with the transient nodal methane data constructed with the 1-D longwall model. The method was successful for all six scenarios constructed from the boundary sensitivity analysis and reported all instances where methane emissions spike above regulatory thresholds.

A 2-D CFD model was then constructed to generate downwind methane profiles for three production scenarios: the shearer near the HG, the shearer midway, and the shearer near the TG. Methane inlets defined at the boundaries consisted of long-term desorbed methane from past activity (gob) and face, methane from recently exposed coal located behind the shearer, and the methane released from the cutting head of the shearer. The model consisting of the shearer near the TG resulted in the average highest emissions rate "recorded" at Node 10 of $0.52 \% \mathrm{CH}_{4}$. A maximum emission event was also recorded from this model at Node 8 located nearer the shearer which was $1.22 \% \mathrm{CH}_{4}$.

Overall, the first-generation prototype of the MWS displayed the desirable characteristics of a useful tool that may one day provide a safer and more productive work environment underground. Though the full extent of its capabilities and limitations are unknown at this time, the contributions made in the laboratory through experimental and simulated data provided a significant start and window for future development.

\subsection{Recommendations for Future Work}

From the initial evaluation of the MWS completed here, future work should aim to further validate system response characterizations through a deployable "smart" system. The smart system would utilize the environmental monitoring data collected from each of the 10 nodal units to advise an optimized production plan or at least provide a safety forecast so that preventive action may be taken before a shutdown occurs. The 1-D model could be further developed to demonstrate this 
objective. A simple feedback control scheme would utilize the sharped signals (methane concentrations) at the MWS nodes to make a decision on shearer rate. This way the shearer can recognize the onset of rising methane emissions downwind and slow down to avoid a shutdown. Alternatively, if instances where ventilation air is stable and abundant, then an increase in production rate may be possible without methane emissions approaching the $1 \%$ threshold.

At the time of this work, only one of the MWS units was fitted with the Gasmitter sensor to build system response characteristics. The next step would be to integrate a Gasmitter sensor into all 10 of the MWS units. This would also require a redesigned "sensor block" which would need to house only the temperature, pressure, and humidity sensors. The block would likely be placed downstream of the Gasmitter unit to keep methane response times low. The Gasmitter provided the best option over the MOS and IR type sensors. If future compensation and reliable accuracy could be retained by the MQ-4 (MOS) sensor then future research would benefit greatly from its lower detection limit and sensitive response it provides at a low cost.

Anemometers were initially proposed on MWS units located near regular measurement sites near the HG and TG. Further integration and utilization of continuous air velocity measurements could significantly improve the systems awareness to a potential negative event. Velocity measurement data may provide a useful correlation to methane formation, which would help reinforce the certainty of danger and preemptively generate a corrective response. 


\subsection{References}

[1] U.S. Energy Information Administration, "Short-Term Energy Outlook. U.S. Coal Summary (years 2018-2021)," U.S. Energy Informaation Administration, Washington DC, 2020.

[2] J. J. Sammarco, J. L. Kohler and T. Novak, "Safety Issues and the Use of SoftwareControlled Equipment in the Mining Industry," in IEEE Industry Applications Society 32nd Annual Meeting, New Orleans, 1997.

[3] "CFR: Title 30 Part 75," 9 March 2020. [Online]. Available: https://ecfr.io/Title30/pt30.1.75.

[4] Alpha Foundation, "Who We Are," [Online]. Available: https://www.alphafoundation.org/who-we-are/. [Accessed 26 May 2020].

[5] R. B. Krog, "Critical Analysis of Longwall Ventilation Systems and Removal of Methane," The Research Repository @ WVU, 2016.

[6] M. Myszkowski and U. Paschedag, "Longwall Mining in Sceams of Medium Thickness: Comparison of Plow and Shearer Perfromance under Comparable Conditions," Caterpillar Inc., 2013.

[7] S. Schatzel, R. Krog, F. Garcia and J. Marshall, "Prediction of longwall methane emissions and the associated consequences of increasing longwall face lengths: a case study in the Pittsburgh Coalbed," in U.S./North American Mine Ventilation Symposium, University Park, PA, USA, 2006.

[8] W. P. Diamond and F. Garcia, "Prediction of Longwall Methane Emissions: An Evaluation of the Influence of Mining Practices on Gas Emissions and Methane Control Systems," NIOSH-Publications Dissemination, Cincinnati, OH, USA, 1999.

[9] S. Krickovic and C. Findlay, "Methane Emission Rate Studies in a Central Pennsylvania Mine," U.S. Dept. of the Interior, Bureau of Mines, 1971.

[10] Kentucky Geological Survey, University of Kentucky, "Earth Resources-Our Common Wealth-Coal Rank," 2019. [Online]. Available: https://www.uky.edu/KGS/coal/coalrank.php.

[11] W. P. Diamond, J. C. LaScola and D. M. Hyman, "Results of Direct-Method Determination of the Gas Content of U.S. Coalbeds," Information Circular (United States, Bureau of Mines); 9067, 1986. 
[12] G. W. Mitchell, Longwall Mining, In Monograph 26 - Australaian Coal Mining Practice ed., 2006, pp. 357-359.

[13] S. J. Schatzel, C. O. Karacan, R. B. Krog, G. S. Esterhuizen and G. V. R. Goodman, "Guidlines for the Prediction and Control of Methane Emissions on Longwalls," Information Circular 9502, 2008.

[14] M. Tutak and J. Brodny, "Predicting Methane Concentration in Longwall Regions Using Artifical Neural Networks," Internation Journal of Environmental Research and Public Health, 2019.

[15] C. O. Karacan, "Modeling and prediction of ventilation methane emissions of U.S. longwall mines using supervised neural networks," International Journal of Coal Geology, 2008.

[16] J. W. Grubb, "Preventative Measures For Spontaneous Combustion In Underground Coal Mines," Colorado School of Mines, Golden, 2008.

[17] R. B. Krog, S. J. Schatzel and H. N. Dougherty, "Methane emissions and airflow patterns along longwall faces and through bleeder ventilation systems," International Journal of Mining and Mineral Engineering, vol. 5, no. 4, p. 328-349, 2016. doi: 10.1504/IJMME.2014.066580.

[18] V. Gangrade, S. J. Schatzel, S. P. Harteis and J. D. Addis, "Investigating the Impact of Caving on Longwall Mine Ventilation Using Scaled Physical Modeling," Min Metall Explor. Author manuscript, Pittsburgh, 2019.

[19] W. P. Diamond, "Methane Contol for Underground Coal Mines," United States Bureau of Mines (Information Circular, 9395), 1994.

[20] GFG Instrumentation, "AP 1018: Understanding catalytic LEL combustible gas sensor performance," 2013. [Online]. Available: http://goodforgas.com/wpcontent/uploads/2013/12/AP1018_Combustible-sensor-performance_6_30_13.pdf.

[21] CSE, "140B Methane Monitor," [Online]. Available: https://www.csecorporation.com/Product-140B-Methane-Monitor. [Accessed 15 May 2020].

[22] M. J. McPherson, "Chapter 6. Ventilation Surveys," in Subsurface Ventilation Engineering, 2006.

[23] F. Garcia and J. Cervik, "Method Factors for Anemometer Measurments at Pipe Outlets," Bureau of Mines (Report of Investigations, 9061), Pittsburgh, 1987. 
[24] B. Belle, "Real-time air velocity monitoring in mines - a quintessential design parameter for managing major mine health and safety hazards," in 2013 Coal Operators' Conference, University of Wollongong, 2013.

[25] H. N. Dougherty and C. O. Karacan, "A new methane control and prediction software suite for longwall mines," Pittsburgh, 2011.

[26] Z. Wang, T. Ren, L. Ma and J. Zhang, "Investigations of Ventilation Airflow Characteristics on a Longwall Face-A Computational Approach," Energies, vol. 11, no. 6, 2018. doi: 10.3390/en11061564.

[27] W. Dziurzynski, A. Krach and T. Palka, "Airflow Sensitivity Assessment Based on Underground Mine Ventilation Systems Modeling," Energies, 2017.

[28] P. Skotiniczny, "Transient States in the Flow of the Air-Methane Mixture at the Longwall Outlet, Induced by a Sudden Methane Outflow," Archives of Mining Sciences, vol. 59, no. 4, pp. 887-896, 2014.

[29] D. Johnson, "Health and Safety Interventions," Alpha Foundation, 2018. [Online]. Available: https://www.alpha-foundation.org/wp-content/uploads/2018/06/AFC71968_WVU_Synopsis.pdf.

[30] SparkFun Electronics, "Methane CNG Gas Sensor - MQ-4," [Online]. Available: https://www.sparkfun.com/products/9404. [Accessed 11 July 2020].

[31] Sensors Europe GmbH, "Sensor's New Generation of NDIR Benches," Sensors, Erkrath, 2018.

[32] Global Calibration Gases LLC, "Certification of Gaseous Calibration Standards (MethaneAir 1000ppm), Procedure G1," 2018.

[33] Global Calibration Gases LLC, "Certification of Gaseous Calibration Standards (MethaneAir 1\%), Procedure G1," 2018.

[34] Global Calibration Gases LLC, "Certification of Gaseous Calibration Standards (MethaneAir 2\%), Procedure G1," 2019.

[35] A. P. Barr, "Design and Development of a Multi-Nodal Methane Detection System for Longwall Coal Mining," The Research Respository @ WVU, Morgantown, 2020.

[36] Alicat Scientific, "Technical Data for Alicat MC-Series Mass Flow Controllers," 2019. [Online]. Available: https://documents.alicat.com/specifications/DOC-SPECSMIDFLOWCONTROLLERS.pdf.

[37] Alicat Scientific, "Technical Data for Alicat M-Series Mass Flow Meters," 2018. [Online]. Available: https://documents.alicat.com/specifications/Alicat_Mass_Meter_Specs.pdf. 
[38] H. K. Versteeg and W. Malalasekera, Comutational Fluid Dynamics, 2nd ed., Pearson Education Limited, 2007.

[39] E. Kreyszig, H. Kreyszig and E. J. Norminton, "Chapter 12: Partial Differential Equations (PDEs)," in Advanced Engineering Mathmatics: 10th Edition, John Wiley \& Sons, Inc., 2011, pp. 540-604.

[40] D. Anderson, J. Tannehill and R. Pletcher, "Chapter 4: Application of Numerical Methods to Selected Model Equations," in Computational Fluid Mechanics and Heat Transfer, Taylor \& Francis Goup, 2012, pp. 103-120.

[41] "Chapter 2: Advection Equation".

[42] F. Sanjaya and S. Mungkasi, "A Simple but accurate explicit finite difference method for the advection-diffusion equation," in IOP Conf. Series: Journal of Physics: Conf. Series 909, Orlando, 2017.

[43] ANSYS, "ANSYS FLUENT 12.0 Theory Guide," ANSYS, Inc., 2009. [Online]. Available: https://www.afs.enea.it/project/neptunius/docs/fluent/html/th/main_pre.htm.

[44] Sensors Europe GmbH, "Operating Manual Gasmitter," Sensors, Erkrath, 2018.

[45] M. R. Madireddy and N. N. Clark, "Sequential inversion technique and differential coefficient approach for accurate instanteous emissions measurement," Morgantown, 2006.

[46] M. R. Madireddy and N. N. Clark, "Attempts to Enhance the'Differential Coefficients Method' for Reconstruction of Transient Emissions from Heavy-Duty Vehicles," Morgantown.

[47] D. Ajtay and M. Weilenmann, "Compensation of the Exhaust Gas Transport Dynamics for Accurate Instantaneous Emission Measurements," Enviromental Science \& Tachnology, 2004.

[48] D. W. Oliver, "Implications of Sampling Methods on Geospatial Mapping of Methane Sources," The Research Respository @ WVU, Morgantown, 2019.

[49] J. M. Cimbala, "Dynamic System Response," Penn State University, 2014.

[50] K. Raeen, "A Study of The Gibbs Phenomenon in Fourier Series and Wavelets," The University of New Mexico, Albuquerque, 2008.

[51] Zhengzhou Winsen Electronics Technology Co., Ltd, "Flammable Gas Sensor Model: MQ4," Zhengzhou, China, 2014. [Online]. Available: https://cdn.sparkfun.com/datasheets/Sensors/Biometric/MQ-4\%20Ver1.3\%20\%20Manual.pdf. 
[52] Dynament, "Methane Infrared Gas Sensors," [Online]. Available: https://www.dynament.com/gas-types/methane/. 


\subsection{Appendix}

Appendix A-1: MQ-4 (MOS) Sensor Specifications

\begin{tabular}{|c|c|c|c|}
\hline \multicolumn{3}{|c|}{ Model } & MQ-4 \\
\hline \multicolumn{3}{|c|}{ Sensor Type } & Semiconductor \\
\hline \multicolumn{3}{|c|}{ Standard Encapsulation } & Bakelite, Metal cap \\
\hline \multicolumn{3}{|c|}{ Target Gas } & Methane \\
\hline \multicolumn{3}{|c|}{ Detection range } & $300 \sim 10000 \mathrm{ppm}\left(\mathrm{CH}_{4}\right)$ \\
\hline \multirow{3}{*}{$\begin{array}{l}\text { Standard Circuit } \\
\text { Conditions }\end{array}$} & Loop Voltage & $\mathrm{V}_{\mathrm{c}}$ & $\leq 24 \mathrm{~V} \mathrm{DC}$ \\
\hline & Heater Voltage & $\mathrm{v}_{\mathrm{H}}$ & $5.0 \mathrm{~V} \pm 0.1 \mathrm{~V} \mathrm{AC}$ or $\mathrm{DC}$ \\
\hline & Load Resistance & $\mathbf{R}_{\mathbf{L}}$ & Adjustable \\
\hline \multirow{5}{*}{$\begin{array}{l}\text { Sensor character } \\
\text { under standard } \\
\text { test conditions }\end{array}$} & Heater Resistance & $\mathrm{R}_{\mathrm{H}}$ & $26 \Omega \pm 3 \Omega$ (room tem.) \\
\hline & $\begin{array}{l}\text { Heater } \\
\text { consumption }\end{array}$ & $\mathbf{P}_{\mathrm{H}}$ & $\leq 950 \mathrm{~mW}$ \\
\hline & Sensitivity & s & $\begin{array}{l}\mathrm{Rs}(\text { in a ir) } / \mathrm{Rs}(\text { in } \\
\left.5000 \mathrm{ppmCH}_{4}\right) \geq 5\end{array}$ \\
\hline & Output Voltage & Vs & $\begin{array}{c}2.5 \mathrm{~V} \sim 4.0 \mathrm{~V}(\text { in } 5000 \mathrm{ppm} \\
\left.\mathrm{CH}_{4}\right)\end{array}$ \\
\hline & Concentration Slope & $\alpha$ & $\leq 0.6\left(R_{5000 p p m} / R_{1000 p p m} C_{4}\right)$ \\
\hline \multirow{3}{*}{$\begin{array}{l}\text { Standard test } \\
\text { conditions }\end{array}$} & \multicolumn{2}{|c|}{ Tem. Humidity } & $20^{\circ} \mathrm{C} \pm 2^{\circ} \mathrm{C}: 55 \% \pm 5 \% \mathrm{RH}$ \\
\hline & \multicolumn{2}{|c|}{ Standard test circuit } & $\begin{array}{l}\mathrm{Vc}: 5.0 \mathrm{~V} \pm 0.1 \mathrm{~V}: \\
\mathrm{V}_{\mathrm{H}}: 5.0 \mathrm{~V} \pm 0.1 \mathrm{~V}\end{array}$ \\
\hline & \multicolumn{2}{|l|}{ Preheat time } & Over 48 hours \\
\hline
\end{tabular}

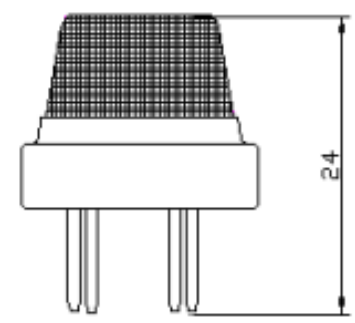

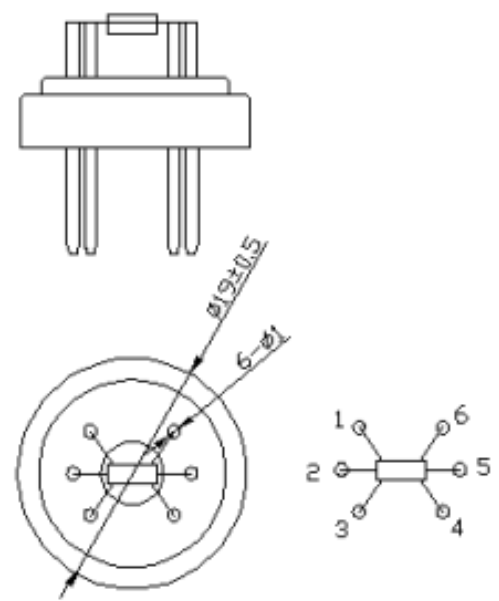

Fig1.Sensor Structure

Unit: $\mathrm{mm}$ 
Appendix A-2: Dynament (IRS) Sensor Specifications

\begin{tabular}{|c|c|}
\hline \multicolumn{2}{|c|}{ GENERAL SPECIFICATION } \\
\hline Operating Voltage Range: & $3.0-5.0 \mathrm{~V} \mathrm{d.c.}$ \\
\hline Operating Current: & Average current $15 \mathrm{~mA}$. See graph on page 7 \\
\hline Operating temperature range: & $-20^{\circ} \mathrm{C}$ to $+50^{\circ} \mathrm{C}\left(-4^{\circ} \mathrm{F}\right.$ to $\left.122^{\circ} \mathrm{F}\right)$ \\
\hline Warm up time: & To final zero $\pm 2 \%$ of full scale: 1 minute @ $20^{\circ} \mathrm{C}\left(68^{\circ} \mathrm{F}\right)$ ambient \\
\hline Storage temperature range: & $-20^{\circ} \mathrm{C}$ to $+50^{\circ} \mathrm{C}\left(-4^{\circ} \mathrm{F}\right.$ to $\left.122^{\circ} \mathrm{F}\right)$ \\
\hline Humidity range: & 0 to $95 \%$ RH non-condensing. \\
\hline Digital signal format: & 8 data bits, 1 stop bit, no parity. $2.8 \mathrm{~V}$ logic level \\
\hline Standard baud rates: & $38,400,19,200,9600,4800$ \\
\hline User configurable parameters: & $\begin{array}{l}\text { Full-scale value, resolution, } \\
\text { Sensor 'zero' function } \\
\text { Sensor 'span' function }\end{array}$ \\
\hline MTBF: & $>5$ years \\
\hline Weight: & 15 grams \\
\hline Pressure & $\pm 5 \%$ of the calibration pressure to maintain the accuracy limits \\
\hline
\end{tabular}

\begin{tabular}{|c|c|}
\hline \multicolumn{2}{|c|}{ HYDROCARBON CHANNEL SPECIFICATION } \\
\hline Methane measuring range: & $0-5 \%, 0-100 \%$ volume or both \\
\hline Hydrocarbon measuring range & $0-100 \%$ LEL equivalent \\
\hline Resolution: & $\begin{array}{l}0.01 \% \text { for readings up to } 5 \% \text { volume methane } \\
0.1 \% \text { for readings from } 5 \% \text { up to } 100 \% \text { volume methane } \\
0.01 \% \text { propane for all readings }\end{array}$ \\
\hline Accuracy: & $\begin{array}{l} \pm 10 \% \text { of the reading @ } 20^{\circ} \mathrm{C}\left(68^{\circ} \mathrm{F}\right), 1 \text { bar pressure, applied } \\
\text { gas. }\end{array}$ \\
\hline Response Time T90: & $<30$ s @ $20^{\circ} \mathrm{C}\left(68^{\circ} \mathrm{F}\right)$ ambient \\
\hline Zero Repeatability: & $\pm 1 \%$ of full scale @ $20^{\circ} \mathrm{C}\left(68^{\circ} \mathrm{F}\right)$ ambient \\
\hline Span Repeatability: & $\pm 2 \%$ of full scale @ $20^{\circ} \mathrm{C}\left(68^{\circ} \mathrm{F}\right)$ ambient \\
\hline Long term zero drift: & $\begin{array}{l} \pm 1 \% \text { of full scale per month @ } 20^{\circ} \mathrm{C}\left(68^{\circ} \mathrm{F}\right) \text { ambient, } \\
\text { (max } \pm 3 \% \text { of full scale per year) }\end{array}$ \\
\hline $\begin{array}{l}\text { Temperature performance: } \\
\text { - May not be appllcable when uaing gas crose-reterence factors }\end{array}$ & $\begin{array}{l} \pm 0.1 \% \text { volume or } \pm 10 \% \text { of reading up to } 50 \% \text { of full scale, } \pm \\
15 \% \text { of reading from } 50 \% \text { to } 100 \% \text { of full scale, or } 2 \% \text { of full } \\
\text { scale whichever is greater over the range }-20^{\circ} \mathrm{C} \text { to }+50^{\circ} \mathrm{C}\left(-4^{\circ} \mathrm{F}\right. \\
\left.\text { to } 122^{\circ} \mathrm{F}\right)\end{array}$ \\
\hline $\begin{array}{l}\text { User configurable parameters and } \\
\text { functions: }\end{array}$ & $\begin{array}{l}\text { Sensor 'zero' function } \\
\text { Sensor 'span' function } \\
\text { Over-range value }\end{array}$ \\
\hline
\end{tabular}




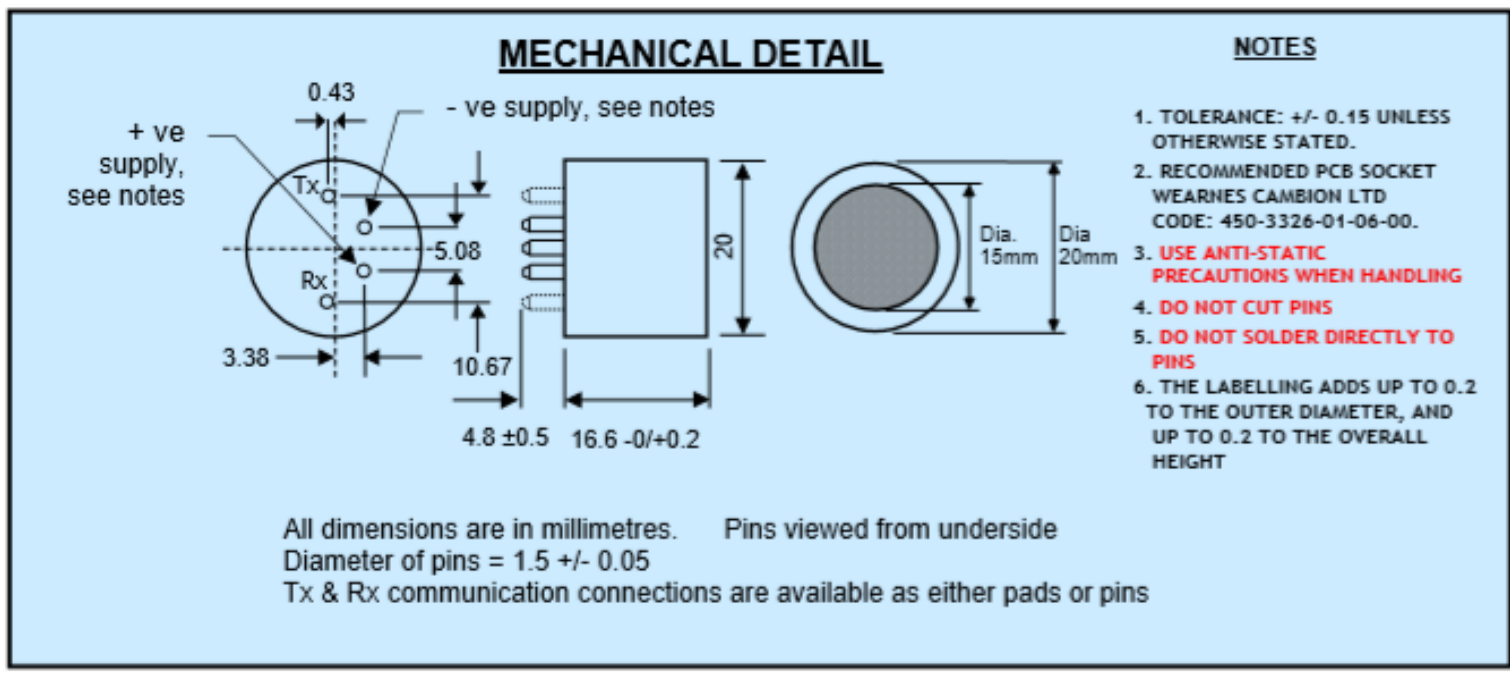


Appendix A-3: Gasmitter (NDIR) Sensor Specifications

\begin{tabular}{|c|c|}
\hline \multicolumn{2}{|r|}{ Specifications } \\
\hline Measuring principle & Non dispersive infrared sensor (NDIR) dual wavelength \\
\hline \multicolumn{2}{|r|}{ Measuring Response $\mathrm{e}^{1}$} \\
\hline Linearity Error & $\leq \pm 1 \% \mathrm{FS}^{*}$ \\
\hline Lower detection limit & $<0,5 \% \mathrm{FS}^{*}$ \\
\hline Repeatability at zero & $\pm 0,2 \% \mathrm{FS}^{*}$ \\
\hline Repeatability at span & $\pm 1 \% \mathrm{FS}^{*}$ \\
\hline Long term stability & $\pm 2 \% \mathrm{FS}^{*}$ (12 months under laboratory conditions) \\
\hline \multicolumn{2}{|r|}{ Influencing Variables $^{1}$} \\
\hline Temperature dependence at zero & $\pm 0,5 \% \mathrm{FS}^{*}$ per $10 \mathrm{~K}$ \\
\hline Temperature dependence at span & $\pm 1 \% \mathrm{FS}^{*}$ per $10 \mathrm{~K}$ \\
\hline Pressure dependence at zero & $0 \%$ \\
\hline Pressure dependence at span & $<0,2 \% \mathrm{FS}^{*}$ per $10 \mathrm{mbar}$ (in the range of $800 \ldots 1200 \mathrm{mbar}$ ) \\
\hline \multicolumn{2}{|r|}{ Time Response } \\
\hline Warm up & within 10 s operational, less than 30 minutes to reach specification \\
\hline Response time $\left(\mathrm{T}_{90}\right)$ & 3...45s (depending on used sensor element, flow, tube length, digital attenuation) \\
\hline \multicolumn{2}{|r|}{ Gas Inlet Conditions } \\
\hline Ambient temperature & $0 . . .50^{\circ} \mathrm{C}$ in process $/-20 \ldots 60^{\circ} \mathrm{C}$ in storage \\
\hline Gas pressure & $800 \ldots 1200 \mathrm{mbar}$ \\
\hline Ambient humidity & $<95 \%$ RH (non condensing) \\
\hline Flow range (gas) & $0,1 \ldots 0,75 \mathrm{I} / \mathrm{min}$ (constant) \\
\hline \multicolumn{2}{|r|}{ Calibration } \\
\hline Zero- / Spanpoint calibration & Zero- and spanpoint adjustable with software command / Zeropoint via button on the PCB \\
\hline \multicolumn{2}{|r|}{ Electric Properties } \\
\hline Operating voltage & $12 \mathrm{VDC}(10 \ldots 42 \mathrm{VDC})$ \\
\hline Power consumption & Max. 3W \\
\hline Status / Failure visualization & Status and failure LED on the PCB \\
\hline Analog output (linearized) & $0 . . .20 \mathrm{~mA}, 4 \ldots 20 \mathrm{~mA} ;$ Max. $50 \Omega$ load at current output \\
\hline Digital output & RS232-Interface, USB-Interface \\
\hline \multicolumn{2}{|r|}{ Dimensions } \\
\hline PCB dimension & $160 \times 50 \mathrm{~mm}$; Height : 45mm (connectors and tubes) \\
\hline Weight & $\max .800 \mathrm{~g}$ \\
\hline Tube connector & $3 \mathrm{~mm}$ (outside diameter ); Hose inside diameter $<3 \mathrm{~mm}$ \\
\hline
\end{tabular}

"FS= full scale

${ }^{1}=$ Referred to $1013 \mathrm{mbar}$ sample gas pressure, $25^{\circ} \mathrm{C}$ ambient temperature and $0,75 \mathrm{l} / \mathrm{min}$ constant gas flow.

Disclaimer: Specifications are subject to change without notice. While due caution has been exercised in the production of this document, possible errors and omissions are unintentional.

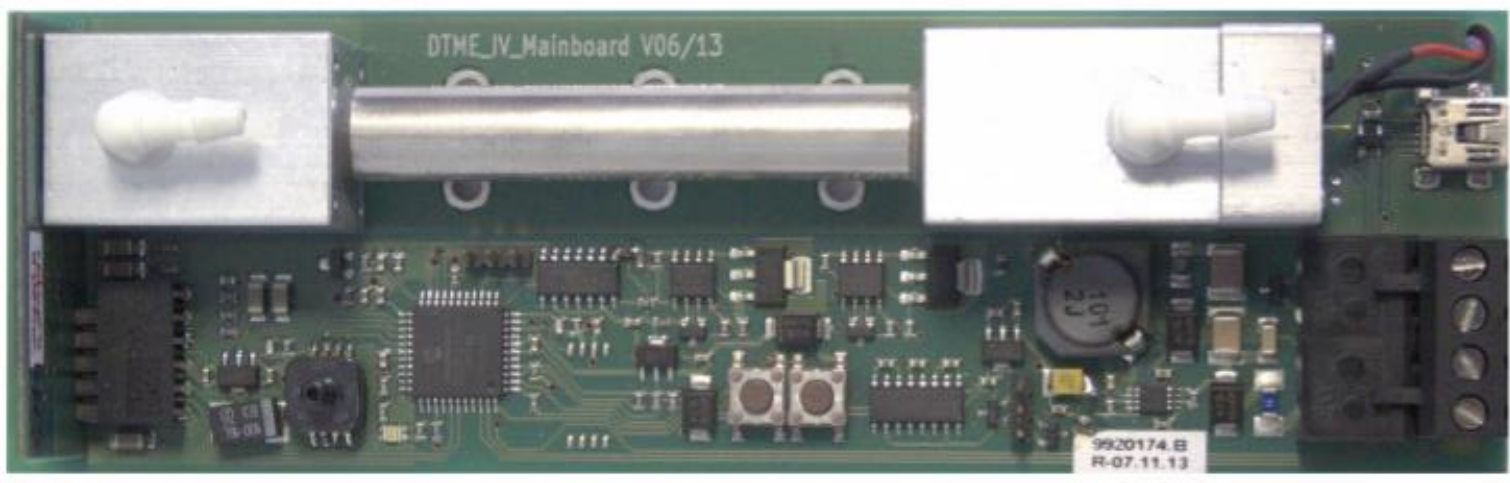


Appendix B: MATLAB code for Study on Discretized Schemes (Upwind, Lax, Lax-Wendroff)

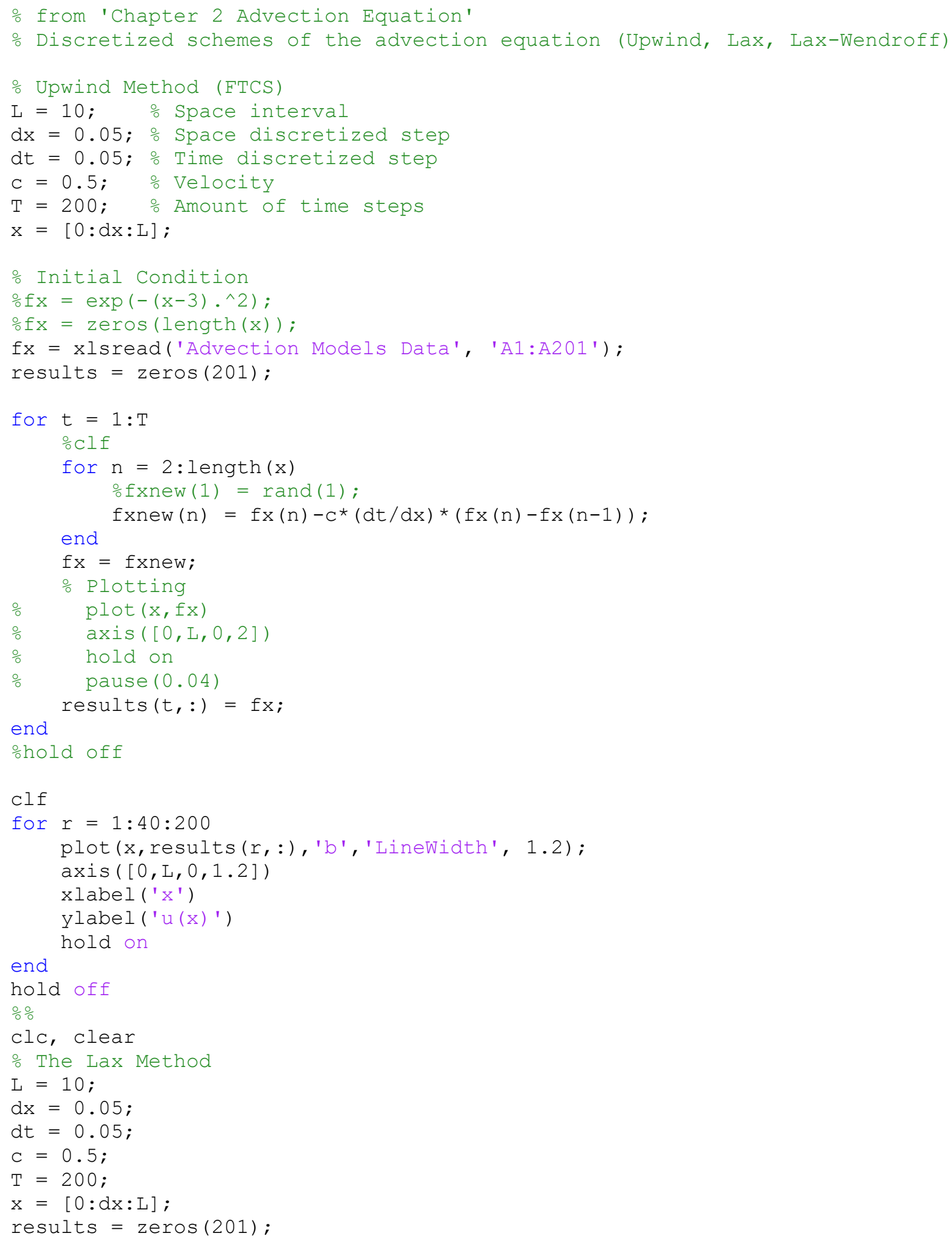




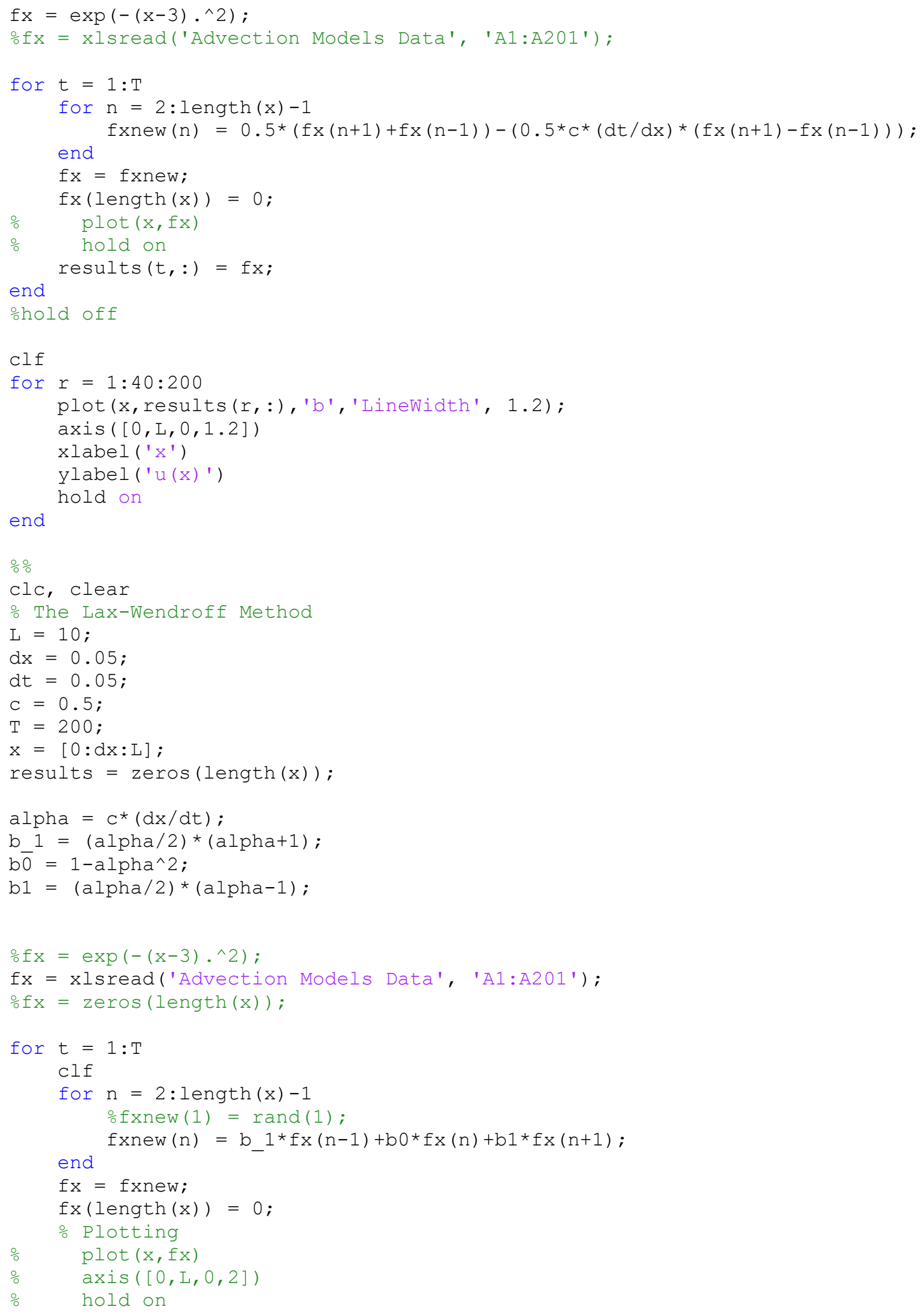




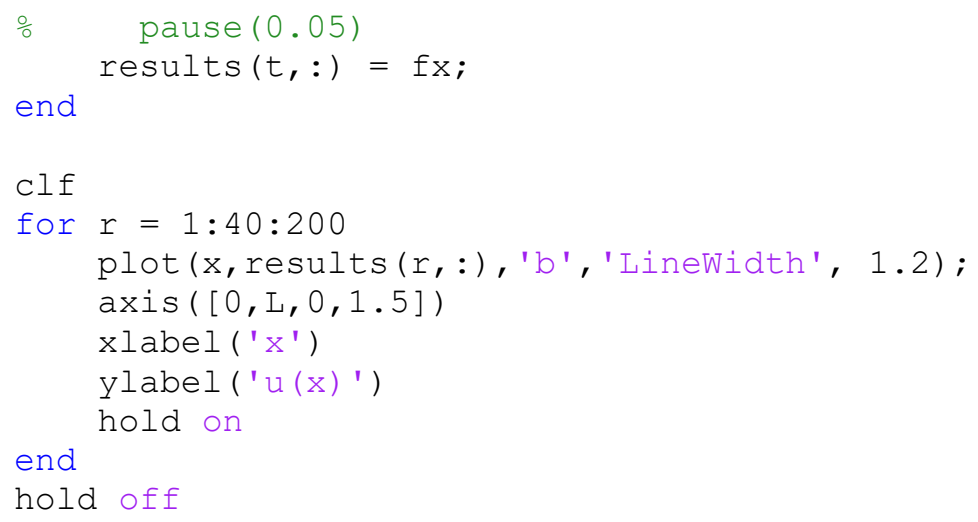




\section{Appendix C: MATLAB code for 1-D Longwall Model}

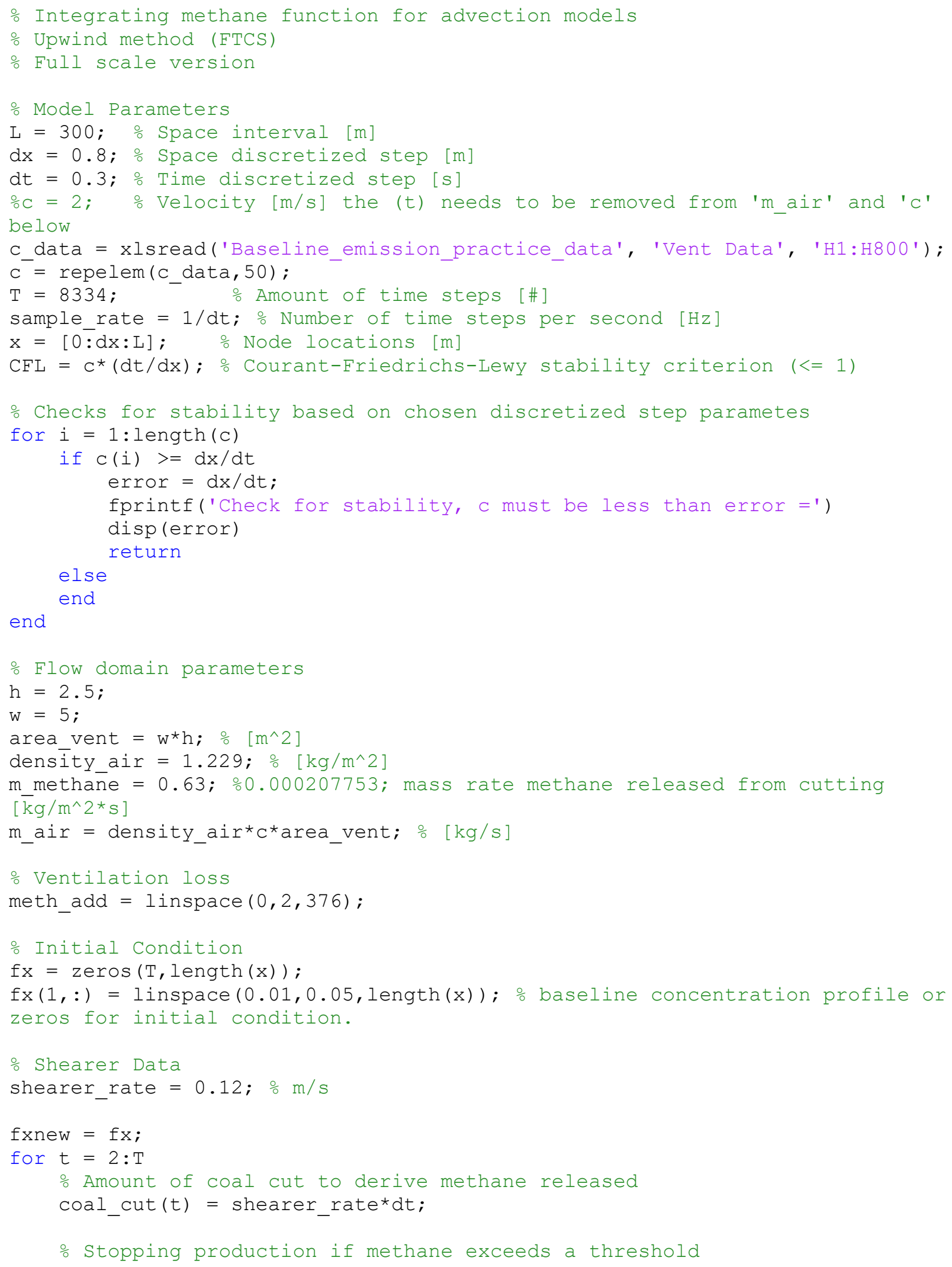




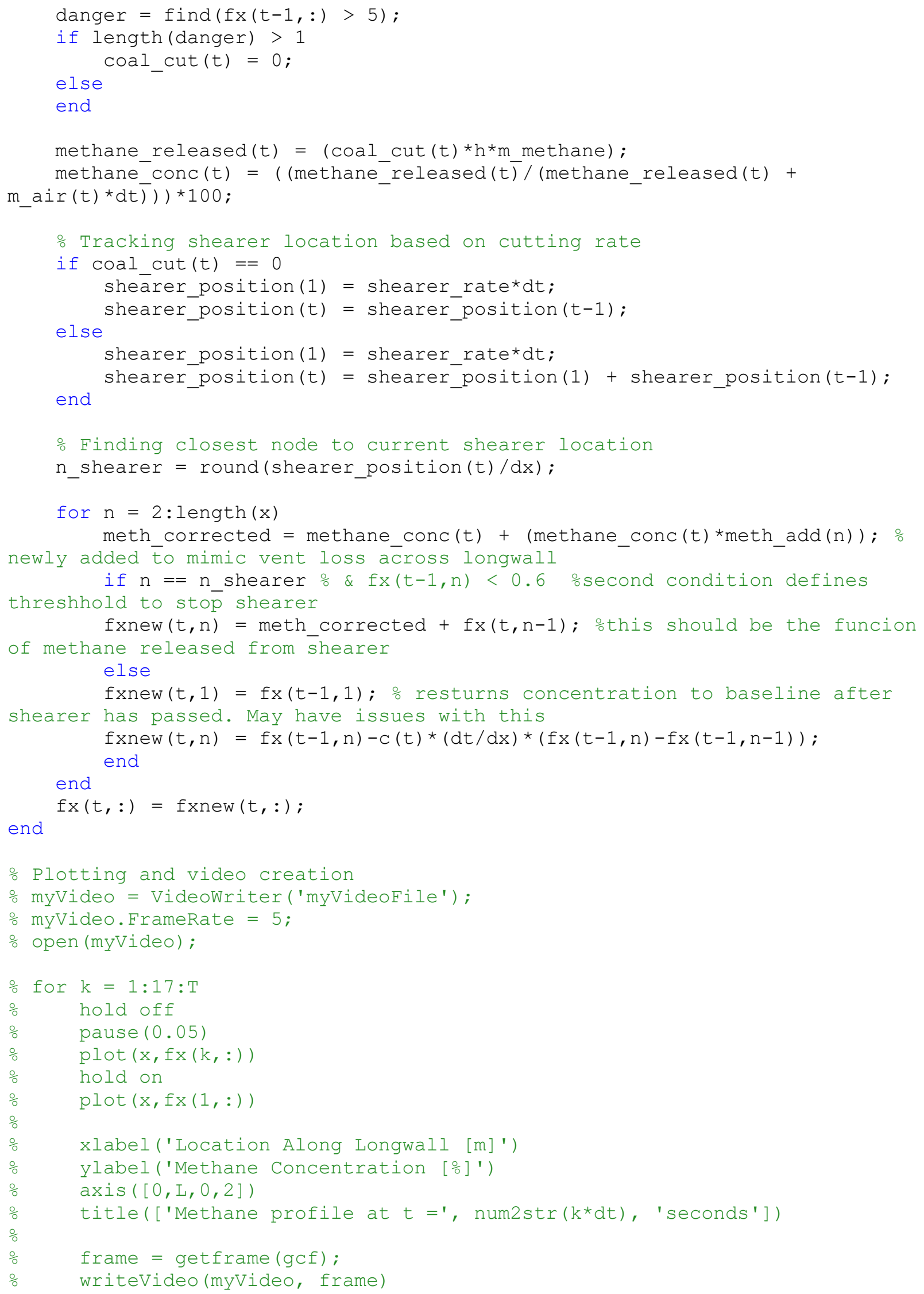




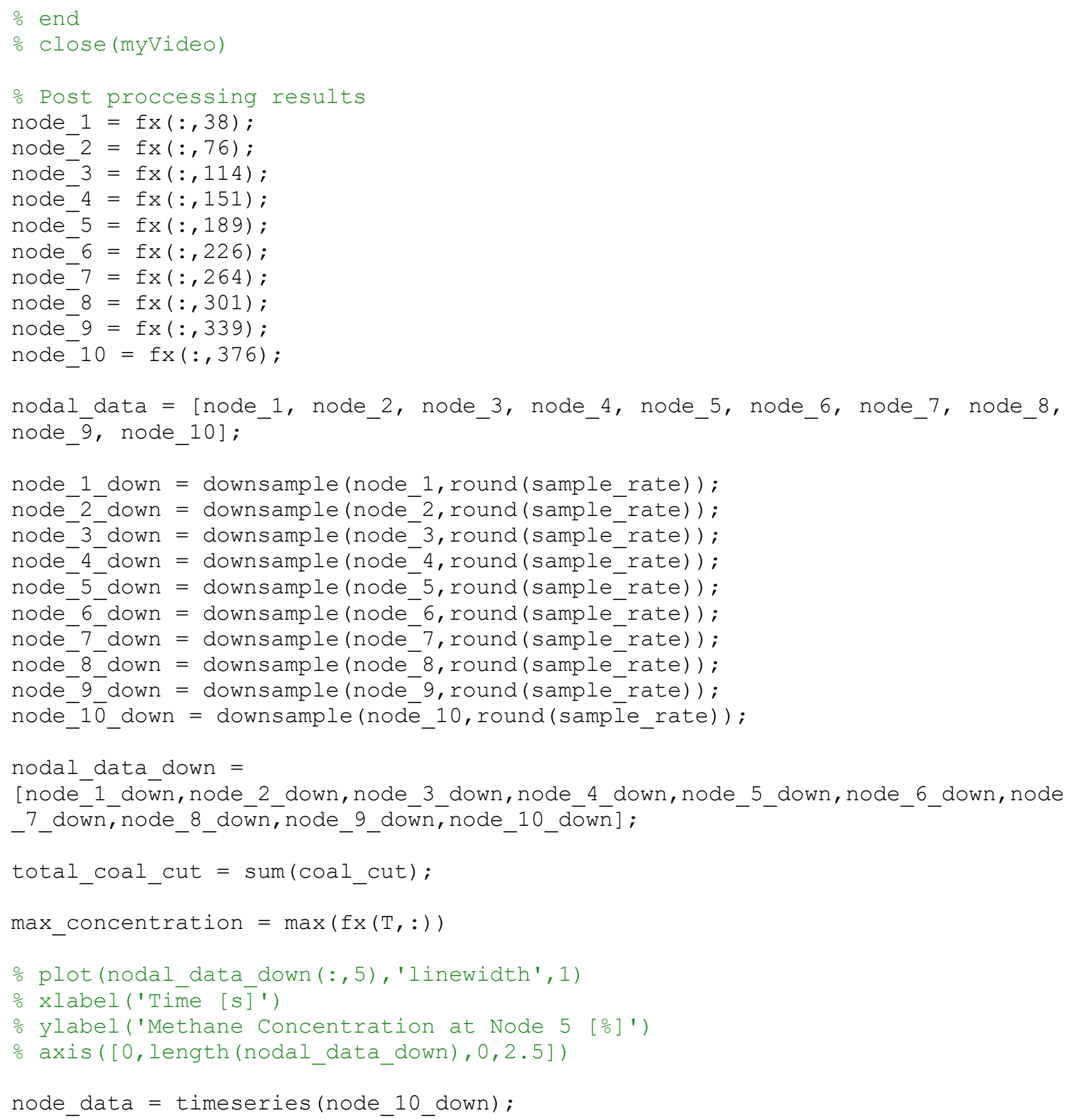




\section{Appendix D: MATLAB code for conditional MWS reconstruction technique}

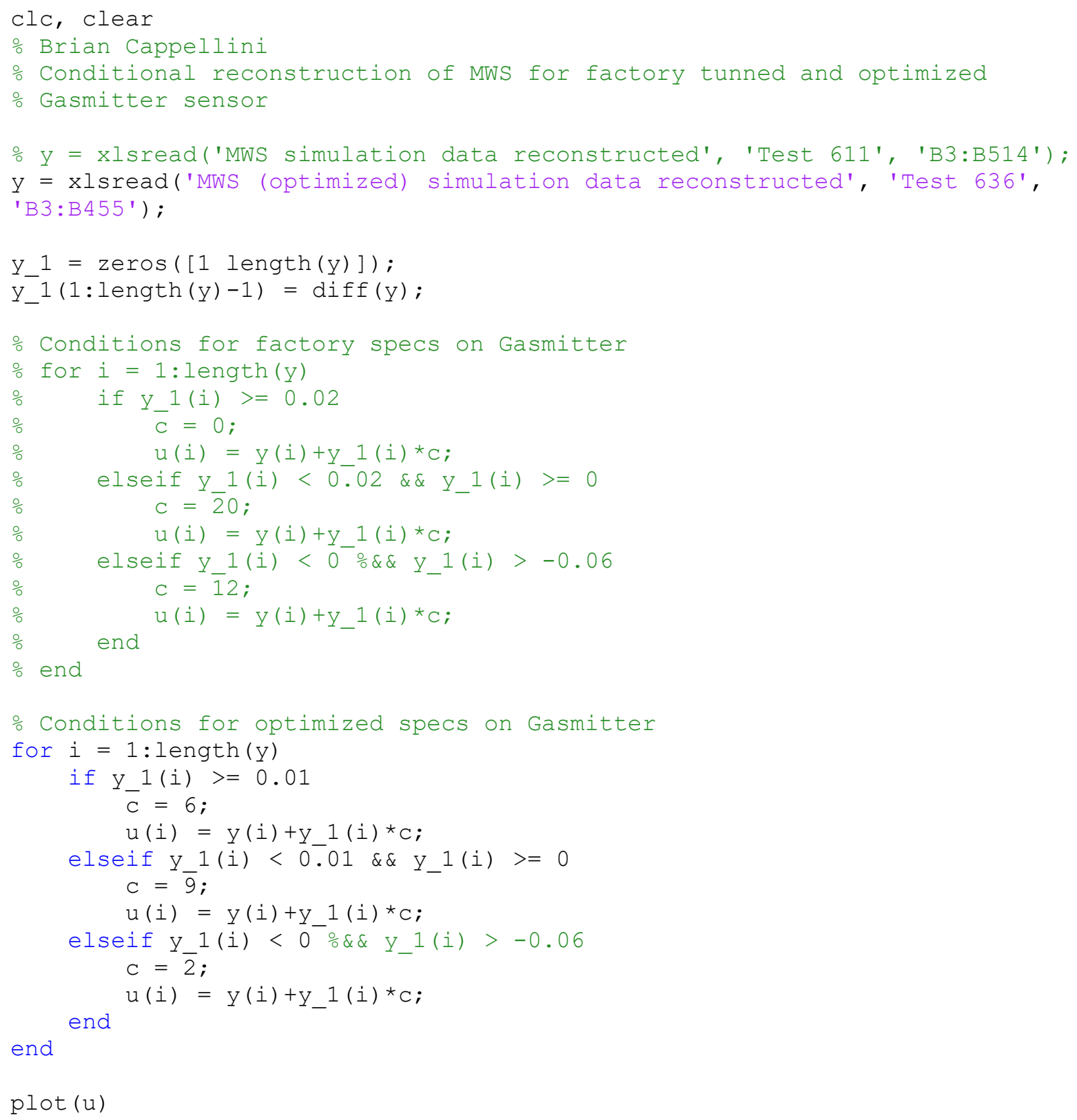




\subsection{Disclaimer}

This study was sponsored by the Alpha Foundation for the improvement of Mine Safety and Health, inc. (ALPHA FOUNDATION). The views, opinions and recommendations expressed herein are solely those the authors and do not imply any endorsement by the ALPHA FOUNDATION, its Directors and Staff. 